University of Louisville

ThinkIR: The University of Louisville's Institutional Repository

Electronic Theses and Dissertations

8-2017

\title{
Attending to systemic racism : advancing public health's approach to youth violence prevention.
}

\author{
Billie Faith Castle \\ University of Louisville
}

Follow this and additional works at: https://ir.library.louisville.edu/etd

Part of the Public Health Education and Promotion Commons

\section{Recommended Citation}

Castle, Billie Faith, "Attending to systemic racism : advancing public health's approach to youth violence prevention." (2017). Electronic Theses and Dissertations. Paper 2755.

https://doi.org/10.18297/etd/2755

This Doctoral Dissertation is brought to you for free and open access by ThinkIR: The University of Louisville's Institutional Repository. It has been accepted for inclusion in Electronic Theses and Dissertations by an authorized administrator of ThinkIR: The University of Louisville's Institutional Repository. This title appears here courtesy of the author, who has retained all other copyrights. For more information, please contact thinkir@louisville.edu. 
ATTENDING TO SYSTEMIC RACISM: ADVANCING PUBLIC HEALTH'S APPROACH TO YOUTH VIOLENCE PREVENTION

\author{
By \\ Billie Faith Castle \\ B.S., Howard University, 2012 \\ M.P.H., Texas A\&M University, 2014
A Dissertation
Submitted to Faculty of the
School of Public Health and Information Sciences
of the University of Louisville
In Partial Fulfillment of the Requirements
for the Degree of \\ Doctor of Philosophy in Public Health Sciences \\ Department of Health Promotion \& Behavioral Sciences \\ University of Louisville \\ Louisville, KY
}

August 2017 
Copyright 2017 by Billie Faith Castle

All rights reserved 

ATTENDING TO SYSTEMIC RACISM: ADVANCING PUBLIC HEALTH'S APPROACH TO YOUTH VIOLENCE PREVENTION

\author{
By \\ Billie Faith Castle \\ B.S., Howard University, 2012 \\ M.P.H., Texas A\&M University, 2014 \\ A Dissertation Approved on
}

August 4, 2017

by the following Dissertation Committee:

Monica Wendel, Dr.P.H., M.A. Dissertation Chair

Jelani Kerr, Ph.D., MSPH

Derrick Brooms, Ph.D.

Aaron Rollins, Ph.D. 


\section{DEDICATION}

This dissertation along with all my future work is dedicated to

Braylen Brayshun Foulcard

August 8, 2000 - October 23, 2016

You were taken from us too soon, but I promise to work to make sure other moms and families don't go through what Kesia and our family are going through.

Love you forever and always. 


\section{ACKNOWLEDMENTS}

First and foremost, I want to thank God. It is through Him that all things have been and will continue to be possible. I am merely a vessel, here to do the work and fulfill the purpose I was created for. I realize that this dissertation and all my work is bigger than me. I realized that my timeline was not His timeline, but it all works together for my good and His glory. If you asked me if I would have been here doing this work and at this place, I would have laughed and said no, but God had greater plans and a path that I choose to continue to walk in daily. I am happy His plan is better than what I planned and His grace and mercy are sufficient. I remain in awe of His works and continue to give Him praise in all that I do.

To my mother, Virginia Evelyn Bowie Castle! I love you with all my heart. THANK YOU for everything you have done and scarified for me to be the woman that I am today. Thank you for your prayers, your guidance, and your listening ear. Sometimes I knew you did not get it, but you never complained about me complaining and for that I am forever grateful. Thank you for supporting my dreams and me as I have moved around and gone further than I dreamed I would be in distance and in plans. Thank you for loving me unconditional and everything that you have done for Ashley and I through the years. I love you with all my heart and this is not just for me, you share in this accomplishment as well. 
I would not be who I am without being able to witness your strength, love, perseverance, dedication, tenacity, and wittiness. I am truly your carbon copy, but I wouldn't want to be the copy of anyone else. I love you and truly acknowledge everything you have done for me and I got you!

Ashley, we may fuss and fight, but I wouldn't trade you for another sister any day of the week. You challenge me and make me better. You make sure everyone sees how we are both individuals and that we have our own paths. Thank you for always being in my corner and ready to stand up for me, even when I don't want to stand up for myself. Thank you for the laughs. I love you and thanks for Austin and Aubrey. They are pretty cool! Thanks Austin and Aubrey for the random calls and Facetime chats that brightened my day!

To my village! Thank you all from near and far from the bottom of my heart. Finishing this dissertation would not have been possible without the support and love from my family and friends. Thank you family for everything and understanding when l've missed so many things over the years. I love all my cousins, but a special acknowledgement to the Bowie Granddaughters, who stick together and these ladies have been there throughout the entire journey and I say thank you, Nicki, Kelli, Deanna, Tishia, and Torie. I can't leave out Terrell, TJ, and Tobias, I love you all. Thank you to my church family for your prayers and for always checking on me and providing support when I come home. Mr. McFarland had been calling me "Dr. Faith," since I worked at the snowball stand in middle school. Even though he won't actually be able to see me as Dr. Faith, I know he's proud of me and I truly miss him. Thank you to my church family here 
in Louisville. Thank you for picking up and providing what I needed in the absence of my home church.

Caitlin, Kiara, Lauren, Nimi, Janelle, Jarrod, Dom, Henry, Aishia, Asha, Jelisa, Khirsten, Brian, Tomika, Gabe, Arielle, Colette, Nida, MAGS, Dr. Craig, Ms. Yvette, the LYVV Fellows, and all my peeps that truly provided me with laughs, listened to me vent, listened to my ideas, saw me ugly cry, took my mind off of everything that was going on, cooked (thanks for the fried chicken Jarrod), and supported me, THANK YOU! I really made it through this process with all your support and love. I am forever grateful to be surrounded by ambitious and talented people, who inspire me to be better and to do great things. I know we all have bright futures ahead of us and I am happy that you all are on the journey with me and I am happy to be a part of your journeys as well. I guess I can keep you all around.

Monique, when we started as GAs at CCHD nearly five years ago, I didn't think the journey would continue to take us to where we are now. We would talk and do our work, but the friendship we have developed is one of the best things that came out of us sharing the office space together. Thank you for your prayers! When I needed pushing, you pushed; when I need that extra encouragement, you provided it; when I just wanted to sulk, you told me sulk for a minute, but made sure I got back to work. Thank you! Thanks for listening to all my crazy ideas, but they are paying off. I really appreciate the support and for bringing me along on this journey. Thanks for advocating for me and for seeing 
things I couldn't see. Thanks to Malachi and Imani also, but they have to get out my business.

To my committee. Thank you. Each of you provided me with different things that I am forever grateful to your contributions to this accomplishment. Dr. Kerr, thank you for heling me to improve my methods and how I think about and approach theory. I appreciate the feedback on my methods and for helping me realize I wasn't too crazy during data analysis. Dr. Brooms, I am forever grateful for stumbling across your course "Black Communities in the U.S." Your courses and the discussions in your classes were helpful in filling a gap and propelling me into literature and topics that are necessary for my work and identity development. Thank you again, because I don't think you actually know how grateful I am to have meet you and be able to engage in thoughtful conversations with such a brilliant mind. Dr. Rollins, thank you for in the beginning helping me to think through my general ideas and the courses I have taken with you as well. Getting outside of the public health courses were extra helpful in merging my passion with different disciplines and needed understanding of public affairs.

Monica, we've been together for five years, but it wasn't until we came to Louisville where we worked more closely than we did in Texas. I am thankful for everything we've been able to work on. Thank you for pushing me to think beyond what I know and to actually go deeper. Thanks for encouraging my ideas but also helping me to work through them and develop as a researcher. I appreciate that you give me space to do what I love and incorporate my passion into the work. I have learned so much from you and appreciate the fact that you 
are willing to teach those around you and help them grow to get to where they want to be. Thanks for the help throughout this process.

To anyone else I may miss, charge it to the dissertation. It took a lot out of me, but I learned so much and I am grateful for the journey and where it will take me. To the future Billie who will read this (because she's crazy and will revisit the document), never stop. You did it! Never doubt yourself. Regardless of what you may think, you are smart, brilliant, and deserve all the things that are happening. You are more than worthy. You know your purpose, promise, and goals. Just because you didn't do things the way people may have expected you to do them, you got it done. Don't worry about what others think about you, you are a force and you will reap great things. Stay the course. You're awesome and fabulous and the you whose writing this worked hard to make sure the you that's reading this will never forget to treasure this moment and accomplishment. Live life with no regrets! 


\begin{abstract}
ATTENDING TO SYSTEMIC RACISM: ADVANCING PUBLIC HEALTH'S APPROACH TO YOUTH VIOLENCE PREVENTION

Billie F. Castle
\end{abstract}

August 4, 2017

This dissertation examines how the field of public health addresses the impact of systemic racism on health and how that informs public health's approach to youth violence prevention. Beginning with an overview of youth violence, it breaks down the concepts of race and racism and how they are addressed within the science. It also reviews concepts that contribute to risk and protective factors of youth violence. The dissertation is written from a Critical Race Theory approach, argues that the social environment contributes to why youth violence is pervasive in certain neighborhoods, and promotes action from a macro-level approach.

Seven chapters cover systemic racism, public health, youth violence, and the impact of neighborhood. Chapter One overviews youth violence in the United States, as well as the social construction of race. Chapter Two explores several areas of interest relevant to understanding the theoretical underpinnings and conceptualization of the study based on current literature. A discussion of the existing literature and gaps around the topics of risk and protective factors of violence, systemic racism, social norms of youth violence, sociopolitical 
development in youth, racial/ethnic identity development, and engagement in violent behavior are presented. Chapter Three outlines the methodology utilized to answer the research questions of the study. Chapters Four, Five, and Six are distinct manuscripts providing context on how public health approaches systemic/institutional/structural racism, the impact of residential segregation on youths' participation in violent behaviors, and additional factors contributing to youth violence. Results show that the Public Health literature does not explicitly address systemic racism, and though recognized as a social determinant of health, it is not a substantial focus throughout the field. Using poverty rate or neighborhood grades do not show differential effects of youth participation in violent behaviors, and other institutional-level characteristics need to be explored. According to local Louisville youth, racism at the individual and institutional levels is a factor contributing to youth violence (Chapter Six). Overall, this dissertation addresses the gap in incorporating the topics of systemic racism in Public Health practice and research and provides evidence of the impact of racism and the social environment on youth violence. 
TABLE OF CONTENTS

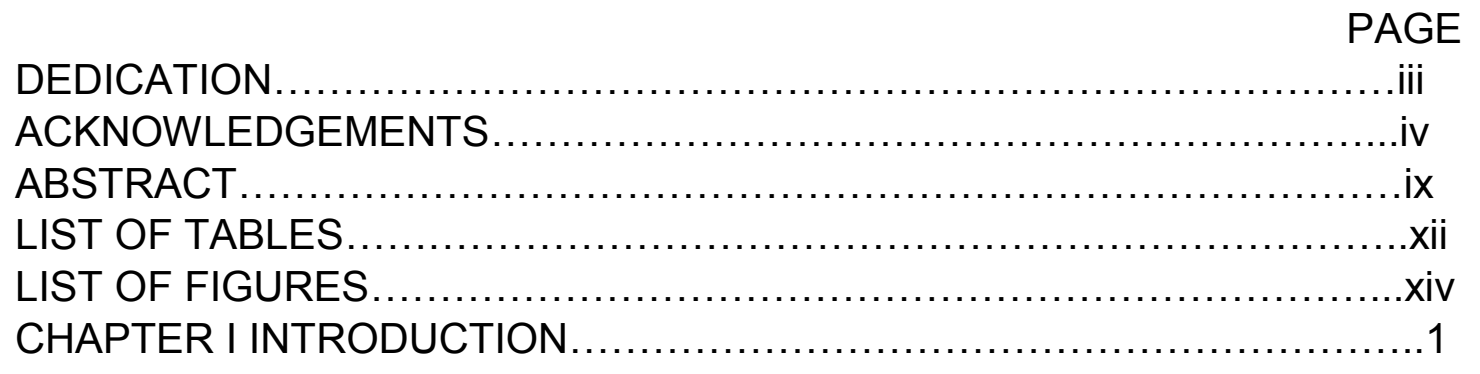

CHAPTER II REVIEW OF THE LITERATURE..............................15

Youth Violence ...................................................... 15

Systemic Racism as a Public Health Problem..........................23

Impact of Social Norms on Youth Violence...............................29

Sociopolitical Development in Youth Development......................32

Racial and Ethnic Identity and Engagement in Violent Behavior.........33

Gaps in the Literature .............................................. 37

Contributions of the Proposed Study.................................38

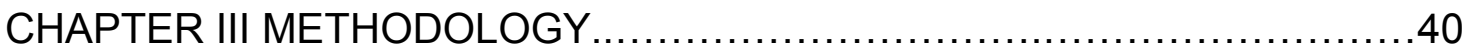

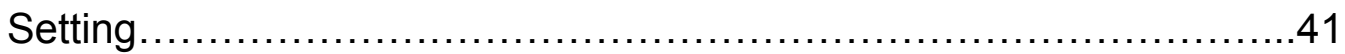

Data Collection Methodology ........................................ 47

Analysis Plan ........................................................ 48

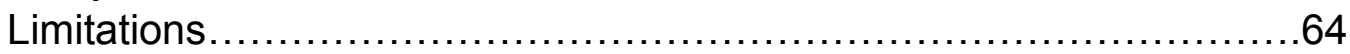

CHAPTER IV PAPER 1: Public health's approach to systemic racism:

A systematic literature review...........................................6

CHAPTER V PAPER 2: Are we talking behavior or environment? ..............90

CHAPTER VI PAPER 3: Norms? Says Who? A look into additional factors of the social norms of youth violence.............................115

CHAPTER VII DISCUSSION................................................ 154

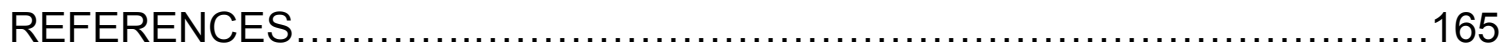

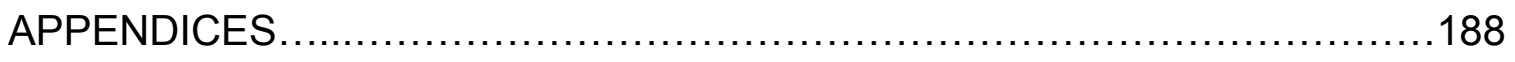

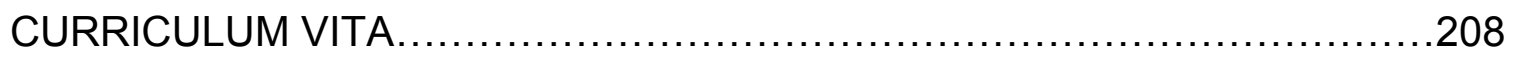


1. 2016 U.S. Population Characteristics...................................5

2. 2012 and 2013 Crime Rates by Louisville Metro Police Department

Divisions

3. Public Health Journals Eligible for Systematic Literature Review

4. Selected YVPRC 2017 School Survey Quantitative Constructs

Utilized in this Study. .56

5. Coding Scheme for Quantitative Constructs Used in this Study 63

6. Public Health Journals Eligible for Systematic Literature Review

7. Systematic Literature Review Themes and Articles $.80-81$

8. Selected YVPRC 2017 School Survey Quantitative Constructs

Utilized in this Study. .97

9. One-Way Random Effects ANOVA Model. 102

10. Random Coefficients (Selected Predictors of Louisville Youth

Participation in Violent Behaviors) Model.

11. Random Coefficients (Selected Predictors to Determine Louisville

Youth Participation in Violent Behaviors) Model. 106

12. Random Coefficients (Social Norms of Youth Violence in Louisville) Model. 108

13. Contextual Model with Neighborhood Poverty Rates 
14. Contextual Model with Neighborhood HOLC Grade Category

15. Crime Rates by Division as provided by Louisville Metro

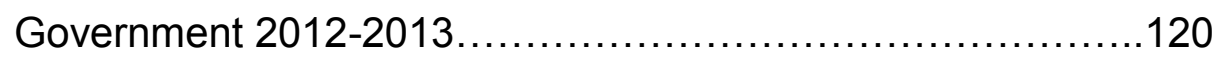

16. Selected YVPRC Constructs Included in this Study ...................127

17. Descriptive Norms (Peer Behavior) of Louisville Youth to

Determine Local Norms of Violence............................132

18. Injunctive Norms of Louisville Youth to Determine Local Norms

of Violence ..................................................... 135

19. Louisville Youth's Exposure to Community Violence....................137

20. Louisville Youth Engagement in Various Violent Behavior.............138

21. Cultural Identity of Louisville Students............................140-141 


\section{LIST OF FIGURES}

FIGURE $\quad$ PAGE

1. Systematic Literature Review PRISMA Flow Diagram................79 


\section{CHAPTER I}

\section{INTRODUCTION}

\section{The Burden of Youth Violence}

In recent years, violence has been categorized as a serious public health problem and much attention and focus have been directed towards reducing and preventing it with a public health approach. Since 1965, homicide and suicide have consistently been among the top 15 leading causes of death in the U.S. (suicide for all ages; suicide and homicide for males) (Centers for Disease Control and Prevention [CDC], National Center for Injury Prevention 2009; CDC, National Center for Health Statistics, Division of Violence Prevention (n.d.); Dahlberg \& Mercy, 2009). During the 1980s, homicide and suicide reached epidemic proportions among youth and members of minority groups (Dahlberg \& Mercy, 2009). Between, 1985 and 1991, homicide rates among 15 to 19 year-old males increased 154 percent, raising concerns and provoking a call for new solutions (CDC, 1994; Dahlberg \& Mercy, 2009). With the growing acceptance of behavioral interventions to prevent the three leading causes of death - heart disease, cancer, and stroke - a public health approach to preventing behavioral challenges that lead to violence was considered a potentially effective strategy (Dahlberg \& Mercy, 2009).

While all violence is important to consider and address, this study will focus specifically on youth violence. Youth violence is "when young people aged 
$10-24$ years intentionally use physical force or power to threaten or harm others" (David-Ferdon \& Simon, 2014, p. 6). The definition includes intent with committing the act-no matter the outcome and "use of physical force or power" to broaden the definition to "include neglect and all types of physical, sexual and psychological abuse, as well as suicide and other self-abusive acts" (Krug, Dahlberg, Mercy, Zwi, \& Lozano, 2002, p. 5). There are a variety of outcomes of committing such acts such as death, illness and disability, and quality of life (Krug et al., 2002). Youth violence not only affects the victims, but also their families, friends, and communities: "violence involving young people adds greatly to the costs of health and welfare services, reduces productivity, decreases the value of property, disrupts a range of essential services and generally undermines the fabric of society" (Krug et al., 2002, p. 25).

In $2014,4,300$ youth were victims of homicide in the U.S. - an average of 12 each day (CDC, 2014). Nationally, homicide is the third leading cause of death for youth ages 10 to 24 , the fifth leading cause of death for youth between the ages of 10 and 14 , third for youth between the ages of 15 and 24 , and the leading cause of death for Black youth between the ages of 10 and 24 (CDC, 2016). Also in $2014,501,581$ youth were treated in emergency departments for injuries sustained from physical assaults (CDC, 2014).

In Kentucky, intentional injury is the leading cause of death among persons 10 to 24 years of age (CDC, 2015). Additionally, Kentucky's homicide rate for this same age group is 10 times higher for Black males $(38.7 / 100,000)$ than for white males $(3.9 / 100,000)(C D C, 2013)$. It is also important to note that 
there is a difference between intentional and unintentional injuries. Unintentional injuries include traffic injuries, fire-related injuries, falls, drownings, and

poisonings (Krug, Sharma, \& Lozano, 2000). Assaults, self-inflicted violence, and war are considered intentional injuries (Krug et al., 2000). Violent deaths - which include homicides and suicide - "results from the intentional use of physical force or power, threatened or actual, against oneself, another person, or a group or a community" (CDC, 2016) annually. Youth homicides and assault-related injuries result in an estimated $\$ 18$ billion in combined medical and work loss costs (CDC, 2014). These data are alarming, and the prevalence of youth violence is likely underestimated as a large proportion goes unreported.

\section{Social Determinants of Health}

Disparities in youth violence are present because some communities and subgroups of youth experience more risks and fewer protective influences than others (David-Ferdon \& Simon, 2014). According to the World Health Organization (WHO), "the social determinants of health are the conditions in which people are born, grow, work, live, and age, and the wider set of forces and systems shaping the conditions of daily life" (WHO, 2017). These conditions are shaped by the "distribution of money, power, and resources at global, national, and local levels and are responsible for health inequities" (WHO, 2017). All types of violence are strongly associated with social determinants "such as weak governance, poor rule of law, cultural, social and gender norms, unemployment, income and gender inequality, rapid social change, and limited educational opportunities" (WHO, 2017). These social determinants create a social climate 
conducive to violence, and the impact they have on youth are crucial to the health of the whole population and the economic development of the nation (Viner et al., 2012).

To get a better understanding of social determinants in the U.S., an overview of the current characteristics of the U.S. population will provide context (Table 1). In 2013, the U.S. population was 311 million (Trevelyan et al., 2016). During 2013, the population was evenly divided between males (49\%) and females $(51 \%)$, and the median age of the population was 38 years (Trevelyan et al., 2016). Almost one-third (32\%) of the population aged 25 and older had completed a bachelor's degree or higher (Trevelyan et al., 2016), and 88 percent of adults had at least a high school diploma or General Education Diploma (GED) (Ryan \& Bauman, 2016). Less than two-thirds (63\%) of the civilian population ages 16 and over were in the labor force in 2013 (Trevelyan et al., 2016). As of July 1, 2015, the U.S. Census Bureau (2016) estimated that nearly two-thirds (63.9\%) of the population were homeowners (United States Census Bureau, 2017). The median household income in 2015 dollars was $\$ 53,889$ and 13.5 percent of the population lived in poverty (United States Census Bureau, 2017). In 2014, the life expectancy at birth was 78.8 years (Kochanek, Murphy, Xu, \& Tejada-Vera, 2016). The overall unemployment rate for the U.S. was five percent (5.3) (United States Bureau of Labor Statistics, 2016). 
Table 1

2016 U.S. Population Characteristics

\begin{tabular}{|c|c|c|c|c|c|}
\hline$\underline{\text { Characteristic }}$ & U.S. & White & Black & Hispanic & Asian \\
\hline Race $^{1}$ & & $\overline{76.9 \%}$ & $\overline{13.3 \%}$ & $17.8 \%$ & $\overline{5.7 \%}$ \\
\hline $\begin{array}{l}\text { Median } \\
\text { Household } 2\end{array}$ & $\$ 53,657$ & $\$ 60,256$ & $\$ 35,398$ & $\$ 42,491$ & $\$ 74,297$ \\
\hline Poverty Rate $^{2}$ & $13.5 \%$ & $10.1 \%$ & $26.2 \%$ & $23.6 \%$ & $12 \%$ \\
\hline Unemployment $^{3}$ & $5.3 \%$ & $4.6 \%$ & $9.6 \%$ & $6.6 \%$ & $3.8 \%$ \\
\hline $\begin{array}{l}\text { Life } \\
\text { expectancy }{ }^{4}\end{array}$ & 78.8 & 78.8 & 75.2 & 81.1 & \\
\hline
\end{tabular}

\section{Racial Disparities in Social Determinants}

While the national statistics illustrate the country in aggregate much variation exist in social determinants when considering the same categories across racial and ethnic groups. The U.S. Department of Health and Human Services (2008) defines health disparities as "a particular type of health difference that is closely linked with social, economic, and/or environmental disadvantage. Health disparities adversely affect groups of people who have systemically experienced greater obstacles to health based on their racial or ethnic group, religion, socioeconomic status, gender, mental health, cognitive, sensory, or physical disability, sexual orientation, geographic location, or other characteristics historically linked to discrimination or exclusion" (p. 28). There is

\footnotetext{
${ }^{1}$ United States Census Bureau. (2017). QuickFacts. Retrieved July 07, 2017, from https://www.census.gov/quickfacts/

${ }^{2}$ DeNavas-Walt, C., \& Proctor, B. D. (2015). Income and poverty in the United States: 2014. US Census Bureau, Current Population Reports.

${ }^{3}$ United States Bureau of Labor Statistics. (2016, September). Labor force characteristics by race and ethnicity, 2015. Retrieved January 13, 2017, from https://www.bls.gov/opub/reports/race-andethnicity/2015/pdf/home.pdf

${ }^{4}$ Kochanek, K. D., Murphy, S. L., Xu, J., \& Tejada-Vera, B. (2016). Deaths: final data for 2014. National vital statistics reports: from the Centers for Disease Control and Prevention, National Center for Health Statistics, National Vital Statistics System, 65(4), 1.
} 
no consistent racial terminology as well as consistent reporting for racial and ethnic groups across data sources such as the Centers for Disease Control and Prevention (CDC), U.S. Census Bureau, U.S. Department of Health and Human Services, and U.S. Bureau of Labor Statistics (data sources used). Table 1 includes U.S. demographic characteristics as well as characteristics for racial and ethnic groups. Data are missing for some racial and ethnic groups because of lack of reporting or the combination of groups such as those who identified as American Indian or Alaska Native and two or more races. Data for those groups were not included because it does not accurately represent the differences amongst racial and ethnic groups because it is assumed that disparities are the same across all groups. For the continuation of this study, the following terms will be used to describe racial and ethnic groups: white, Black, Asian, and Hispanic.

The median income for Black households was $\$ 35,398$ in 2014 , compared to Asians at $\$ 74,297$, white households at $\$ 60,256$, and Hispanic households at $\$ 42,491$ (DeNavas-Walt \& Proctor, 2015). For Blacks, the poverty rate was 26.2 percent, which equals roughly 10.8 million people in poverty, compared to 12.7 percent whites, 12.0 percent (2.1 million people) for Asians, and 23.6 percent (13.1 million) for Hispanics (DeNavas-Walt \& Proctor, 2015).

Across racial and ethnic groups, unemployment was highest for American Indians and Alaska Natives (9.9\%) and Blacks (9.6 \%) (BLS, 2016). Factors that contribute to the labor market differences among the race and ethnicity groups labor include educational attainment; the occupations an industries in which the groups work; the geographic area of the country in which the groups are 
concentrated, including whether they tend to reside in urban or rural settings; and the degree of discrimination encountered in the workplace (BLS, 2016).

Across multiple indicators of health status, racial disparities are substantial and pervasive (Williams \& Collins, 2001). The life expectancy at birth for Hispanics in 2014 was 81.1 years, whites 78.8 years, and 75.2 years for Blacks (Arias, 2016). Blacks have higher death rates than whites for most of the 15 leading causes of death (Williams \& Mohammed, 2009). These higher death rates exist across the life-course with Blacks and American Indians from birth through the retirement years (Williams \& Mohammed, 2009). It is important to understand the demographic and socioeconomic composition of the U.S. racial and ethnic groups because these social determinants are associated with not only health risk factors, disease prevalence, and access to care, but also violence (National Center for Health Statistics, 2016; Williams, Mohammed, Leavell, \& Collins, 2010).

\section{Racial Disparities in Violence}

Black people are six times more likely than white people to die by homicide (Robert J. Sampson, Morenoff, \& Raudenbush, 2005). Homicide is one of the leading causes of death in Black youth and compared to whites and Hispanics, Blacks experience higher rates of violence overall (Sampson et al., 2005). There is clear evidence that "Blacks face dismal and worsening odds when it comes to crime in the streets and the risk of incarceration" (Sampson \& Wilson, 1995, p. 37). Race and ethnicity has not been widely used as a scientifically creditable causal factor of violence, but the external and social 
contexts are differentially impacted by racial and ethnic status in the U.S. (Sampson et al., 2005; Sampson \& Wilson, 1995). Racial and ethnic differences in the risk factors as well as the differences in social determinants listed previously account for the racial and ethnic gaps in violence. This begs the question: when observing racial disparities in violence, are we witnessing the effects of race or the effects of racism?

\section{Race vs. Racism}

Carl von Linne (also known as Carolus Linnaeus) originated the concept of race during the 1700 s, which he used to classify large divisions of homo sapiens (Von Linné, 1956; Witzig, 1996). He divided humans into four main groups based on physical and psychological impressions: Europeans, were classified as "fair...gentle, acute, incentive...governed by laws"; Americans, who were "copper-colored...obstinate, content free...regulated by customs,": Asiatics, who were "sooty...severe, haughty, covetous...governed by opinions"; and Africans, who were "black...crafty, indolent, negligent...governed by caprice" (Von Linné, 1956; Witzig, 1996, p. 675). Later, Johann Blumencbach, a German anthropologist and anatomist, used the word race in 1775 to classify humans into five divisions: Caucasian, Mongolian, Ethiopian, American, and Malay (Blumenbach \& Bendyshe, 1865; Witzig, 1996). He invented the term "Caucasian" because he "believed that the Caucasus region of Asia Minor produced the most beautiful race of men" (Blumenbach \& Bendyshe, 1865; Witzig, 1996, p. 675). They both believed that the human species is one species (Witzig, 1996). Clearly, their classifications were self-serving descriptions and not 
scientific. "These men were the products and producers of the prejudices of their era," and still with great evidence that race is a social construct, society continues to operate based on similar concepts and categories of race (Witzig, 1996, p. 675).

Early definitions of race were inconsistent and were typically self-serving to the creator of the definition (Witzig, 1996). Anthropologist have concluded that the term "race" is not useful:

The term race, as applied to human types, is vague. It can have a biological significance only when a race represents a uniform, closely inbred group, in which all family lines are alike-as in pure breeds of domesticated animals. These conditions are never realized in human types and impossible in large populations. As a folk concept, race is employed to attribute not only physical characteristics but also psychological and moral ones to members of given categories, thus justifying or naturalizing a discriminatory system. (Seymour-Smith, 1986, p. 238)

In more recent years, social scientist, have concluded that race is socially constructed, "meaning that [the] notions of racial difference are human creations rather than eternal, essential categories" (Bonilla-Silva, 2010, p. 8). Race is an "unscientific social construct; that is, the concept of race is created from prevailing social perceptions and is without scientific foundation" (Witzig, 1996, p. 676) and focuses more on color as seen with Linne and Blumencbach, than genetic disposition. Witzig (1996) describes that the second definition of race by 
anthropologist "has fueled racist and eugenic movements with allegedly scientific claims of racial superiority and inferiority" (p. 676).

Race exist within all bodies of law: civil rights (Bell, 1989), immigration law (Bowsher, 1990), federal Indian law (Williams Jr, 1989), property law (Ansley, 1991), contracts law (Williams, 1991), criminal law (Kennedy, 1988), federal courts (Resnik, 1989), family law (Bartholet, 1991; Perry, 1990), and corporate law (Baeza, 1985; Kennedy, 1990; Lopez, 1994).

Human fate still rides upon ancestry and appearance. The characteristics of our hair, complexion, and facial features still influence whether we are figuratively free or enslaved. Race dominates our personal lives. It manifests itself in our speech, dance, neighbors, and friends. Race determines our economic prospects. The race-conscious market screens and selects us for manual jobs and professional careers, red-lines financing for real estate, green-lines our access to insurance, and even raises the price of that care we need to buy. Race permeates our politics. It alters electoral boundaries, shapes the disbursement of local, state, and federal funds, fuels the creation and collapse of political alliances, and twists the conduct of law enforcement (Lopez, 1994, p. 3).

Lopez (1994) details the role of law in reifying racial identities through an analysis of Hudgins v. Wright. In the case, Hudgins "demonstrates that the law serves not only to reflect but to solidify social prejudice, making law a prime instrument in the construction and reinforcement of racial subordination" (Lopez, 1994). In the following chapter, a discussion on the risk and protective factors of youth 
violence from a social-ecological framework are presented. Noticeably policies were not included because of a lack of research or evidence on the impact of policies on a youth's engagement in violence. There are overwhelming amounts of policy implications for violence intervention and prevention evidence, however, a lack of evidence reviewing policies that create the social determinants and subsequently the racial disparities that exist within the context of violence. "Racism" involves the "prediction of decisions and policies on considerations of race for the purpose of subordinating a racial group" (Feagin \& Bennefield, 2014, p. 7; Ture \& Hamilton, 1967, p. 3). The question now is, are we discussing and addressing racial disparities or disparities created through racism?

\section{Systemic Racism}

Ture and Hamilton (1967) describe institutional racism - what we term systemic - as a "less overt" and "less identifiable in terms of specific individuals committing the acts. But it is no less destructive to human life" (p. 4). Feagin's $(2013 ; 2014)$ systemic racism theory details five dimensions of U.S. racism: "dominant racial hierarchy; comprehensive white racial framing; individual and collective discrimination; social reproduction of racial-material inequalities; and racist institutions integral white domination of Americans of color" (p.7). For centuries, whites have benefited in the form of socioeconomic resources from the unjustly practices their ancestors gained through slavery, segregation, and various forms of racial oppression (Feagin \& Bennefield, 2014). Still today, those resources inherited unjustly along with discrimination have created barriers for people of color to have access to better jobs, quality education, healthy and safe 
neighborhoods, quality health care, and political power (Feagin \& Bennefield, 2014). At the root, systemic racism has created the conditions in which people of color experience variations in social determinants and high levels of violence.

\section{Relevance in Public Health}

Traditionally, public health has focused its discussion of root causes on social determinants: lack of education, lack of jobs, poverty, and risk and protective factors; however, many of those determinants are impacted by racism, which largely remains invisible. The earliest mentions of racism published in a public health journal was published by Jones (2000) as she describes three levels of racism: institutionalized, personally mediated, and internalized. However, she does not make mention of "extensive critical race research" or contextualize the personally mediated level of racism within institutionalized racism (Feagin \& Bennefield, 2014, p. 8). Krieger (2003) names racism as a determinant of population health, and defends the need for more racism research. Gee and Ford (2011) discuss structural racism and how its "relationship to health inequities remains under-studied" (p. 115). They also take

necessary steps for "analyzing the impact of white-controlled systemic racism on health care" (Feagin \& Bennefield, 2014, p. 8).

The public health community is reluctant to examine the impacts of past racial oppression on U.S. public health institutions as well as topics such as violence and racial disparities that exist within the social determinants within the literature. Public health has operated within the white racial frame which encompasses "a broad and persisting set of racial stereotypes, prejudices, 
ideologies, images, interpretations and narratives, emotions, and reactions to language accents, as well as racialized inclinations to discriminate" which has aggressively defended this unequal and unjust society (Feagin \& Bennefield, 2014, p. 8; Feagin, 2013, p. 3). The beginning of this introduction was written in the "standard" public health contextualization of a problem, it focuses on health problems and racial disparities, "neglecting the white perpetuators of racist practices and institutions" (Feagin \& Bennefield, 2014, p. 8) that created these problems. Public health problems are contextualized from the perspective of what the individual has or has not done to get to the impact of certain behaviors, not, how the social conditions in which they live impact their behavior. Therefore, this study will situate the analysis of the impact of systemic racism on youth violence by including traditional racial-realism founders of critical race theory and draw upon institutional racism research of critical researchers such as Ture and Hamilton, Joe Feagin, and Eduardo Bonilla Silva, as well as taking a Critical Race Theory Approach to creating the methodology and analyzing data.

\section{Proposed Study}

The purpose of this study is to examine how the field of public health addresses the impact of systemic racism within the literature and how (if) that informs public health's approach to youth violence prevention. It examines the impact of systemic racism on West Louisville cultural identity, engagement in violent behavior, and their views on the social norms of violence. It will serve to expand on Krieger's (2003) ideal of recognizing racism as a determinant of population health and contribute to the growing need for more racism research 
within the field of public health. Additionally, the results of this study will provide evidence and understanding of how systemic racism has created conditions in which youth violence is pervasive.

In October 2015, the Office of Public Health Practice (OPHP) was designated as a National Centers of Excellence Youth Violence Prevention Research Center (YVPRC) by the Centers for Disease Control and Prevention. YVPRC is conducting a research project centered on the creation and evaluation of a three-year social norming campaign to reduce youth violence in West Louisville by influencing the social context of youth in Louisville. The campaign seeks to cultivate a positive racial identity and foster community dialogue around difficult issues such as racial and social justice. In doing so, YVPRC hopes to raise critical consciousness in an effort to promote racial justice and reduce youth violence. Using data from the YVPRC's 2017 School Survey and pre-campaign focus groups, this study will explore the relationship between systemic racism and multiple individual predictors of youth participating in violent behaviors. 


\section{CHAPTER II}

\section{REVIEW OF THE LITERATURE}

\section{Introduction}

The proposed research covers several areas of interest; and an understanding of the theoretical underpinnings and current literature in each one is foundational for conceptualizing the study. To provide such context, this chapter offers a background on risk and protective factors for youth violence, systemic racism, social norms of youth violence, sociopolitical development in youth development, racial and ethnic development, and engagement in violent behavior are offered in the following narrative. Further, the narrative provides a summation of the current literature discussing the gaps among current research and a discussion on the unique contribution this study will make to the literature.

\section{Youth Violence}

Youth violence research provides an understanding of factors that increase the likelihood for violence victimization and perpetration in some populations compared to others. Youth violence is "when young people aged 10 - 24 years intentionally use physical force or power to threaten or harm others" (David-Ferdon \& Simon, 2014, p. 6). The probability of participating in violent behaviors increases during the second decade of life. Between the ages of 10 and 20, youth are at greatest risk for violent activity; over half of youth who 
engage in violent activity, begin in this age range (United States [U.S.] Census Bureau, 2012). Youth's skills, experiences, and characteristics of their relationships and community influence the likelihood of them engaging in violence - bullying, fighting, and gang-related violence (National Center for Injury Prevention and Control Division of Violence Prevention, 2013).

Risk factors increase the likelihood that people will experience violence, while protective factors decrease the likelihood that people will experience violence or increase their resilience when faced with risk factors (Wilkins, Tsao, Hertz, Davis, \& Klevens, 2014). Numerous risk and protective factors for youth violence, exist at multiple levels of the socioecological model, which takes into account factors at the intrapersonal, interpersonal, institutional, community, and public policy levels (McLeroy, Bibeau, Steckler, \& Glanz, 1988). The socioecological model "focuses attention on the environmental causes of behavior and to [help] identify environmental interventions" (McLeroy et al., 1988, p. 366). Viewing risk and protective factors in the concept of how the environment impacts behavior, provides perspective for youth violence. The socioecological model assumes that by changing the social environment an individual will subsequently change their behavior.

While more research focuses on risk factors, it is equally important to understand protective factors in efforts to prevent youth violence (CDC, 2016). Violence risk factors are not fixed; their predictive values change depending on a young person's development, social, and cultural factors (DHHS, 2001; WHO \& Krug, 2002). Identifying risk and protective factors, along with determining when 
they emerge, are critical for understanding violence as well as creating violence prevention and intervention efforts. Violence prevention efforts must align appropriately with youth's developmental stage.

\section{Risk Factors for Youth Violence}

Violence risk factors are not fixed; their predictive values change depending on a young person's development, social, and cultural factors (DHHS, 2001; WHO \& Krug, 2002). Some risk factors for violence appear in early childhood, while others do not become noticeable until adolescence.

Intrapersonal Level. At the individual level, biological, psychological, and behavioral characteristics are factors that affect the potential for violent behaviors (WHO \& Krug, 2002). According to the CDC (2016), history of violent victimization; attention deficits, hyperactivity or learning disorders; history of early aggressive behavior; involvement with drugs, alcohol, or tobacco; low intelligence quotient (IQ); poor behavioral control; deficits in social cognitive or informationprocessing abilities; high emotional distress; history of treatment for emotional problems; antisocial beliefs and attitudes; and exposure to violence and conflict in the family are intrapersonal risk factors that can predict wherein a youth will participate in violent behaviors (WHO \& Krug, 2002).

Gender has also been found to be a risk factor for violence (Herrenkohl et al., 2000). Males are more likely to engage in serious violence because boys are socialized into roles that encourage higher levels of physical aggression (Herrenkohl et al., 2000; Oliver, 1989). They also exhibit violence differently than females (Herrenkohl et al., 2000). "Males use physical force to express hostility 
towards others, while females express hostility through indirect and verbal forms of aggression" (Herrenkohl et al., 2000, p. 177).

Interpersonal Level. These individual characteristics do not exist in isolation and are influenced by relationships and the social environment. At the interpersonal level, relationships youth have with their family, friends, and peers strongly affect aggressive and violent behaviors (WHO \& Krug, 2002). Authoritarian childrearing attitudes; harsh, lax, or inconsistent disciplinary practices; low parental involvement; low emotional attachment to parents or caregivers; low parental education and income; parental substance abuse or criminality; poor family functioning; and poor monitoring and supervision of children are family risk factors that put youth at risk for violent behaviors (CDC, 2016). Of these, parental behavior and family environment are central factors (WHO \& Krug, 2002). Youth's peers can influence each other in negative or positive ways through the shaping of their interpersonal relationships (WHO \& Krug, 2002). Association with delinquent peers; involvement in gangs; social rejection by peers; lack of involvement in conventional activities such as after school and community programming; poor academic performance; and low commitment to school and social failure are peer and social risk factors that put youth at risk for violent behaviors (CDC, 2016).

Organizational Level. Youth spend on average eight hours a day in school and are shaped by many of the interactions that happen within the organization; however, "there are no large or moderate risk factors for [youth] violence within the school" (Office of the Surgeon General, 2001). Yet, in early 
adolescence, poor attitude and performance in school, particularly if it leads to academic failure, is a risk factor (Office of the Surgeon General, 2001). Students who attend schools that are located in socially disorganized neighborhoods are more likely to have a high rate of violence than those who attend schools in other neighborhoods (Office of the Surgeon General, 2001; Laub \& Lauritsen, 1998). Peer groups operate in the neighborhood and in school, therefore, interpersonal and community-level factors also exist at this level (Office of the General, 2001). The dominant peer culture of a school can influence the risk of becoming involved in violence, regardless of a young person's view on violence (Felson, Liska, South, \& McNulty, 1994; Office of the Surgeon General, 2001).

Community Level. Communities influence youth as well as their families, the nature of their peer groups, and situations to which they are exposed (WHO \& Krug, 2002). Youth living in urban areas are more likely to engage in violent behavior than youth who live in rural areas (Elliott, Huizinga, \& Menard, 2012; Farrington, 1998; Thornberry, Huizinga, \& Loeber, 1995). Likewise, those living in communities with high levels of crime are at greater risk to be involved in violent behavior than those living in communities with low levels of crime (Farrington, 1998; Kelly, 2010; Thornberry et al., 1995). Diminished economic opportunities; high concentrations of poverty; high levels of transiency; high levels of family disruption; low levels of community participation; socially disorganized neighborhoods (CDC, 2016); and communities with a high density of alcohol outlets (Resko et al., 2010) increase the risk of youth participating in violent behaviors. Additionally, a community culture that opposes conventional 
mainstream institutions youth find to be unjust (i.e., law enforcement, criminal justice system, education), yields social norms in which violence is promoted as a mechanism for earning respect (Anderson, 1999; Stewart \& Simons, 2010).

Societal Level. Societal factors can create conditions conducive to violence (WHO \& Krug, 2002). Poverty, political structures, and cultural influences are societal factors that are associated with youth violence (WHO \& Krug, 2002). Cultural norms that support aggression toward others (WHO \& Krug, 2002); media violence (Anderson et al., 2010); societal income inequity (Fajnzlber, Lederman, \& Loayza, 2002; Kennedy, Kawachi, Prothrow-Stith, Lochner, \& Gupta, 1998; Messner, 1988; Nivette, 2011); and harmful norms around masculinity and femininity (CDC, 2016; Connolly, Pepler, Craig, \& Taradash, 2000; Espelage, Basile, \& Hamburger, 2012; Krug, Mercy, Dahlberg, \& Zwi, 2002) are societal risk factors that create conditions in which youth violence is more likely to occur. Societal level factors do not just create conditions for youth, but for all. These factors influence how people view others, and policies created at this level can positively or negatively affect risk, as well as intervention and prevention efforts.

\section{Protective Factors for Youth Violence}

Protective factors can work to reduce or mitigate risk for youth violence (David-Ferdon \& Simon, 2014). Though protective factors have not been studied as extensively or rigorously as risk factors (Aisenberg \& Herrenkohl, 2008), youth who are exposed to more protective factors and fewer risk factors are less likely to engage in violence (David-Ferdon \& Simon, 2014; Pollard, Hawkins, \& Arthur, 
1999; Resnick, Ireland, \& Borowsky, 2004; Stouthamer-Loeber, Loeber, Wei, Farrington, \& Wikström, 2002). In remaining consistent, it is important to examine protective factors through a socioecological perspective to account for the environmental factors that impact behaviors.

Intrapersonal Level. According to the CDC (2016), individual protective factors include intolerant attitude towards deviance; high IQ; high grade point average (as an indicator of high academic achievement); positive social orientation; highly developed social skills/competencies; highly developed skills for realistic planning; religiosity; and skills in solving problems non-violently (Lipsey \& Derzon, 1998; Resnick et al., 2004; Wilkins et al., 2014).

Interpersonal Level. As with the all factors, individual level factors do not exist in isolation from interpersonal level factors. At the interpersonal level, family protective factors include connectedness to family or adults outside the family; ability to discuss problems with parents; perceived high parental expectations about school performance; frequent shared activities with parents; consistent presence of parent during at least one of the following: when awakening, when arriving home from school, at evening mealtime, or going to bed; involvement in social activities; and parental/family use of constructive strategies for coping with problems (provision of models of constructive coping) (CDC, 2016; Lipsey \& Derzon, 1998; Resnick et al., 2004). Family factors are substantial determinants in a youth's participation in violent behaviors.

Peer and social protective factors can enforce or deconstruct family factors and the relative influence of peer factors increases as youth progress into 
adolescence. Peer and social protective factors include possession of affective relationships with those at school that are strong, close, and prosocially-oriented; commitment to school (an investment in school and in doing well at school); close relationships with non-deviant peers; membership in peer groups that do not condone antisocial behavior; involvement in prosocial activities; and exposure to school climates characterized by intensive supervision, clear behavior rules, consistent negative reinforcement of aggression, and engagement of parents and teachers (CDC, 2016; Lipsey \& Derzon, 1998; Resnick et al., 2004; Wilkins et al., 2014).

Organizational Level. In addition to family factors, school is another protective factor found to buffer the risks of youth violence (Office of the Surgeon General, 2001). Youth who are committed to school and those who have embraced the goals and values of the institution are unlikely to engage in violence because they would not want to jeopardize their achievement or standing with adults (Jessor, Van Den Bos, Vanderryn, Costa, \& Turbin, 1995; Office of the Surgeon General, 2001). It is important to note that commitment to school is not the opposite of poor attitude or performance in school (Office of the Surgeon General, 2001). School gives youth a place to excel socially and academically. The recognition provided from teachers or the institution is important to adolescent development, and recognition from teachers or the institution may be the only source of recognition a youth receives (Office of the Surgeon General, 2001). It can also provide them with motivation to seek continued educational or job skills training opportunities (Office of the Surgeon 
General, 2001). Extracurricular activities "give adolescents an opportunity to participate in constructive group activities and achieve recognition for their efforts" and are also considered a protective factor (Office of the Surgeon General, 2001). However, "schools with a culture of violence may be unable to exert their very important protective function" (Office of the Surgeon General, 2001).

Community Level. The amount of community support and connectedness a youth has, can also serve as a protective factor of youth violence (Widome, Sieving, Harpin, \& Hearst, 2008; Wilkins et al., 2014). Youth with intentions of adding value to their community are less likely to get involved in violence (Widome et al., 2008). Few community-level protective factors are identified in the literature, because most are difficult to isolate and measure to prove their effectiveness (Lösel \& Farrington, 2012). However, Lösel and Farrington (2012) found that living in a nondeprived, nonviolent, and cohesive neighborhood has positive effects on youth. Protective factors are present in some communities more than others, much of which has to do with the social conditions that impact the community.

\section{Systemic Racism as a Public Health Problem}

For centuries, people of color have suffered mentally and physically from the impact of the public health problem of systemic racism. Racial inequalities are pervasive in the social determinants of health and should be assessed in the context of society's white-racist roots and contemporary structural-racist realities (Feagin \& Bennefield, 2014). Ture and Hamilton (1967) define racism as "the 
predication of decisions and polices on considerations of race for the purpose of subordinating a racial group and maintaining control over that group." Racism is covert and overt (Ture \& Hamilton, 1967, p. 3). It exists in two forms: "individual whites acting against individual Blacks [individual racism], and acts by the total white community against the Black community [institutional racism]" (Ture \& Hamilton, 1967, p. 4). The latter, for the purpose of this study termed "systemic racism," operates within "established and respected forces in the society, and receives far less public condemnation than the first type" (Ture \& Hamilton, 1967, p. 4).

Post-Jim Crow era, "the white commonsense view on racial matters is that racists are few and far between, that discrimination has all but disappeared, and that most whites are color blind" (Bonilla-Silva, 2010, p. 25). Today, "new racism" has emerged and is evident in "more sophisticated and subtle" practices (BonillaSilva, 2010). Bonilla-Silva (2010, p. 26) has found that this racial structure consists of five elements: "(1) the increasingly covert nature of racial discourse and racial practices; (2) the avoidance of racial terminology and the ever-growing claim by whites that they experience "reverse racism;" (3) the elaboration of a racial agenda over political matters that eschews direct racial references; (4) the invisibility of most mechanisms to reproduce racial inequality; and (5) the reticulation of some racial practices characteristic of the Jim Crow period of race relations." Many have moved towards using a colorblind approach to addressing issues; and, this approach still creates racial inequalities. Many whites have created barricades that exclude them from the U.S. racial reality and they have 
taken a colorblind approach to engagement (Bonilla-Silva, 2010). This new racism has given us phrases such as "post-racial America" or "I don't see color," especially with the election of President Barack Obama (Bonilla-Silva, 2010). However, neglecting to address race or creating practices and policies which include the contextualization of race will continue to yield the same results.

The new racism is evident in social, economic, political, and ideological areas, and it can be seen in public health. For example, one of the goals of Health People 2020, is to achieve health equity and eliminate health disparities. Within the stated goal, the differences to eliminate occur by gender, race or ethnicity, education or income, disability, living in rural localities, or sexual orientation (U.S. Department of Health and Human Services, 2010). The steps to eliminate health disparities are not clearly explained throughout the plan. Health disparities are defined as the "health differences that adversely affect socially disadvantaged groups" (Braveman et al., 2011, p. S150). What is important to note is how socially disadvantaged groups are defined: "the unfavorable social, economic, or political conditions that some groups of people systemically experience based on their relative position in social hierarchies" (Braveman et al., 2011, p. S151). Social disadvantage is reflected through the social determinants of health; however, there are no numerical cutoffs for disadvantage, or to expand on what Braveman et al. (2011) and many within public health have failed to identify, the intersectionality that occurs amongst these groups.

Braveman et al. (2011) discuss' the definitions and the concept of achieving equity by eliminating health disparities by criticizing the approach because it 
broadens the context in which health disparities exist. It further jeopardizes "the limited resources allocated to specifically address racial/ethnic disparities, by spreading these resources more thinly among other disadvantaged groups?" (Braveman et al., 2011, p. S153). But does it have to? Audre Lorde's concept of intersectionality is that the experiences of oppression overlap, and "it is a means of capturing both the structural and dynamic aspects of multiple discrimination, thus affecting both theory and practice" (Morgan, 2003, p. 46). When health disparities are discussed, the intersectionality of race or ethnicity, gender, education or income, disability, living in rural areas, or sexual orientation are largely absent.

Public health in the U.S. operates within a white racial frame which encompasses "a broad and persisting set of racial stereotypes, prejudices, ideologies, images, interpretations and narratives, emotions, and reactions to language accents, as well as racialized inclinations to discriminate" which has aggressively defended this unequal and unjust society (Feagin \& Bennefield, 2014, p. 8; Feagin, 2013, p. 3). Public health decision-makers are majority white, and most operate - consciously or not - within this white frame creating a "prowhite and anti-racial-others orientations" (Feagin \& Bennefield, 2014, p. 8). This operation has created discriminatory practices which account for the institutionalized inequalities in health care and health (Feagin \& Bennefield, 2014). Research on racial matters classify inequalities in terms of racial "disparities," failing to explain the foundational and systemic racism of the U.S. in creating the inequalities (Feagin, 2013). 
Recently, published research has identified racism in the context of health care and health disparities (Feagin \& Bennefield, 2014; Gee \& Ford, 2011; Krieger, 2003; Paradies, 2006; Walters et al., 2011). Jones (2000) published the earliest mentions of racism in a public health journal as she describes three levels of racism: institutionalized, personally mediated, and internalized. Jones (2000) fails to mention critical race research in her descriptions of racism or even contextualizes the personally-mediated level of racism within institutionalized racism. Most of this research takes the necessary steps for "analyzing the impact of white-controlled systemic racism on health care;" however, there is a need to shift the way the field of public health contextualizes problems and speak to the impact of systemic racism (Feagin \& Bennefield, 2014, p. 8).

Extensive research exists surrounding the impact of self-reported racism and discrimination and health (Brondolo, Rieppi, Kelly, \& Gerin, 2003; Calvin et al., 2003; Krieger, 1999, 2003; Krieger, Rowley, Herman, \& Avery, 1993; Paradies, 2006; Williams, Neighbors, \& Jackson, 2003; Williams \& WilliamsMorris, 2000). However, most of the literature focuses on perceived racism and discrimination and does not explore the impact of systemic racism on health. Bhopal and Donaldson (1998) proposed that terms such as White, Caucasian, European, Europid, Western, and Occidental, not be used in research because they are nonspecific, and the comparisons misleading; however, terms such as reference, control, or comparison are better, so readers will not make assumptions about comparison populations. By this concept, they suggested that research "move past this understandable anxiety and their proposal with greater 
openness that has heretofore been possible" (Fullilove, 1998, p. 1298). Fullilove (1998, p. 1298), discusses how Bhopal and Donaldson (1998) want researchers to "examine life factors that shape health outcomes." However, Fullilove (1998, p. 1298) points out that in the U.S., "social systems organize around racial inequality and clearly shape health outcomes." She poses the question, "if racism is a principal factor organizing social life, why not study racism, rather than race?" Fullilove (1998, p. 1298) makes a valid point, if public health is concerned with systems and structures that influence population health, not just studying racism on the individual level in adequate. Racism should be studied at the systemic level as well.

\section{Systemic Racism and Youth Violence}

While it is important to understand how systemic racism is a public health problem, it is equally as important to understand the impact systemic racism has on youth violence. A continued source of stress for Black youth as they transition into adulthood is racial discrimination (Caldwell, Kohn-Wood, Schmeelk-Cone, Chavous, \& Zimmerman, 2004; Krieger, 1990; Sellers, Caldwell, Schmeelk-Cone \& Zimmerman, 2003.) Substantial evidence indicates that racial discrimination is a fundamental part of the social structure in the lives of Black people (Cross, Parham, \& Helms, 1998; Jackson, Brown, Williams, Torres, Sellers, \& Brown, 1996; Williams, Spencer, \& Jackson, 1999). However, the experience of racial discrimination varies over the life course (Caldwell et al., 2004). Romero and Roberts (1998) found that older youth are more likely than younger youth to perceive racial discrimination; however, youth may not yet fully understand the 
concept. They also found that Black youth reported higher levels of perceived racial discrimination than other youth. Youth who perceive that society does not value their racial group may engage in violent behaviors as a way to cope with stressful racial experiences (Caldwell et al., 2004). This research illuminates a lack of research on the impact of systemic racism on youth and youth violence by focusing perceived racism and discrimination.

\section{Impact of Social Norms on Youth Violence}

Social norms are social attitudes of approval and disapproval, specifying what ought to be done and what ought not to be done (Sunstein, 1996). Social norms theory describes situations in which individuals incorrectly perceive the attitudes or behavior of peers and other community members to be different from their own when in fact they are not (Berkowitz, 2005). Descriptive norms provide a standard from which people do not want to deviate (Schultz, Nolan, Cialdini, Goldstein, \& Griskevicius, 2007). Injunctive norms refer to perceptions of what is commonly approved or disapproved within the culture (Schultz et al., 2007).

Descriptive norms were shown to have a larger effect on behavior than injunctive norms; however, injunctive norms have a larger effect on attitudes than descriptive norms (Melynk, van Herpen, \& van Trijp, 2010). Youth perceive their peers being involved in activities that they may not necessarily be involved in or want to be involved. They also perceive people feel a certain way about things, when actually they may not. Understanding the descriptive and injunctive norms surrounding youth violence are important to understanding whether youth will participate in violence and how they perceive violence. 
Evidence from existing interventions supports the alteration of social norms regarding violent behavior at both the individual and interpersonal levels, but much of it focuses on dating or gender-based violence (Fabiano, Perkins, Berkowitz, Linkenback, \& Stark, 2003; Foshee et al., 1998). Harvard University's School of Public Health implemented "Squash It!," a mass media youth violence prevention campaign in the 1990s targeting norms of violence. Results from the campaign suggest success in changing behavior, especially in Black youth; however, Harvard never officially published results from the campaign to document their findings. Other campaigns have published evidence that social norming media campaigns can be effective in changing behavior (Berkowitz, 2004; Goldstein \& Cialdini, 2007; Randolph \& Viswanath, 2004; Schultz et al. 2007).

Social norms in a community impact youth behavior regardless of the individual youth's attitudes toward that behavior (Stewart \& Simons, 2010). There is evidence that neighborhood-level street culture where street culture is dominant significantly predicts violent behavior (Steward \& Simons, 2010). Goldstein and Cialdini (2007) suggest that a primary mechanism to affect social norms on individual behavior is through the creation of one's social identity.

Social norms counteract the incorrect perception of norms by collecting accurate data in regards to the actual behavior of the population and exposing the population to accurate perceptions of how majority of the social group behaviors, as well as behaviors they approve or condone (Haines, Perkins, Rice, \& Barker, 2005). Anderson's (1999) seminal ethnographic study of inner city 
culture uncovered the mechanisms underlying social norms of violence among urban youth. He found that structural patterns of social and economic disadvantage and racial inequality foster a community "street culture" that engenders violence (Anderson, 1999). Disadvantaged and unequal structures create a sense of pessimism and hopelessness in communities which leads to a culture that seeks to undermine and oppose mainstream norms (Bruce, Roscigno, \& McCall, 1998; Hughes \& Short, 2005; Kubrin \& Weitzer, 2003; Melynk et al., 2010). This neighborhood culture has a great influence on individual behavior (Anderson, 1999); therefore, a community's opposition to mainstream norms emphasizes the importance of acquiring and maintaining the respect of others in the community is accomplished by demonstrating toughness and retribution for wrongs using violence (Anderson, 1999; Melynk et al., 2010). In this environment, if a person is challenged, individuals are expected - even obligated - to respond with violence (Hughes \& Short, 2005; Rich \& Grey, 2005).

Urban youth's culture of violence is complicated by a law enforcement and criminal justice system that discriminates against Blacks (Unnever, 2008). Carr, Napolitano, \& Keating (2007, p. 467) found that youth in neighborhoods with disproportionately high burdens of violent crime "reported being stopped for no good reason, harassed, treated roughly, as well as encountering dishonest and lackadaisical police," which leads to beliefs of procedural injustice and cultural attenuation. Therefore, many youth of color who live in urban areas subscribe to the understanding that if they want justice, they have to take matters into their own hands because no one will do it for them (Anderson, 1999). 


\section{Sociopolitical Development in Youth Development}

In most youth development literature, youth are seen "as objects of policy rather than as actors who possess the rights and abilities to shape policy" (Watts \& Guessous, 2006, p. 59). Therefore, the adult-only approach to creating solutions for social problems disempowers youth, and fails to mobilize "their capacity to resist and challenge unjust institutional practices" (Watts \& Guessous, 2006, p. 59). Watts and Guessous (2006, p. 60) define sociopolitical development (SPD) "as a product of both liberation and developmental psychology. It is the evolving, critical understanding of the political, economic, cultural, and other systemic forces that shape society and one's status within it, and the associated process of growth in relevant knowledge, analytic skills, and emotional faculties" (Watts, Williams, \& Jagers, 2003, p. 60). SPD stresses the importance of understanding the cultural and political forces that shapes one's status in society (Watts et al., 2003). It also acknowledges oppression and the influence of social forces outside the individual (Watts et al., 2003).

Flanagan (2004) believes that "civic - if not political - development has established itself," (Watts and Guessous, 2006, p. 60) even though there is little to no research or theory to support the concept of civic development. Kahne and Westheimer (2003) argue that a "good citizen" is framed in three ways "(1) citizenship manifested in individual acts such as volunteering; (2) citizenship in local community affairs, staying informed on local and locational issues; and (3) the justice-oriented citizen is who, like the participatory citizen, emphasizes collective work toward community betterment while maintaining a more critical 
stance on social, political, and economic issues" (Watts et al., 2003). However, youth do not hold much of this social power exclusively; it operates within adult and parental authority and formal institutions such as school (Watts et al., 2003). SPD argues that youth should hold power within each of these settings.

It is important for youth to conduct a social analysis to help them make connections between life in their communities and larger social forces (Ginwright, 2002). When people identify with certain groups, they are more willing to work to enhance the collective good rather than seeking individual gain (Brewer \& Gardner, 1996). Opportunities through faith-based organizations and other practical organizations provide youth spaces to develop leadership skills and to be recruited into civic action (Verba, Schlozman, \& Brady, 1995). This strategy is a way for people in lower socioeconomic status overcome class disparities (Verba, Schlozman, and Brady 1995). The concept of sociopolitical development is relatively young, and there is no evidence yet of its impact on youth violence; however, there are implications that it can be used as a mechanism for violence prevention.

\section{Racial and Ethnic Identity and Engagement in Violent Behaviors}

Youth violence data are often descriptive, reporting racial and ethnic differences in violent behaviors with little to no examination of how sociocultural factors such as racial identification or racial discrimination may influence the perpetration or avoidance of engaging in violent behaviors (Caldwell et al., 2004; Hammond \& Yung, 1993). Failing to examine sociocultural influences alongside racial and ethnic differences in violent behaviors provides only partial information 
(Caldwell et al., 1993; Jagers, 1996). The U.S. Office of the Surgeon General (2001) classifies race as a risk marker rather than factor of youth violence, because race proxies for other known risk factors such as poverty, living in a single parent home, low school achievement, and "being exposed to neighborhood disadvantage, gangs, violence, and crime." The link between race and violence is based on social and political distinctions rather than biological differences (Office of the Surgeon General, 2001). Ethnicity has also been proposed as a risk factor for youth violence; however, little to no evidence supports this claim (Office of the Surgeon General, 2001). Youth from ethnic minorities face discrimination and face stressors when their family culture conflicts with the dominant U.S. culture; however, their family culture can also serve as a protective factor (Office of the Surgeon General, 2001).

Helms (1990) defined racial identity as "a sense of group or collective identity based on one's perception that he/she shares a common racial heritage with a particular racial group." Racial identity development theory "concerns the psychological implications of racial-group membership; that is, belief systems that evolve in reaction to perceived differential racial-group membership" (Helms, 1990). Racial identity includes a common thread of historical experiences, and a member's "sense of group potency" depends on how they choose to identify (Helms, 1990).

It is important to note the difference between race and ethnicity. Keeping in line with Helms (1990) development of racial identity definition, she used Krogman's (1945) definition of race: "a sub-group of peoples possessing a 
definite combination of physical characters, of genetic origin, the combination of which to varying degrees distinguishes the sub-group from other sub-groups of mankind." She used Casas' (1984) definition of ethnicity, "as a group classification of individuals who share a unique social and cultural heritage (customs, language, religion, and so on) passed on from generation to generation."

The establishment of a racial identity is important to Black youth's selfworth (Caldwell et al., 2004; Cross, Parham, \& Helm, 1998; Phinney, 1990; Sellers, Rowley, Chavous, Shelton, \& Smith, 1997; Spencer, Cunningham, \& Swanson, 1995). Racial socialization is a primary mechanism through which Black youth gain both a positive racial identity and strategies to cope successfully with racial discrimination (Hughes, 2003; Phinney \& Chavira, 1995). Black parent's racial socialization strategies shape children's racial identity (AlejandroWright, 1999; Demo \& Hughes, 1990; Neblett, Smalls, Ford, Nguyên, \& Sellers, 2009). However, it has also been found that racial socialization messages directed at Blacks' racial identities may be more enduring if they come from nonparental adult family members as opposed to parental figures (Thompson, 1994).

There is growing evidence that salient racial identity is a psychosocial protector in mental health functioning and health risk behaviors (Belgrave et al., 1994; Brook, Balka, Brook, Win, \& Gursen, 1998; Caldwell, Zimmerman, Bernat, Sellers, \& Notaro, 2002; Klonoff \& Landrine, 1999; Rowley, Sellers, Chavous, \& Smith, 1998; Scheier, Botvin, Diaz, \& Ifill-Williams, 1997; Sellers, Caldwell, Schmellk-Cone, \& Zimmerman, 2003). Numerous researchers have argued that 
racial identity is a multidimensional construct (Gonzales \& Cauce, 1995; Phinney, 1992; Romero \& Roberts, 1998; Rotheram-Borus, Lightfoot, Moraes, Dopkins, \& LaCour, 1998; Sanders-Thompson, 1994; Sellers, Smith, Shelton, Rowley, \& Chavous, 1998; Smith, Walker, Fields, Brookins, \& Seay, 1999; Stevenson, 1994). Racial identity attitudes relate to violent behavior in different ways (Caldwell et al., 2004). Paschall and Hubbard (1998) examined the relationship between ethnic identity and violent behavior in African American males between the ages of 12 and 16 . They found that as their ethnic identity increased, their probability of engaging in violence decreased. Another study found that ethnic identity was associated with positive attitudes against fighting in early adolescents for Blacks (Arbona, Jackson, McCoy, \& Blakely, 1999).

There is also evidence that racial identity is associated with experiences with racial discrimination in different ways (Major, Levin, Schmader, \& Sidanius, 1999; Operario \& Fiske, 2001; Sellers et al., 2001; Shelton \& Sellers, 2000). Operario and Fiske (2001) found that when respondents who identify as Asian, African American, or Latino were highly ethnically identified, they had more personal experiences with racial discrimination (Caldwell et al., 2004). Shelton and Sellers (2000) found that African Americans where race was a central part of their identity were more likely to attribute discrimination to racism than African Americans where race is not a central part of their identity (Caldwell et al., 2004). Additionally, Romero and Roberts (1998) found that the "relationship between positive ethnic affirmation and racial discrimination was mediated by attitudes toward other groups, whereas high ethnic exploration was directly related to 
perceptions of racial discrimination" (Caldwell et al., 2004). Brown and Tylka (2010) found that participants who reported higher levels of racial discrimination had high racial socialization messages.

Black males with low racial identity may engage in stereotypically "reactive masculinity" to maintain a positive self-image (McMahon \& Watts, 2002); however, high levels of racial identity has been found to offset the societal stigmatization of being an Black males and reduces violent behavior (Arbona et al., 1999; Caldwell et al., 2004; McMahon \& Watts, 2002; Paschall \& Hubbard, 1998). These findings suggest that Black youth who have a strong sense of racial identity are less likely to engage in violent behaviors (Caldwell et al., 2004). However, many of the studies included small Black samples, "focused primarily on males, examined attitudes and not behavior, considered only main effects, or included unidimensional measures of racial identity" (Caldwell et al., 2004).

\section{Gaps in Existing Literature}

Much of the literature presented hints at other concepts presented with no direct connection. Youth violence risk factors speak of societal level factors such as policies or poverty; however, race and racism are not directly mentioned or researched as a casual factor in which neighborhoods are created in which youth violence is pervasive. Beyond not mentioning race and racism, there is limited evidence of the impact of history on youth violence. It is important to understand historical policies and practices that have created the social environment in which youth violence is pervasive. Connecting the history of not only the U.S., but also the city and community of interest includes context that is important in 
understanding how the community got to where they are now. Youth violence has been contextualized from an individual level perspective; situating the issue in the context of risk and protective factors, not the systems and structures that create the conditions in which youth violence is pervasive or necessarily to an extent for some youth. Systemic racism is a broad topic that has been studied and included extensively in a variety of disciplines; however, public health has not ubiquitously integrated the concept into research or foundational courses. There is much evidence of racial disparities, but many reference back to the social determinants of health, still failing to acknowledge the systemic implications that have created the social determinants and disparities that exist within them. Further, there is a lack of attention to intersectionality within the field and discussion of disparities in public health. Race and ethnicity, gender, sexual orientation, income, and other determinants do not operate exclusively; therefore, they should be discussed and researched from an intersectional viewpoint. Sociopolitical development and racial identity are closely related and are protective factors for youth violence. Connecting sociopolitical development and racial identity development to systemic racism and including the discussions of conditions will provide practitioners with a full understanding of not only their environment, but also provide them with the knowledge to work towards addressing systemic issues within their community.

\section{Contributions of the Proposed Study}

It was important to frame youth violence in the context of systemic racism as opposed to viewing youth violence existing because of risk and protective 
factors. Traditionally, public health contextualizes a problem within the social determinants of health and further the racial disparities that exist within those determinants. However, those determinants and disparities exist because of structural institutions that have created conditions to place certain groups in subordination and then points the blames them for much of the problems that exist. The proposed study starts with a systematic literature review of systemic (structural and institutional) racism within the public health literature, not from the perceptive of individuals, however, at the systems level. The systematic literature review will provide an understanding of how public health literature has addressed systemic racism and provide language on how to move from discussing the issues in context of the behaviors of the individual, but more so, in the context of the impact of systems. Next, this study will examine the impact of systemic racism above and beyond social norms on youth participating in violent behaviors. It will provide a connection between concepts such as systemic racism, which has operated in isolation or without direct mention of how they impact social norms, racial and ethnic identity, exposure to violence, and sociopolitical development. The study will also provide context for additional social norms present amongst youth in Louisville. Subsequently, this research will call for the inclusion of taking a Critical Race Theory approach to addressing problems within public health and looking at systemic racism from a systems perspective when discussing race and racial disparities. 


\section{CHAPTER III \\ METHODOLOGY \\ Introduction}

For centuries, people of color have lived in conditions created through systemic racism. The purpose of this study is to review how public health acknowledges and attends to systemic racism as a root cause of poor health outcomes. The study will also examine the impact of systemic racism and West Louisville youth's social norms of violence on their participation in violent behaviors, and explore additional factors that contribute to their social norms of violence. West Louisville continues to face challenges that are the direct result of systemic racism such as high poverty rates, high crime rates, lack of economic investment, inequality in access to health care, and high unemployment rates. The results of this exploratory study will serve as a call to examine racism within local, state, and federal policies, which have created the conditions in which youth have increased risk factors for participating in violent behaviors. It also seeks to shift the discussion from racial disparities to examining how racism has and continues to produce those disparities.

This study will utilize a mixed methods design to answer three distinct research questions:

Research Question 1: To what extent does the public health literature address systemic racism as an issue or factor influencing health? 
Research Question 2: To what extent does systemic racism relate to West Louisville youth's participation in violent behaviors above and beyond social norms.

Research Question 3: What additional factors contribute to West Louisville youth's view on the social norms of youth violence?

This study utilized data from the University of Louisville's Youth Violence Prevention Research Center (YVPRC) 2017 School Survey and Pre-Campaign focus groups, which was approved by the University of Louisville Institutional Review Board. A systematic literature review will be used to address Research Question 1. Quantitative analysis of school survey data will address Questions 2 and 3, and a qualitative component will explore answers to Question 3 as well.

\section{Setting}

The West End of Louisville, commonly referred to as West Louisville (WL) was the target geographic area of interest for the proposed study. In 2014, 60,749 residents comprised West Louisville, which is made up of nine contiguous neighborhoods (Algonquin, California, Chickasaw, Park DuValle, Park Hill, Parkland, Portland, Russell, and Shawnee), that cover 22 census tracts (Kentucky State Data Center [KSDC], 2014; United States [U.S.] Census Bureau, 2012a). Youth comprise about 24 percent $(14,476)$ of the total West Louisville population (KSDC, 2014; U.S. Census Bureau, 2012a). The overall poverty rate of the area is 42.7 percent, nearly three times the rate of all Louisville Metro LM (16.5\%) (KSDC, 2014). The median household income in West Louisville is $\$ 22,170$ - less than half of Louisville Metros median household income of 
$\$ 46,701$. The overall unemployment rate in West Louisville is 23.3 percent more than twice the rate of Louisville Metro (10.0\%) as a whole (KSDC, 2014; U.S. Census Bureau, 2012b). Participants will be recruited from within Jefferson County Public School (JCPS) District middle and high schools. JCPS educates more than 100,600 students, within 173 schools, by over 6,400 teachers (Jefferson County Public Schools, n.d.).

\section{History of Louisville}

The reputation of West Louisville is that it is crime infested, dirty, ghetto, where all the Black people live in the city, stricken with poverty, violent, unsafe, bad, ugly, and not a great place to live. However, West Louisville has not always been seen this way and many of the conditions have been created through systemic racism. Black people have had a vital presence in Louisville and Jefferson County since the earliest days of settlement (Kleber, 2001). And despite Black people such as Cato Watts and Caesar assisting in the discovery of Louisville, "the lives of African Americans were shaped and constrained by the institution of slavery and by a culture that accepted and justified human bondage" (Kleber, 2001, p. 15). Throughout antebellum, Black people accounted for onethird of the county's population, most of whom were slaves (Kleber, 2001). Many were not slaves in the "traditional" sense; only 30 percent of whites owned slaves, so businesses and less-affluent whites would rent slaves for varying periods of time, and there were various domestic slave trade businesses (Kleber, 2001). 
With the growing population of Black people, Black communities started to develop west and east of downtown (Kleber, 2001). Within these communities, Black people developed their own system of leadership, methods of relations with whites, and means that were helpful to fugitive slaves (Kleber, 2001). At the end of slavery, "racial attitudes and the determination to maintain the subordination of African Americans did not change" (Kleber, 2001, p. 15). During Reconstruction, racial segregation evolved "as a means of ensuring a safe status difference between the races; any condition or interaction that implied white subordination to or equality with African Americans was proscribed" (Kleber, 2001, p. 15). Discrimination, poverty, poor housing, crime and police brutality existed as a norm within the city; however the local Black community continued to develop, but within the limits of "slavery and freedom" in the words of President James A. Garfield (Kleber, 2001, p. 15).

While Black people were developing and sustaining their own communities within these conditions, actual policies began to pass that would distinctly place them in subordination. In 1914, the Louisville Board of Aldermen passed an ordinance that prevented Black residents from moving onto streets that were majority white, and white residents from moving to areas that had been designated Black. In response, the Louisville Chapter of the National Association for the Advancement of Colored People (NAACP) was founded, and two men took Buchanan v. Warley (1917) to the Supreme Court, which ruled the ordinance unconstitutional (Fosl et al., 2013). The city saw an emergence of new 
Black communities: Smoketown, California, and Little Africa, which were wellorganized and comparatively stable (Kleber, 2001).

Despite this victory, several factors contributed to the continued segregation of Black and white communities in the period that followed. Realtors steered white and Black buyers to separate neighborhoods; zoning laws limited multi-family housing, "restrictive covenants" mandated to whom buyers could sell; white community petitions were passed around to keep Blacks out of certain neighborhoods; and the federal Home Owner's Loan Corporation "redlining" deemed most Black neighborhoods "low quality" for investment purposes (Aubespin, Clay, \& Hudson, 2011; Fosl et al., 2013). Redlining "is the refusal of lenders to make mortgage loans in certain areas regardless of the creditworthiness of the individual loan applicant" (Holmes \& Horvitz, 1994, p. 81). This public policy which lies within the context of "lack of available credit typically described as due to racial bias or irrational behavior - is cited as a causal factor in neighborhood deterioration" (Lang \& Nakamura, 1993, p. 224). Appendix A, includes the redlining maps for Louisville compared to a map of WL. The height of Black businesses in Louisville occurred between 1900 and 1930 (Kleber, 2001). The Great Depression brought "massive economic dislocation" (Kleber, 2001, p. 16). However, after World War II, led by Lyman T. Johnson, the local NAACP, and other white liberals, the structure of legal segregation collapsed (Kleber, 2001). During the early 1950s, many local establishments became desegregated through policies. "While the end of legal segregation brought Blacks closer to the goal of racial equality, it still failed to 
achieve it and Louisville remained two communities divided by race" (Kleber, 2001, 17).

Urban renewal in Louisville attempted to level Black residential areas both east and west of downtown Louisville during the late 1950s and early 1960s through the creation of new housing developments. According to the U.S. Department of Housing and Urban Development, the Urban Renewal Project is: a project planned and undertaken by an LPA (Local Public Agency) in an urban renewal area with Federal financial and technical assistance under Title I of the Housing Act of 1949. A project may involve slum clearance and redevelopments rehabilitation and conservation, or a combination of both. It may include acquisition of land, relocation of displaced site occupants, site clearance, installation of site improvements rehabilitation of properties and disposition of acquired land for redevelopment in accordance with the Urban Renewal Plan (U.S. Department of Housing and Urban Development, n.d.).

Urban renewal in Louisville demolished homes and businesses at Old Walnut Street - the heart of African American life in the city and the thriving business district corridor - and the area has never recovered (Aubespin et al., 2011; Fosl et al., 2013; Kleber, 2001). During the 1960s, more than 15,000 white residents left West Louisville and settled to the east and south ends of Louisville (Fosl et al., 2013). Currently, 45 percent of Louisvillians live in segregated areas, and residents of West Louisville face substantial health, social, education, and economic difficulties compared to the rest of the city (Fosl et al., 2013). 
Additionally, Louisville's white-Black dissimilarity index is 68.6 , meaning that 68.6 percent of white people would need to move to another neighborhood to make whites and Blacks evenly distributed across all neighborhoods in Louisville (CensusScope, n.d.). Compared to U.S. Metro Areas, Louisville is ranked $69^{\text {th }}$ out of $318^{5}$ (CensusScope, n.d.). For the purpose of this study, history provides context on how the historical neighborhoods of West Louisville were formed, how they compare to Louisville Metro, and subsequently the conditions within the neighborhood that have put them at higher risk of engaging in violent behaviors based on historical practices, such as redlining.

\section{Violence in West Louisville}

In addition to understanding the socioeconomic demographics of Louisville Metro and West Louisville, it is important to understand violence in West Louisville. Violent crime rates for West Louisville are significantly higher than in surrounding areas. Table 2 shows felony crime rates from Louisville Metro Police Department (LMPD) between 2012 and 2013 for all of Louisville Metro, West Louisville falls within Divisions 1 (Portland, Russell, and Phoenix Hill neighborhoods) and 2 (Shawnee, Chickasaw, and Park DuValle neighborhoods). Felony crime rates within West Louisville range between 69.3 and 126 per 1,000 residents. As provided by LMPD, the juvenile arrest/citation rates for West Louisville are higher than Louisville Metro, ranging from 4.6 to 6.1 per 1,000 residents, compared to 1.1 to 2.3 per 1,000 residents respectively. In 2016, Louisville recorded its highest homicide rate of 113 , tying the deadliest single

\footnotetext{
${ }^{5}$ There are 382 Metropolitan Statistical Areas as delineated by the Office of Management and Budget.
} 
year for homicides, 1971 (Eisenmenger, 2016). From 2009 - 2013, 280 homicides were reported in Louisville. Approximately, 50 percent of those homicides occurred in WL (LMG: OSHN, 2015).

Table 2

2012 and 2013 Crime Rates by Louisville Metro Police Department Divisions

\begin{tabular}{|c|c|c|c|}
\hline LMPD Division & Total Population & $\frac{\text { Felony per } 1,000}{\text { residents }}$ & $\frac{\text { Juvenile arrest }}{\frac{\text { per } 1,000}{\text { residents }}}$ \\
\hline 1 & 28,621 & 126.0 & 6.1 \\
\hline 2 & 49,544 & 69.3 & 4.6 \\
\hline 3 & 119,781 & 37.7 & 2.2 \\
\hline 4 & 72,838 & 64.3 & 2.3 \\
\hline 5 & 62,938 & 30.5 & 1.1 \\
\hline 6 & 89,015 & 36.9 & 1.6 \\
\hline 7 & 110,728 & 26.5 & 1.9 \\
\hline 8 & 119.860 & 15.6 & 16 \\
\hline
\end{tabular}

Louisville Metro Government and many local organizations have shifted their focus to improving the quality of life in West Louisville by providing substantial attention, resources, and political will to alleviate disparities facing the community. These entities as well as University of Louisville's YVPRC have created initiatives to reduce youth violence through a variety of methods. Before the University of Louisville's YVPRC social norming campaign was deployed, they distributed a school survey to gather baseline data regarding the norms of violence that exist, as well as the extent to which youth are being affected by violence. Data from the school survey was used to answer the research questions for this study. 


\section{Data Collection Methodology}

This study utilized a systematic literature review and mixed methods approach to answer the following research questions:

Research Question 1: To what extent does the public health literature address systemic racism as an issue or factor influencing health?

Research Question 2: To what extent does systemic racism relate to West Louisville youth's participation in violent behaviors above and beyond social norms.

Research Question 3: What additional factors contribute to West Louisville youth's view on the social norms of youth violence?

The systematic literature review data collection methods were designed specifically for this study. The YVPRC research team developed the quantitative and qualitative methods for data collection, recruitment, and analysis (qualitative only) as a part of their study. The data were collected to provide baseline data for the creation of their social norming campaign and will be used to measure campaign exposure. The quantitative instrument- school survey - is comprised of validated question sets from multiple surveys, and the qualitative instrument pre-campaign focus groups - was created by the research team. Research Question 1 were answered through a systematic literature review, and questions 2 and 3 were answered using the school survey and pre-campaign focus groups (research question 3). 


\section{Systematic Literature Review}

To answer Research Question 1, a systematic literature review was conducted using the Preferred Reporting Items for Systemic Reviews and MetaAnalysis (PRISMA) standards. According to PRISMA, a systematic review "is a review of a clearly formulated question that uses systematic and explicit methods to identify, select, and critically appraise relevant research, and to collect and analyze data from the studies that are included in the review" (Moher, Liberati, \& Alman, 2009, p. 1). In public health, a great deal of literature exists regarding race and health or racial disparities, but a dearth of literature exists explicitly focusing on systemic racism as a public health issue. Current literature talks about perceptions of racism and discrimination rather than the impact of racism within systems. The purpose of this systematic literature review was to look more closely at racism within public health from the context of the systemic/structural/institutional level (policies) rather than the individual level (perceived racism and discrimination). The systematic review eliminates bias and provides objective findings to draw conclusions that will be useful for determining the extent to which public health addresses systemic racism.

The population of study includes Black people who participated in interventions that looked at a variety of health outcomes in quantitative and qualitative studies along with conceptual and theoretical articles. It also aligns with the population of interest for the overall study.

Eligibility Criteria. Studies published after 1968 were included in the search. Ture and Hamilton (1967), provide the definition for how 
systemic/structural/institutional racism is defined in this study; therefore, studies published after 1968 were eligible for review. Only those in English and conducted within the U.S. were eligible because the foundation of this study reviews systemic racism within the context of U.S. systems. Only peer-reviewed studies in pre-identified public health journals were included to ensure that rigor and scrutiny of others within the field of public health were a part of assessing the research. Only including studies within public health journals excludes the influence of the importance of the topics within other disciplines, but examines what the leading public health journals are publishing regarding the topic. Table 3 includes the agreed upon journals to be included in the study. Additionally, only studies that address systemic, institutional, or structural racism from a systems perspective are eligible for inclusion. 
Table 3

Public Health Journals Eligible for Systematic Literature Review

\begin{tabular}{|c|c|}
\hline American Journal of Health Promotion & American Journal of Public Health \\
\hline Annual Review of Public Health & Community Development Journal \\
\hline Environmental Health Perspectives & Ethnicity and Disease \\
\hline Ethnicity and Health & Family and Community Health \\
\hline Frontiers in Public Health & Global Public Health \\
\hline Health Affairs & Health and Place \\
\hline Health Communication & Health Education and Behavior \\
\hline $\begin{array}{l}\text { Health Education Research } \\
\text { Health Promotion Perspective }\end{array}$ & $\begin{array}{l}\text { Health Promotion Practice } \\
\text { Health Services Management } \\
\text { Research }\end{array}$ \\
\hline Health Services Research & Journal of Community Health \\
\hline Journal of Community Prac & $\begin{array}{l}\text { Journal of Education \& Health } \\
\text { Promotion }\end{array}$ \\
\hline $\begin{array}{l}\text { Journal of Epidemiology \& Community } \\
\text { Health }\end{array}$ & Journal of Health and Social Behavior \\
\hline $\begin{array}{l}\text { Journal of Healthcare for the Poor \& } \\
\text { Underserved }\end{array}$ & Journal of Healthcare Management \\
\hline $\begin{array}{l}\text { Journal of Prevention \& Intervention in } \\
\text { the Community }\end{array}$ & Journal of Primary Prevention \\
\hline Journal of Public Health & $\begin{array}{l}\text { Journal of Public Health Management } \\
\& \text { Practice }\end{array}$ \\
\hline Journal of Public Health Policy & $\begin{array}{l}\text { Journal of Racial Ethnic Health } \\
\text { Disparities }\end{array}$ \\
\hline Journal of Social Issues & Perspective in Public Health \\
\hline Preventing Chronic Disease & Prevention Science \\
\hline $\begin{array}{l}\text { Progress in Community Health } \\
\text { Partnerships }\end{array}$ & Public Health \\
\hline $\begin{array}{l}\text { Qualitative Health Research } \\
\text { Urban Health }\end{array}$ & Social Science and Medicine \\
\hline
\end{tabular}

Information Sources. At the advice of a health sciences librarian, MEDLINE (PubMed), Embase, and EBSCO databases were used for the systemic literature review. MEDLINE is known as one of the most comprehensive databases with only peer-reviewed articles, so it was the first database searched, followed by Embase, which is typically used to check the work of what was found in MEDLINE, and lastly, Ebsco was searched to ensure there were articles 
outside of those found in MEDLINE and Embase. The literature review was completed on March 31, 2017 and includes articles from January 1968 until the date of completion. No authors were contacted to determine if they had published additional articles that fit the criteria, mostly to ensure that whatever was found was accessible to public health practitioners.

Search. The search strategy used for this literature review was standard across all platforms with few variations, most of which are based on the database options. Once the databases were identified, a comprehensive Excel spreadsheet was created to track articles found based on four criteria identification, screen, eligibility, and included. Prior to starting the search, each database was cleared so anything previously searched were not included.

Identification. The search began by typing in the following key words separately: systemic racism, structural racism, institutional racism, racism, racist, racial trauma, racial stress, racial discrimination, racial oppression, racial marginalization, systemic racial disparities, structural racial disparities, and institutional racial disparities. After each key word was initially searched, the number of articles returned was recorded. Next, using the database option of time range, the articles before 1968 were eliminated, as well as those that were not in English were eliminated. In the MEDLINE (PubMed) database, articles can be sorted based on journals, so the articles were sorted alphabetically based on journal titles. Articles in journals on the pre-identified list of journals were selected for the screening process. 
Screening. During the screening process, the abstract for the articles that were in eligible public health journals were read and those that did not fit in the categories of being conducted in the U.S., primary population of study was not Black, and did not address systemic, institutional, or structural racism were excluded. Articles fitting the criteria created for this literature review were moved to the eligibility category. While in the eligibility category, full articles were read for full check and fit for the literature review.

\section{Quantitative Methods - School Survey}

The purpose of the quantitative portion of this study is to understand how systemic racism and the social norms - injunctive and descriptive - of violence impact West Louisville youth's participation in violence. Quantitative research is used for testing objective theories by examining the relationship among variables (Creswell, 2013). According to Creswell (2013), survey research provides a quantitative description of trends, attitudes, or opinions of a population by studying a sample of that population.

The purpose of the YVPRC 2017 School Survey was to gather data that assesses the social norms of youth violence, exposure to violence, perceptions of community, attitudes toward violence, cultural identity, social cohesion, civic responsibility, and sociopolitical development among middle and high school youth in Louisville to measure the effect of their social norming campaign intervention.

Recruitment. Students were recruited from 16 target schools, with a total enrollment of these schools combined at 17,565 (Jefferson County Public 
Schools, n.d.). These schools were selected to comprise an adequate sample of students who reside in West Louisville as a proportion of the overall sample (approximately 1 in 3 students of these schools combined). The paper surveys were distributed to each student through the Family Resource and Youth Service Center (FRYSC) Coordinators. FRYSC coordinators develop and coordinate the resource center programs within JCPS schools. They develop and maintain contact with business and community representatives throughout Louisville (Jefferson County Public Schools, n.d.). FRYSC Coordinators have the contact information (email and/or cell phone) for students and the students' parents/guardians in their respective school. Because the school surveys were voluntary and confidential, parents were notified and given the opportunity to inspect the content of the survey before it was deployed to their student. The FRYSC Coordinator for each school sent the University of Louisville's Institutional Review Board-approved parent email on behalf of the study team informing parents about the survey and its contents, and informing parents how to obtain a copy of the survey for their review if they so desired. The emails were disseminated weekly for three consecutive weeks prior to deploying the email to students containing the link to take the survey. All students in the 16 target schools were invited to participate in the survey. Because the survey was only available in English, students who could not communicate in English were excluded.

Instrument. The YVPRC 2017 School Survey was comprised of validated instruments used in studies across the country. Most of the measures can be 
found in the Centers for Disease Control and Prevention's Youth Violence Compendium of Assessment Tools (Dahlberg, Toal, Swahn, \& Behrens, 2005), as well as Virginia Commonwealth University's Youth Violence Prevention Center (VCU) (Virginia Commonwealth University Clark-Hill Institute for Positive Youth Development, n.d.). Table 4 includes a description of scales used in the instrument to measure the constructs used in this study, along with their reliability/validity and developer. The YVPRC 2017 School Survey can be found in Appendix B. 
Table 4

Selected YVPRC 2017 School Survey Quantitative Constructs Utilized for This Study

\begin{tabular}{|c|c|c|c|c|}
\hline Construct & $\begin{array}{c}\text { Scale/ } \\
\text { Assessment }\end{array}$ & Characteristics & $\frac{\text { Reliability/ }}{\text { Validity }}$ & Developer \\
\hline $\begin{array}{l}\text { Descriptive } \\
\text { Norms of } \\
\text { Violence }\end{array}$ & $\begin{array}{l}\text { Peer } \\
\text { Behaviors } \\
\text { Scale; } 10 \\
\text { items }\end{array}$ & $\begin{array}{l}\text { Measure assessing } \\
\text { youth reports of } \\
\text { friends' involvement } \\
\text { in various activities }\end{array}$ & .88 & VCU \\
\hline $\begin{array}{l}\text { Injunctive } \\
\text { Norms of } \\
\text { Violence }\end{array}$ & $\begin{array}{l}\text { Peer Support } \\
\text { for } \\
\text { Aggression } \\
\text { and } \\
\text { Nonviolence } \\
\text { Scale; } 6 \\
\text { scenarios }\end{array}$ & $\begin{array}{l}\text { Assesses youth's } \\
\text { expectations for } \\
\text { how their peers } \\
\text { would react to } \\
\text { different ways the } \\
\text { youth might respond } \\
\text { to a difficult situation }\end{array}$ & $\begin{array}{l}\text { Support for } \\
\text { Aggression } \\
\text { subscale = } \\
.76 ; \\
\text { Support for } \\
\text { Nonviolent } \\
\text { Behavior } \\
\text { subscale = } \\
.77\end{array}$ & VCU \\
\hline $\begin{array}{l}\text { Cultural } \\
\text { Identity }\end{array}$ & $\begin{array}{l}\text { Multigroup } \\
\text { Ethnic } \\
\text { Identity; } 15 \\
\text { items }\end{array}$ & $\begin{array}{l}\text { Measures ethnic } \\
\text { identity search (a } \\
\text { developmental and } \\
\text { cognitive } \\
\text { component) and } \\
\text { affirmation, } \\
\text { belonging, and } \\
\text { commitment (an } \\
\text { affective } \\
\text { component) }\end{array}$ & .80 & $\begin{array}{l}\text { Phinney, } \\
1992\end{array}$ \\
\hline $\begin{array}{l}\text { Exposure } \\
\text { to violence }\end{array}$ & $\begin{array}{l}\text { Children's } \\
\text { Exposure to } \\
\text { Community } \\
\text { Violence; } 10 \\
\text { items }\end{array}$ & $\begin{array}{l}\text { Measures frequency } \\
\text { of exposure } \\
\text { (through sight and } \\
\text { sound) to violence } \\
\text { in one's home and } \\
\text { neighborhood. }\end{array}$ & .84 & $\begin{array}{l}\text { Richters \& } \\
\text { Martinez, } \\
1990\end{array}$ \\
\hline $\begin{array}{l}\text { Violent } \\
\text { Behavior }\end{array}$ & $\begin{array}{l}\text { Victimization; } \\
10 \text { items }\end{array}$ & $\begin{array}{l}\text { Measures exposure } \\
\text { to violence and } \\
\text { victimization in one's } \\
\text { home, school, and } \\
\text { neighborhood }\end{array}$ & $\begin{array}{l}\text { Not } \\
\text { available }\end{array}$ & $\begin{array}{l}\text { Nadel, } \\
\text { Spellmann, } \\
\text { Alvarez- } \\
\text { Canino, } \\
\text { Lausell- } \\
\text { Bryant \& } \\
\text { Landsberg, } \\
1991\end{array}$ \\
\hline
\end{tabular}




\section{Data Collection}

Each FRYSC Coordinator distributed the survey to the students of his/her respective school one week after the final parent email was sent. Surveys were distributed in a variety of methods throughout the school (homeroom, lunch, or after school programs). FRYSC Coordinators contacted the YVPRC research team when the surveys were completed for their schools. The team scanned in each survey and uploaded the data to SPSS for analysis. The YVPRC team cleaned the data and provided it for the study.

\section{Qualitative Methods - Pre-Campaign Focus Groups}

The purpose of the qualitative portion of this study was to understand the additional factors that influence the social norms of youth violence. Creswell (2013, p. 44) states that "qualitative research begins with assumptions and the use of interpretative/theoretical frameworks that inform the study of research social or human problem." Qualitative researchers collect data in "natural settings sensitive to the people and places under study, and data analysis that is both inductive and deductive and establishes patterns or themes (Creswell, 2013, p. 44)." Qualitative data include "voices of participants, the reflexivity of the researcher, a complex description, and interpretation of the problem, and its contribution to the literature or a call for change," or in the case of the campaign, inform the design of the campaign (Creswell, 2013, p. 44).

The questions created by the YVPRC research team focused on uncovering existing norms - descriptive and injunctive - as well as 
understanding implications of violating the perceived norms. The focus group questions solicited information about what types of media youth are using, for what purposes, how often, and their level of trust in different applications. The data are relevant to this study because they add additional context to the quantitative data from the school surveys.

Recruitment. The YVPRC research team conducted nine focus groups with various WL youth age groups (middle schoolers, high schoolers, and post high schoolers), parents, and police officers. The YVPRC research team has existing community partnerships with local organization such as the Mayor's Office, local clinics and hospitals, youth serving organizations, community centers, libraries, etc. The research team recruited participants through a variety of methods, but mostly through these community partners. The partner organizations recruited potential participants, who then received a flyer with focus group information. Participants ages 11 to 17 received a parental sign consent form by email, mail, or it was hand-delivered before the scheduled focus group. The focus group facilitator reviewed the assent form with participants prior to the focus group, and assent was obtained before the focus group discussion began. Participants ages 18 and older received the consent form by email prior to the focus group; the facilitator reviewed the consent form prior to the discussion and obtained consent before beginning the audio-recording. Youth who participated in the focus groups received a $\$ 25$ incentive.

Inclusion Criteria. In order to participate in the focus groups, individuals had to be:

- Between the ages of 11 and 24 who live in West Louisville; 
- Parents/caregivers of West Louisville youth; or

- Police officers who patrol Divisions 1 and 2.

Exclusion Criteria. Individuals who could not communicate in English or who were unwilling to be audio-recorded were excluded from the study.

Instrument. The pre-campaign focus groups were designed to understand the perspectives and experiences of youth ages 11 to 24 and the adults with whom they interact regularly regarding social norms of violence in the community and where those norms derive from, attitudes toward violence, and the relationship between norms and attitudes on behavior. Secondarily, the focus groups explored youth media use habits to provide information back to campaign development and implementation.

Focus groups were scheduled at a safe public facility (i.e., church, community center, library). When the participants arrived, the research staff conducting the focus group reviewed the minor assent / or participant consent (depending on participant age) with the participants. The focus group facilitator reiterated that participation was voluntary and nothing they said would be reported by name or other identifying information. They also notified participants that the focus group was being audio-recorded to be transcribed for analysis. After any questions were answered, the focus group facilitator began the audio recorder, and started the focus group. When the group ended, the recorder was turned off, and the audio files were subsequently sent for transcription. The topicguide for the groups are attached in Appendix C.

\section{Analysis Plans}

The analysis plan for the proposed study is described for each research 
question separately. Analysis will include extensive use of graphic data displays and significance tests when appropriate.

\section{Research Question 1 Analysis Plan}

RQ1: To what extent does the public health literature address systemic racism as an issue or factor influencing health?

To answer research question one, a systematic literature review will be conducted. Using the criteria from PRISMA, once the selected studies that will be included for review are selected, a thorough review of how the researchers discuss as well as address systemic racism will be documented and discussed to answer the research question (Liberati et al., 2009).

\section{Research Question 2 Analysis Plan}

RQ2: To what extent does systematic racism relate to West Louisville youth's participation in violent behaviors above and beyond social norms?

Behavioral data commonly have a nested structure; for example, these data are from students nested within schools nested within neighborhoods. Early applications of hierarchical linear models (HLM) addressed three general research purposes: improved estimation of effects within individual units, the formulation and testing of hypotheses about cross-level effects, and the partitioning of variance and covariance components among levels (Raudenbush \& Bryk, 2002). To analyze whether there is a relationship between the level of systemic racism a student's neighborhood experiences and their social norms of violence in with their participation in violent behaviors, HLM7 (Scientific Software International) will be used. Multilevel modeling allows a determination of the 
variance into within- (Level 1 model) and between-neighborhood components (Level 2 model) (Raudenbush \& Bryk, 2002).

Using Raudenbush \& Bryk's (2002) model-building strategy, the proposed study will start with the building of an unconditional growth model to estimate the intraclass correlation, then Level-1 random and fixed effects, then followed by level-2 random and fixed effects. Based on likelihood ratio tests, the optimal model fit for Level 1 variables will help determine which variables will be included on both the intercept and slope and then used for Level 2 analysis. Further, the analysis will be ran using restricted maximum likelihood (REML). REML estimates of variance-components adjust for the uncertainty about the fixed effects (McCoach \& Black, 2008).

Individual Level Variables. Data on individual-level variables include injunctive norms, descriptive norms, exposure to violence, participation in violent behavior, and cultural identity. These data were obtained from the YVPRC 2017 School Survey, which was comprised of validated measures to determine the social norms of youth violence in Louisville, as well as other measures looking at local exposure and participation in violence, cultural identity, and sociopolitical development. Many of the scales can be found in the Centers for Disease Control and Prevention's (CDC) Youth Violence Compendium of Assessment Tools (Dahlberg, et al. 2005) as well as the Virginia Commonwealth University's Youth Violence Prevention Center (VCU) (Virginia Commonwealth University Clark-Hill Institute for Positive Youth Development, n.d.). Table 4 includes the constructs utilized for this study from the 2017 School Survey, while Table 5 is 
the coding scheme for quantitative coding schemes utilized to answer Research Question 2.

Dependent variables. Participation in violent behavior was used to measure violent behavior using the victimization scale from the CDC's Youth Violence Compendium, which measures exposure to violence and victimization in one's home, school, and neighborhood (Dahlberg et al., 2005; Nadel et al., 1991). YVPRC only used 10 of the 14 questions from the original scale, and respondents could choose from the options of never, once or twice, a few times, or many times. The items determine whether violence is direct or vicarious. The mean score for each set of question was calculated, with higher scores indicating participation in violent behaviors many times.

Institutional-Level Variables. Students were asked what neighborhood they lived in, providing information to connect individual-level variables to the institutional-level variables. The grades for each neighborhood were recorded and given a code to represent that grade $(A=1 ; B=2 ; C=3 ; D=4)$. Neighborhoods were connected to census tracts in their respective neighborhoods. Some neighborhoods have multiple census tracts, so respondents identifying a particular neighborhood were randomly divided between the census tracts. Each tract included between one and 18 respondents (average $=4$ ). The census provided data on tract characteristics utilized in the study, poverty rate. 
Table 5

Coding Scheme for Quantitative Constructs Utilized in this Study

\begin{tabular}{ll} 
Injunctive Norms & \multicolumn{1}{c}{ Coding Scheme } \\
& $0=$ negative peer reactions \\
& $1=$ neutral peer reactions \\
& $2=$ positive peer reactions \\
& $0=$ friends have not participated in \\
behaviors & $1=$ friends have participated in some \\
behaviors & $2=$ friends have participated in many \\
behaviors & $3=$ friends have participated in all \\
behaviors \\
$0=$ never \\
$1=$ once \\
$2=$ sometimes \\
$3=$ often \\
$0=$ no exposure \\
$1=$ low exposure \\
$2=$ medium exposure \\
$3=$ high exposure \\
$0=$ Strongly Disagree \\
$1=$ Disagree \\
$2=$ Agree \\
$3=$ Strongly Agree \\
Cultural Identity
\end{tabular}

\section{Research Question 3 Analysis Plan}

RQ3: What additional factors contribute to West Louisville youth's view on the social norms of youth violence?

To answer RQ3, a mixed methods approach will be utilized using school survey data and pre-campaign focus group data. The pre-campaign focus group data were analyzed by the YVPRC research team. The project staff who conducted the focus groups reviewed the transcripts along with audio recordings for accuracy.

A constructivist grounded theory approach was utilized. According to 
Charmaz (2014), constructivism is a social scientific perspective that addresses how realities are made, by including subjectivity into view and assuming that people, including the researchers, construct the realities in which they participate. The researcher explores the person's experiences and includes multiple views of the experience, creating connections, and then constructing an interpretation (Charmaz, 2014). A constructivist approach is a $360^{\circ}$ view of not only how but also why participants place meaning and actions on their experiences (Charmaz, 2014). Researchers who take a constructivist grounded theory (CGT) approach take into account how the participants view their experience, as well as the researcher's view and how the broader environment affects the experience and situation. Contrary to objectivist grounded theory, CGT links multiple realities that move past traditional approaches that yielded abstract theories, moving grounded theory into interpretive social science (Charmaz, 2014).

Pre-campaign focus group transcripts started with initial coding, or line-byline coding using gerunds (or -ing verbs). Glaser (1978) explains how gerunding helps to not only detect processes but also helps a researcher stick to the data (Charmaz, 2014). After completing initial coding, the researcher went through the data and completed process coding. Process coding or in vivo codes, includes adopting codes directly from the data (Charmaz, 2014). Coding helped to connect the researcher to the data and helped to direct the researcher to concepts for further exploration. Process codes were grouped based on conceptual relationship and read through thoroughly. Broader themes were created based on the process code groupings, leaving block quotes to 
accompany the process codes to remain true to statements made by participants and to provide context for the themes.

These data will be used to expand the results found in the school survey in regards to the social norms of youth violence. The pre-campaign focus groups will provide data on the actual personal behaviors and attitudes, including protective behaviors related to violence; perceived peer behaviors related to violence; and perceived peer attitudes and beliefs related to violence. Table 4 includes the quantitative constructs utilized to answer Research Question 3. Table 5 includes the coding scheme for the questions.

\section{Limitations}

Threats to internal and external validity have been reduced by using valid and reliable instruments from samples similar to the students who were recruited for the proposed study. Response bias from students is a limitation of this study. Sometimes participants are not honest in their survey responses or respond how they think they should respond because of "consequences," or how they will be perceived for participating in certain behaviors. The survey is also asking about some "unfavorable" behaviors. Students with prosocial norms are more likely to attend school, complete the survey, and check emails from the school. Therefore, it is more likely that students in the sample are exposed to protectives factors.

The variables measuring the impact of institutional (systemic racism) level bring several limitations. Given the limited literature attending to systemic racism in public health, few metrics have been developed to accurate measure the 
impact of institutional level policies and practices. Policies shaped by racism are evident at local, state, and federal levels. Additionally, there are several indicators that can be used to measure systemic racism in combination of neighborhood (institutional) level indicators such as neighborhood median income, poverty rate, and unemployment rate. The institutional level variables indicators used in this study are exploratory and provide a foundation for attempting to measure the impact of systemic racism within neighborhoods. 


\section{CHAPTER IV}

\section{PUBLIC HEALTH'S APPROACH TO SYSTEMIC RACISM: A SYSTEMATIC LITERATURE REVIEW}

\section{Introduction}

For centuries, people of color have suffered mentally and physically from the impact of the public health problem of systemic racism. Racial inequalities are pervasive in the social determinants of health and should be assessed in the context of society's white-racist roots and contemporary structural-racist realities (Feagin \& Bennefield, 2014). Ture and Hamilton (1967) define racism as "the predication of decisions and polices on considerations of race for the purpose of subordinating a racial group and maintaining control over that group" (Ture \& Hamilton, 1967, p. 3). Racism is covert and overt. It exists in two forms: "individual whites acting against individual Blacks [individual racism], and acts by the total white community against the Black community [institutional racism]" (Ture \& Hamilton, 1967, p. 4). The latter, for the purpose of this study, termed "systemic racism," operates within "established and respected forces in the society, and receives far less public condemnation than the first type" (Ture \& Hamilton, 1967, p. 4).

Post-Jim Crow era, "the white commonsense view on racial matters is that racists are few and far between, that discrimination has all but disappeared, and that most whites are color blind" (Bonilla-Silva, 2010, p.25). Today, "new racism" 
has emerged and is evident in "more sophisticated and subtle" practices (BonillaSilva, 2010). Bonilla-Silva (2010, p. 26) has found that this racial structure consists of five elements:

"(1) the increasingly covert nature of racial discourse and racial practices; (2) the avoidance of racial terminology and the ever-growing claim by whites that they experience 'reverse racism;' (3) the elaboration of a racial agenda over political matters that eschews direct racial references; (4) the invisibility of most mechanisms to reproduce racial inequality; and (5) the reticulation of some racial practices characteristic of the Jim Crow period of race relations."

Many have moved towards using a colorblind approach to addressing issues, and, this approach still creates racial inequalities. Color-blind racism is an ideology that "explains contemporary racial inequality as the outcome of nonracial dynamics" (Bonilla-Silva, 2017, p. 3). Compared to Jim Crow racism, color blindness is "racism lite" (Bonilla-Silva, 2017, p. 3). Instead of overtly showing racism, it is expressed in covert ways, where whites "enunciate positions that safeguard their racial interests without sounding 'racist'" (BonillaSilva, 2017, p. 4). Many whites have created barricades that exclude them from the U.S. racial reality and they have taken a colorblind approach to engagement (Bonilla-Silva, 2010). This new racism has given us phrases such as "post-racial America" or "I don't see color," especially with the election of President Barack Obama (Bonilla-Silva, 2010). However, neglecting to address race or creating practices and policies which include the contextualization of race will continue to 
yield high disparities in the form of high crime rates, low educational attainment, poor health outcomes, to name a few.

The "new racism" is evident in social, economic, political, and ideological areas, and it can also be seen in public health within gaps and disparities that exist in a variety of health outcomes. An example, is the large Black-white disparities in premature birth and low birth weight. Braveman et al. (2011) speaks to the disparity and that there are biological mechanisms that plausibly contribute to the disparities that "reflect phenomena shaped by social contexts and thus are, at least theoretically, avoidable" (p. S151). However, Braveman et al. (2011) and the practitioners who provide the data for the claim do not call out racism as the effect of the social context. In fact, in Braveman et al.'s (2011) article, which proposes a definition of health disparities, mentions how health disparities are avoidable, "but causality need not be established" (p. S149). This gets to the "new racism" and how racism is not seen as a causal factor in shaping the social context in which Black mothers live. Causality should in fact be established to get to the root of the health outcome. In another example, one of the goals of Healthy People 2020, is to achieve health equity and eliminate health disparities (Braveman et al., 2011). Within the stated goal, the differences to eliminate occur by gender, race or ethnicity, education or income, disability, living in rural localities, or sexual orientation (U.S. Department of Health and Human Services, 2010). However, the steps to eliminate health disparities are not clearly explained throughout the plan. Health disparities are defined as the "health differences that adversely affect socially disadvantaged groups" (Braveman et al., 2011, p. 
S150). What is important to note is how socially disadvantaged groups are defined: "the unfavorable social, economic, or political conditions that some groups of people systemically experience based on their relative position in social hierarchies" (Braveman et al., 2011, p. S151). Social disadvantage is reflected through the social determinants of health; however, there are no numerical cutoffs for disadvantage, or to expand on what Braveman et al. (2011) and many within public health have failed to identify, the intersectionality that occurs amongst these groups. Braveman et al. (2011) discuss the definitions and the concept of achieving equity by eliminating health disparities by criticizing the approach because it broadens the context in which health disparities exist. It further jeopardizes "the limited resources allocated to specifically address racial/ethnic disparities, by spreading these resources more thinly among other disadvantaged groups" (Braveman et al., 2011, p. S153). But does it have to? Audre Lorde's concept of intersectionality is that the experiences of oppression overlap, and "it is a means of capturing both the structural and dynamic aspects of multiple discrimination, thus affecting both theory and practice" (Morgan, 2003, p. 46). When health disparities are discussed in public health, the intersectionality of race or ethnicity, gender, education or income, disability, living in rural areas, or sexual orientation are largely absent.

Public health in the U.S. operates within a white racial frame which encompasses "a broad and persisting set of racial stereotypes, prejudices, ideologies, images, interpretations and narratives, emotions, and reactions to language accents, as well as racialized inclinations to discriminate" which has 
aggressively defended this unequal and unjust society (Feagin \& Bennefield, 2014, p. 8; Feagin, 2013, p. 3). The white racial frame exists to help society define, interpret, confront, and act in their everyday world (Feagin, 2013). In this frame, whiteness is centered and normalized throughout many institutions social, home, public spaces, the media, workplace, courts, policy, and the cooperate world. Operating at both the interpersonal and institutional level, it rationalizes the structures that perpetuate inequalities, injustices, and racial patterns. Today, whites and whiteness is viewed positively and virtuous by those who consider themselves white and often by those who do not (Feagin, 2013). 'White narratives of the U.S. historical development still accent whites' superiority - that is that whites are typically more American, moral, intelligent, rational, attractive, and/or hard working than other racial groups - and courage over centuries" (Fegin, 2013, p. 94). At the institutional level, the white racial frame "conceals much of the injustice of the systemically racist reality from those who adopt elements of the white frame, and to view societal inequalities as normal" (Feagin, 2013, p. 146). For centuries, institutions have continued to operate within this frame and justify their continued separation of people by race to continue to evaluate whites as superior.

Public health decision-makers are majority white, and many operate consciously or not - within this white frame creating a "pro-white and anti-racialothers orientation" (Feagin \& Bennefield, 2014, p. 8). This operation has created discriminatory practices which account for the institutionalized inequalities in health care and health (Feagin \& Bennefield, 2014). For example, the lack of 
trust between healthcare providers/practitioners and minority patients due to studies such as the Tuskegee Experiment and the use and replication of Henrietta Lacks' cells without consent have contributed to the distrust between Black people and health care providers. Research on racial matters classifies inequalities in terms of racial "disparities," failing to explain the foundational and systemic racism of the U.S. in creating the inequalities through historical policies and practices (Feagin, 2013).

Recently, published research has identified racism in the context of health care and health disparities (Feagin \& Bennefield, 2014; Gee \& Ford, 2011; Krieger, 2003; Paradies, 2006; Walters et al., 2011). Jones (2000) published the earliest mentions of racism published within a public health journal as she describes three levels of racism: institutionalized, personally mediated, and internalized. Jones (2000) fails to mention critical race research in her descriptions of racism or even to contextualize the personally-mediated level of racism within institutionalized racism. Most of this research takes the necessary steps for "analyzing the impact of white-controlled systemic racism on health care;" however, there is a need to shift the way the field of public health contextualizes problems and speak to the impact of systemic racism (Feagin \& Bennefield, 2014, p. 8).

Bhopal and Donaldson (1998) proposed that terms such as White, Caucasian, European, Europid, Western, and Occidental, not be used in research because they are nonspecific, and the comparisons misleading; however, terms such as reference, control, or comparison are better, so readers 
will not make assumptions about comparison populations. By this concept, they suggested that research "move past this understandable anxiety and their proposal with greater openness that has heretofore been possible" (Fullilove, 1998, p. 1298). However, Fullilove (1998, p. 1298) points out that in the U.S., "social systems organize around racial inequality and clearly shape health outcomes." She poses the question, "if racism is a principal factor organizing social life, why not study racism, rather than race?" Fullilove (1998, p. 1298) makes a valid point: if public health is concerned with systems and structures that influence population health, studying racism on the individual level in adequate. Extensive research exists surrounding the impact of self-reported racism and discrimination and health (Brondolo, Rieppi, Kelly, \& Gerin, 2003; Calvin et al., 2003; Krieger, 1999, 2003; Krieger, Rowley, Herman, \& Avery, 1993; Paradies, 2006; Williams, Neighbors, \& Jackson, 2003; Williams \& Williams-Morris, 2000). However, most of the literature focuses on perceived racism and discrimination and does not explore the impact of systemic racism on health. Racism should be studied at the systemic level. This paper employs a systematic literature review to understand the extent to which the public health literature addresses systemic racism as an issue or factor influencing health.

\section{Methods}

According to Preferred Reporting Items for Systematic Reviews and MetaAnalyses (PRISMA), a systematic review "is a review of a clearly formulated question that uses systematic and explicit methods to identify, select, and critically appraise relevant research, and to collect and analyze data from the 
studies that are included in the review" (Moher, Liberati, \& Alman, 2009, p. 1). In public health, a great deal of literature exists regarding race and health or racial disparities, but a dearth of literature exists explicitly focusing on systemic racism as a public health issue. Current literature discusses the perceptions of racism and discrimination but not the impact of racism within systems. The purpose of this systematic literature review was to look more closely at racism within public health from the context of the systemic/structural/institutional level (policies) rather than the individual level (perceived racism and discrimination). The systematic review process limits bias and provides objective findings, allowing us to draw conclusions regarding the extent to which public health addresses systemic racism.

Studies that look at the impact of systems on Black populations were included based on interventions that looked at a variety of health outcomes in quantitative and qualitative studies along with conceptual and theoretical articles.

Eligibility Criteria. Studies published after 1968 were included in the search. Ture and Hamilton (1967), provide the definition for how systemic racism is defined in this study; therefore, only studies published after 1968 were eligible for review. Only studies in English and conducted within the U.S. were eligible because the foundation of this study reviews systemic racism within the context of U.S. systems. Only peer-reviewed studies in pre-identified public health journals were included to ensure that rigor and scrutiny of others within the field of public health were a part of assessing the research. Only including studies within public health journals excludes the influence of the importance of the 
topics within other disciplines, but examines what the leading public health journals are publishing regarding the topic. Additionally, only studies that address systemic, institutional, or structural racism from a systems perspective were eligible for inclusion.

Information Sources. At the advice of a health sciences references librarian, MEDLINE (PubMed), Embase, and EBSCO databases were used for the systemic literature review. MEDLINE is known as one of the most comprehensive databases with only peer-reviewed articles, so it was the first database searched, followed by Embase, which is typically used to check the work of what was found in MEDLINE, and lastly, Ebsco was searched to ensure identification of possible articles outside of those found in MEDLINE and Embase. The literature review was completed on March 31, 2017 and includes articles from January 1968 until the date of completion. No authors were contacted to determine if they had published additional articles that fit the criteria, mostly to ensure that whatever was found was accessible to public health practitioners.

Search. The search strategy used for this literature review was standard across all platforms with few variations, most of which were based on the database options. Once the databases were identified, a comprehensive Excel spreadsheet was created to track articles found based on four criteria: 1) identification, 2) screen, 3) eligibility, and 4) included. Prior to starting the search, each database was cleared so anything previously searched were not included. 
Identification. The search began by typing in the following key words separately: systemic racism, structural racism, institutional racism, racism, racist, racial trauma, racial stress, racial discrimination, racial oppression, racial marginalization, systemic racial disparities, structural racial disparities, and institutional racial disparities. After each key word was initially searched, the number of articles returned was recorded. Next, using the database option of time range, the articles before 1968 were eliminated, as well as those that were not in English. In the MEDLINE (PubMed) database, articles can be sorted based on journals, so the articles were sorted alphabetically based on journal titles. Articles in journals on the pre-identified list of journals were selected for the screening process. Table 6 is the list of public health journals eligible for the systematic literature review. 
Table 6

Public Health Journals Eligible for Systematic Literature Review

\begin{tabular}{|c|c|}
\hline American Journal of Health Promotion & American Journal of Public Health \\
\hline Annual Review of Public Health & Community Development Journal \\
\hline Environmental Health Perspectives & Ethnicity and Disease \\
\hline Ethnicity and Health & Family and Community Health \\
\hline Frontiers in Public Health & Global Public Health \\
\hline Health Affairs & Health and Place \\
\hline Health Communication & Health Education and Behavior \\
\hline Health Education Research & Health Promotion Practice \\
\hline Health Promotion Perspective & $\begin{array}{l}\text { Health Services Management } \\
\text { Research }\end{array}$ \\
\hline esearch & Journal of Community Health \\
\hline Jourr & $\begin{array}{l}\text { Journal of Education \& Health } \\
\text { Promotion }\end{array}$ \\
\hline $\begin{array}{l}\text { Journal of Epidemiology \& Community } \\
\text { Health }\end{array}$ & Journal of Health and Social Behavior \\
\hline $\begin{array}{l}\text { Journal of Healthcare for the Poor \& } \\
\text { Underserved }\end{array}$ & Journal of Healthcare Management \\
\hline $\begin{array}{l}\text { Journal of Prevention \& Intervention in } \\
\text { the Community }\end{array}$ & Journal of Primary Prevention \\
\hline Journal of Public Health & $\begin{array}{l}\text { Journal of Public Health Management } \\
\text { \& Practice }\end{array}$ \\
\hline Journal of Public Health Policy & $\begin{array}{l}\text { Journal of Racial Ethnic Health } \\
\text { Disparities }\end{array}$ \\
\hline Journal of Social Issues & Perspective in Public Health \\
\hline Preventing Chronic Dise & Prevention Science \\
\hline $\begin{array}{l}\text { Progress in Community Health } \\
\text { Partnerships }\end{array}$ & Public Health \\
\hline $\begin{array}{l}\text { Qualitative Health Research } \\
\text { Urban Health }\end{array}$ & Social Science and Medicine \\
\hline
\end{tabular}

Screening. During the screening process, the abstract for articles in eligible public health journals were read, and those that did not fit the eligibility criteria were excluded. Articles did not have to have the exact words of systemic, institutional, or structural racism; however, they had to address systemic/structural problems that influence health inequity. Abstracts fitting the criteria created for this literature review were moved to the eligibility category. 
Eligibility. Full articles from the screening category were reviewed to ensure they met eligibility criteria to be included in the study. At this point articles were reviewed to ensure that they discuss the impact of systems and structures, did not include behavioral implications, and were focused on the impact of systemic racism on Black people. After further review, articles that indirectly address systemic or institutional impacts of racism on health problems were included in the results section of this paper.

\section{Results}

Exactly 70,273 articles were identified with the key terms of the literature review. After applying eligibility criteria, 2,961 articles were screened and 1,711 were eligible after initial screening. A total of 98 articles met the inclusion criteria for this review. Many of the articles were published after 2000 , as such a topic as this is very nascent in the public health literature. Four major themes emerged during the review of included articles - conceptual and theoretical approaches to addressing systems, policy implications, residential and racial segregation, and overall systemic impact. Figure 1 depicts the flow of article identification and Table 7 depicts the themes and articles that reflect each theme. 
Figure 1 Systematic Literature Review PRISMA Flow Diagram
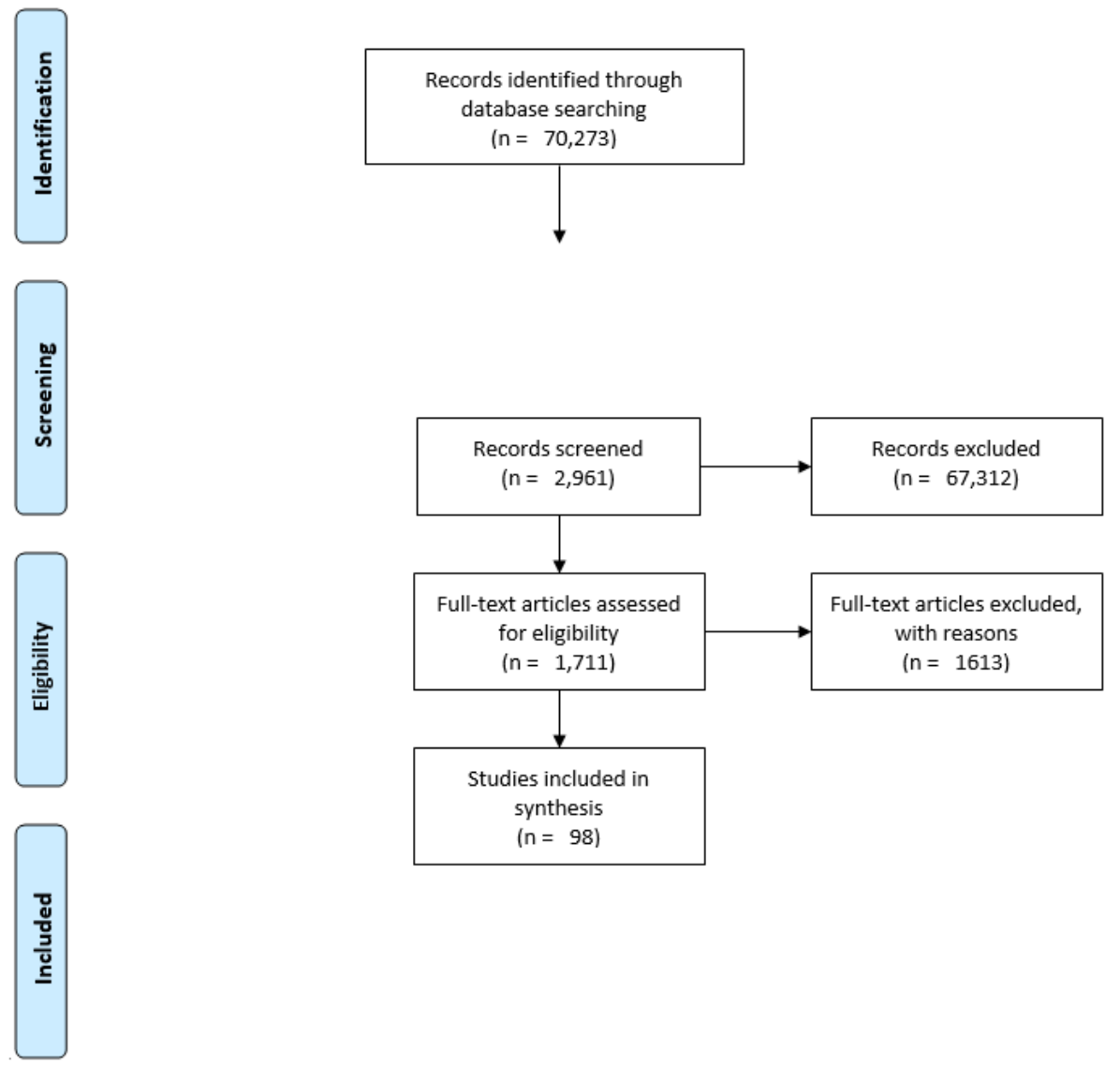
Table 7

Systematic Literature Review Themes and Identified Articles

Betancourt, Green, Carrillo, and

Ananeh-Firempong (2003)

Bowleg (2012)

Browne, Pitner, and Freedman (2013)

Came \& Griffith, 2017

Carrillo et al. (2011)

Ford \& Airhihenbuwa, (2010)

Gee, Walsemann, \& Brondolo, 2012

Griffith, Johnson, Ellis, \& Schulz, 2010

Bliss, Mishra, Ayers, and Lupi (2016)

Exworthy and Washington (2006)

LaVeist, Sellers, \& Neighbors, 2001
Conceptual and Theoretical Articles

Griffith, Yonas, Mason, \& Havens, 2010

Havens, Yonas, Mason, Eng, \& Farrar, Smedley and Myers (2014) 2011

Hutto \& Green, 2016

Jee-Lyn García and Sharif (2015)

King, 1996

Krieger, 2012

Kruger, Carty, Turbeville, French-

Turner, \& Brownlee, 2015

Paradies (2006)

Policy Implications

Menefee (1996)

Morin et al. (2002)
Rencher and Wolf (2013)

Smedley, 2012

Thomas, Quinn, Butler, Fryer, \&

Garza, 2011

Trinh-Shevrin, Islam, Nadkarni,

Park, \& Kwon, 2015)

Vardeman-Winter, 2017

Yonas et al., 2006

Noonan, Velasco-Mondragon, \&

Wagner, 2016

Pestronk \& Franks, 2003 
Armstrong, Strogatz, \& Wang, 2004

Beard et al. (2009)

Cerda, Tracy, \& Galea, 2012

Cubbin, LeClere, \& Smith, 2000

Cummings, Wen, and Ko (2016)

Fabio, Li, Strotmeyer, \& Branas, 2004

Fabio, Sauber-Schatz, Barbour, \& Li (2009)

Friedman, Cooper, \& Osborne, 2009

Acevedo-Garcia, Rosenfeld, Hardy, McArdle, \& Osypuk, (2013)

Arriola, (2017)

Buckner-Brown et al. (2011)

Clark, (2001)

Cooper et al., (2001)

Crawford et al. (2013)

Dillon and Basu (2014)

Feagin and Bennefield (2014)

Franzini, Caughy, Spears, \& Eugenia Fernandez Esquer, 2005
Residential and Racial Segregation Frye et al. (2014)

Grady, 2006; Walton, 2009

Hong and Burnett-Zeigler (2016)

Jones, 2013

Kimbro \& Denney, 2013

Kravitz-Wirtz, 2016

Mendez, Hogan, \& Culhane, (2011)

Mendez, Hogan, \& Culhane, 2014

Overall Systemic Impact Hogan et al. (2013)

Iguchi, Bell, Ramchand, and Fain (2005)

Krieger, (2003)

Lane et al., (2004)

Lin-Fu (1987)

Lukachko, Hatzenbuehler, \& Keyes (2014)

Mazul, Salm Ward, \& Ngui, (2017)

McAllister, Thomas, Wilson, \& Green, (2009)

Nomaguchi \& House, (2013) Quach et al. (2012)
Parker \& Stansfield, 2015

Ransome, Kawachi, Braunstein, \& Nash, 2016

Reid, Dovidio, Ballester, \& Johnson, 2014

Schempf, Strobino, and O'Campo (2009)

Schulz et al., 2008

Williams \& Collins, 2001

Witt et al. (2015)

Quach et al. (2012)

Rosner and Markowitz (1997)

Shavers et al. (2012)

Ulmer, Harris, \& Steffensmeier, 2012

Wallace, Crear-Perry, Richardson,

Tarver, \& Theall, (2017)

Wallace, Mendola, Danping, \& Grantz, (2015)

Wallington, Blake, Taylor-Clark, and

Viswanath (2010)

Williams (2012) 
Conceptual and Theoretical Articles. Practitioners provide a range of conceptual and theoretical models for moving forward with not only addressing systemic racism but also conducting research that provides context on the impact of systemic racism on a variety of health issues. For example Smedley, 2012 and Smedley \& Myers, 2014 provide an overview on the conceptual and methodological challenges in research on racism and discrimination and how it impacts policy. Others provide an anti-racism praxis to train and support allies in addressing inequalities in public health (Came \& Griffith, 2017; Havens, Yonas, Mason, Eng, \& Farrar, 2011; Kruger, Carty, Turbeville, French-Turner, \& Brownlee, 2015; Thomas, Quinn, Butler, Fryer, \& Garza, 2011). Ford and Airhihenbuwa (2010) adapted the Critical Race Theory approach to create a Public Health Critical Race Framework for research and practice. Bowleg (2012) details the importance of using an intersectional theoretical framework in public health theory, research, and policy to fulfill its commitment to social justice. This is important towards moving towards addressing race and racism and how they impact our multiple identities in a variety of ways and being more equitable in research and practice.

As equity is on the radar and promotion of many public health professionals as way to improve health outcomes, it is important to include community in undoing racism (Yonas et al., 2006), but as a way to increase minority voices in researching health disparities (Rencher \& Wolf 2013). Within the same concept, Browne, Pitner, and Freedman (2013) examined how community members responded to health disparities research and created 
pedagogical strategies for examining racialized contexts. What is interesting about this article is that one of the themes amongst the participants was "structural racism does not exist." Participants felt that health disparities were created to divide and segregate populations and that many community members do not see the larger context in which their health is impacted. The view of the participants show how the white racial frame plays into how some contextualize their situation, especially with many of the systems reinforcing similar messages. This calls for further examination of the impact of white racial framing on how minorities view minority communities and well as historical policies and practices.

Policy Implications. While much of systemic racism is rooted in policies, only seven articles addressed policy implications that fit within this study. It is important to view systemic racism from the perspective of environmental factors that impact behavior. Menefee (1996) analyzes major health policies to prove the health system is rooted in racial discrimination and perpetuates racial discrimination in education, employment, and housing. Bliss et al. (2016), describes the Minnesota Department of Health's shift from traditional behavioral public health approach, to addressing the factors that actually create health with a Health in All Policies approach to addressing the social determinates of health. Other practitioners provide understanding of how it takes structural changes to improve the health of Black people (Noonan, Velasco-Mondragon, \& Wagner, 2016; Pestronk \& Franks, 2003) and that Black people with a system-blaming orientation live longer than those who self-blame for racism (LaVeist, Sellers, \& Neighbors, 2001). It is important to detail the impact of historical systemic 
policies and procedures have had on the social environment to determine how they can be rectified through a macro-level approach.

Residential and Racial Segregation. Throughout the identification stages, a major theme amongst many articles provide an explanation of the impact of residential and racial segregation on a variety of health issues. While residential and racial segregation stems from historical housing policies, a majority of the articles did not link residential and racial segregation to redlining, which was inherently deemed discriminatory (Hillier, 2003). However, much of their implications point to the creation of certain neighborhoods which disproportionally impact Black residents. There were several articles that did not directly name residential segregation; however, their definitions for example, of neighborhood composition and findings directly align with the practice of residential and racial segregation (Frye et al. 2014; Cummings, Wen, \& Ko, 2016; Witt et al. (2015).

Overall Systemic Impact. Lastly, many articles pointed directly at the impact of systemic racism on overall health (Clark, 2001; Franzini, Caughy, Spears, \& Eugenia Fernandez Esquer, 2005; Krieger, 2003) and a variety of health outcomes. As with not directly naming residential or racial segregation, many authors do not specifically name systemic racism. Lin-Fu (1987) discusses the overall impact the health care system has on ethnic minority women and the implications for the health concerns for the population. Iguchi, Bell, Ramchand, and Fain (2005) provide insight on how racial disparities within the criminal justice system translate to health disparities for minorities. Wallington, Blake, 
Taylor-Clark, and Viswanath (2010) describe the influence news coverage has on health topics and agenda setting at the institutional and policy levels and provide insight on how public health practitioners can inform communication with local media to advance the dialogue on health disparities. This can be linked to how the media operates within the white racial frame, perpetuating certain stereotypes and messages, but also the role public health practitioners can play in changing the narrative.

Shavers et al. (2012) also conducted a literature review to determine racial/ethnic discrimination in the receipt of health care, looking at system level factors that contribute to discriminatory health care services, however, they did not find studies that addressed institutional racism impacts health care delivery to racial/ethnic minority populations. Additionally, Feagin and Bennefield (2014) provide an overview of systemic racism in U.S. health care and public health institutions. Their review of public health is minimal in that public health rarely addresses the structural forces that create the conditions in which disparities are present. Feagin and Bennefield (2014) point out that majority of public health decision makers are white, and the focus of research on racism is sparse. Buckner-Brown et al. (2011) provide an overview of Centers for Disease and Control Prevention's, Racial and Ethnic Approaches to Community Health $(\mathrm{REACH})$ programs that have implemented policies and organizational practices to improve the social conditions that can reduce health disparities. It is important to understand how one of the leading public health institutions approaches race to improve social conditions as well as the tools they provide for other 
practitioners to incorporate the approach in practice. However, much of their contextualization of health issues do not approach it from macro-levels impact of race and racism.

\section{Discussion}

Across most articles, a consistent pattern was a lack of using the terms racism, or even naming systemic issues. Discrimination, stigma, and bias were used to describe racism or inferences of systemic racism, but most would describe implications for changes at the systemic and structural levels. Public health is just now getting to a point of acknowledging racism at the systemic level as an impact to health (Mays, Cochran, Barnes, 2007; Paradies et al., 2006; 2013; 2015; Williams \& Mohammed, 2009). There is overwhelming evidence at individual level of the impact of racism, discrimination, and bias; however, there needs to be an evaluation and more addressing of systemic racism on health and the social determinants of health.

Articles eliminated from the search mostly focused on behavioral implications of racism on health and provided individual or interpersonal implications for reducing health disparities. While it is important to focus on how behavioral or implicit bias contribute to health disparities, much of the behavioral or implicit bias that provide for the reinforcement of the behavioral choices public health practitioners make when working within the field and creating interventions. It takes a critical examination on not only the systemic and structural implications of racism, but also in moving towards health equity it takes 
having conversations on the impact of racism past, present, and future to move towards reducing health disparities.

Rice et al. (2016) found in their study that Black residents (half the participants) felt they have little control over things that happen in their neighborhood and little confidence in their ability to change things where they live. Since residential segregation emerged as theme in this literature review, it is important to view how Black residents feel in making changes or even the implications for change in their community. This also plays into the white racial frame many have lived within and that has been perpetuated for centuries, but also the narrative that has been created by the systems and structures and those with power. While most are surviving within the conditions that were created for them, many are hopeless in seeing that a change will ever happen. Liu, Chen, and Glymour (2011) provide some hope in that they found that school desegregation legislation decreased common-cause mortality rates for Black male adolescents. This offers evidence in how structural changes can improve health (life expectancy); however, it is important to conceptualize and make systemic and structural changes that impact multiple health and social outcomes.

Public health practitioners recognize systemic racism as a root cause of health outcomes; however, the field does not talk about the implications of systemic racism or create interventions or recommend policies that address the root causes. Public health has focused on changing behaviors rather than changing the environments in which the behaviors are "necessary" to survive. Intervention approach stems from a tendency toward victim blaming (Ryan, 
1976). However, many disparities are mostly categorized based on race first, and then social determinants such as educational attainment, socioeconomic status, neighborhood development, and so on.

Throughout the included literature, there is an absence of discussion surrounding the social determinants of health. For example, one article that pointed at implications for the impact of systemic racism on school readiness (McAllister, Thomas, Wilson, \& Green, 2009) and one article provided insight on how racial disparities within the criminal justice system translate to health disparities for minorities (Iguchi, Bell, Ramchand, and Fain, 2005). However, much of the discussions happen in isolation, without an overview of how there are many factors at play. It is important for public health practitioners to look at the impact of systemic racism across all determinants of health. The public health approach to issues needs to expand beyond taking an approach to change behaviors, but to change systems and structures that will change the environments in which the behaviors are necessary. More importantly, public health practitioners need to actively call out racist practices and move towards utilizing practices that are not only equitable but consider the implications of race in decisions. Additionally, there needs to be more minority representation within public health decision making, and not as figureheads with borrowed power (Petitt, 2009), but actually centering minority experiences in decision making, research methods, and analysis.

\section{Conclusion}


While the concept of systemic racism is not new, the field of public health can draw upon the concepts and theories used in other fields, such as Sociology. For public health practitioners, it is always important to view health within the socioecological framework; however, there much work exist up until the community-level with most focusing on behavioral interventions. It is important to include the contextualization of history not just within the U.S., but the history of the community of interest. The community did not just end up with a high concentration of people who experience many disparities, historical policies and practices also contribute to the social environment in which many of the behaviors or present and pervasive. Through a macro-level approach, with ratification of policy and systems will we see a drastic reduction of health and racial disparities. Above all, it also takes public health practitioners actually being champions of social justice and calling out racism and racist practices and policies that continue to create the disparities that practitioners work tirelessly to eliminate and protect where people live, work, worship, learn, and play. Only through directly naming and addressing systemic racism, directly will public health ever achieve its goal of equity. 


\section{CHAPTER V}

\section{ARE WE TALKING BEHAVIOR OR ENVIRONMENT?}

\section{Introduction}

A growing body of research within the field of public health provides much evidence that racism is a social determinant of health (Brondolo, Gallo, \& Myers, 2009; Brondolo, Ver Halen, Pencille, Beatty, \& Contrada, 2009; Dressler, Oths, \& Gravlee, 2005; Ford \& Airhihenbuwa, 2010a, 2010b; Gee \& Ford, 2011; Jee-Lyn García \& Sharif, 2015; Jones, 2000, 2001, 2002; Krieger, 2003; Marmot et al., 2008; McKenzie, 2003; Nuru-Jeter et al., 2009; Paradies et al., 2013; David R Williams, 1999). Many topics, such as health disparities, discrimination, and residential segregation are discussed within the field without "explicit acknowledgement of their connection to racism" (Jee-Lyn García \& Sharif, 2015, p. e27). Racism, is "the prediction of decisions and policies on considerations of race for the purpose of subordinating a racial group and maintaining control over that group" (Ture \& Hamilton, 1967, p. 3). Without the direct acknowledgement of the impact of systemic racism on health outcomes, there is a continuation of gaps between disadvantaged groups because of the failure to acknowledge the main symptom. Racism is structural. It goes deeper than individual attitudes and behaviors; racism permeates institutional policies and societal norms and has for centuries (Bonilla-Silva, 2010; Feagin, 2013; Feagin \& Bennefield, 2014; Jones, 2000, 2002). Many institutional policies and societal norms were created to 
impact the upstream determinants which are "features of the social environment, such as socioeconomic status and discrimination, that influence individual behavior, disease, and health status" (Gehlert et al., 2008, p. 340).

Disadvantaged groups have been forced to take the blame for the impact of upstream determinants on a variety of health outcomes, with interventions suggesting a change to their behavior. However, with no changes to the social environment in which these conditions are pervasive, it is difficult for someone to change their behavior when there remain structural and systemic barriers that impede progress. This study seeks to examine the impact of systemic racism through the upstream factor of residential segregation in Louisville, Kentucky on local youth's participation in violent behaviors above and beyond the social norms of violence.

\section{Background}

Residential segregation has been linked to a variety of health outcomes, including violence (Acevedo-Garcia \& Lochner, 2003; Acevedo-Garcia, Lochner, Osypuk, \& Subramanian, 2003; Elliott \& Ageton, 1980; Fabio, Li, Strotmeyer, \& Branas, 2004; Green, Strolovitch, \& Wong, 1998; Hindelang, Hirschi, \& Weis, 1981; Logan \& Messner, 1987; Peterson \& Krivo, 1993; Shihadeh \& Flynn, 1996; Smith \& Jarjoura, 1988; Subramanian, Acevedo-Garcia, \& Osypuk, 2005; D. R. Williams \& Collins, 2001; J. R. Williams \& Gold, 1972). While some link residential segregation to race and racism, much of residential segregation is not discussed in terms of racist policies and practices, such as redlining, creating neighborhoods that would in turn have high concentrations of poverty, low 
educational attainment and investment, and a variety of disparities. In 2017, Louisville Forward, the economic development entity of Louisville Metro Government, released interactive maps exploring the impact of redlining in Louisville today (Bowling, 2017). The maps provide context on how historical neighborhoods within the city were formed with a comparison of poverty, race, property values, vacant properties, home ownership, mortgage lending, development trends, and zoning between the neighborhoods.

The Home Owners Loan Corporation (HOLC) was established in 1933 by President Franklin Roosevelt to protect homeowners at the risk of foreclosure by providing $\$ 3$ billion to assist 40 percent of the population with assistance (Poe, 2017). Local realtors and lenders were employed to complete comprehensive real estate surveys for over 200 cities in the United States (U.S.) (Poe, 2017). The grading system used in the real estate surveys graded residential areas from one to four, and created a "residential apartheid" (Poe, 2017). "Areas with African Americans, as well as those with older housing and poorer households, were consistently given a fourth grade, or 'hazardous,' rating and colored red" (Hillier, 2003, p. 395; Poe, 2017). Later it was found that the areas colored red were redlined, which refers to "lending (or insurance) discrimination that bases credit decisions on the location of a property to the exclusion of characteristics of the borrower or property" (Hillier, 2003, p. 395).

In Louisville, the HOLC, as well as local realtors and lenders described the grading system locally as: 
In establishing the grade of an area, such factors as these are considered: intensity of the sale and rental demand; percentage of home ownership; age and type of buildings; economic stability of area; social status of the population; sufficiency of public utilities; accessibility of schools, churches, and business centers; transportation methods; topography of the area; and the restrictions set up to protect the neighborhoods. The price level of the homes is no the guiding factor (Poe, 2017).

Race played a major role in determining neighborhood grades. The "restrictions set up to protect the neighborhoods" referred to "deed restrictions prohibiting the sales of property to Blacks" (Poe, 2017). While race was also at play in determining neighborhood grades, so was class. The racial zoning ordinance of 1914 in Louisville allowed Black domestic workers to live in white neighborhoods; therefore, it was acceptable for domestic workers to live in proximity to whites, but "the notion of middle class Blacks moving into an area was considered a threat" (Poe, 2017). This practice was utilized in Black neighborhoods as well. A section of the Russell neighborhood known as "Old Walnut Street" - the heart of Black life in the city and the thriving business district corridor - between $20^{\text {th }}$ and $28^{\text {th }}$ Streets of Chestnut, was the only predominantly Black area to receive anything higher than a Fourth Grade ranking (Aubespin, Clay, \& Hudson, 2011; Fosl et al., 2013; Kleber, 2001; Poe, 2017). This section of Russell was described as being "occupied by negroes... of a better type than those surrounding" (Poe, 2017). While one section of Russell received above the Fourth Grade, the eastern section of the neighborhood was characterized as the 
"worst area of the city," with a "low type property and inhabitants" (Poe, 2017). This area would later become targeted for urban renewal and turned into Beecher Terrace and City View housing complexes (Poe, 2017). These areas now have high rates of crime, poverty, and face many social and health inequities.

The surveys were shared with major banking institutions and kept private from the public. Newer construction was favored in the eastern neighborhoods of the city and "the social characteristics of a community weighed heavily in property valuation" (Poe, 2017). Remnants of the practices are evident today. The western part of Louisville, commonly referred to as West Louisville, continues to face challenges that are the direct result of systemic racism (e.g. redlining) such as high poverty rates, high crime rates, lack of economic investment, inequality in access to health care, high rates of vacant and abandoned properties, and high unemployment rates. Neighborhood culture has a great influence on individual behavior (Anderson, 1999), and those that suffer from the impact of unequal structures will oppose the mainstream norms and create a culture of survival (Bruce, Roscigno, \& McCall, 1998; Hughes \& Short, 2005; Kubrin \& Weitzer, 2003; Melynk et al., 2010). Most of these systems and structures have discriminated against Black people (Unnever, 2008), which in Louisville, the majority of the Black population lives in West Louisville. The purpose of this study is to explore systemic racism and residential segregation and their relationship to the distribution of youth violence within Louisville. It also 
seeks to shift the discussion from racial disparities to examining how racism has and continues to produce those disparities.

\section{Methods}

\section{Study Population}

This study used data from the University of Louisville's Youth Violence Prevention Research Center (YVPRC) 2017 School Survey and the $2011-2015$ American Community Survey 5-year estimates. The YVPRC research team along with school staff recruited survey participants from within Jefferson County Public Schools (JCPS) District middle and high schools. Middle and high school students from 16 target schools with a combined enrollment of 17,565 were recruited to participate in the survey (Jefferson County Public Schools, n.d.). These schools comprise an adequate sample of students who reside in West Louisville as a proportion of the overall sample (approximately 1 in 3 students of these schools combined). The YVPRC 2017 School Survey included nearly 1,900 participating students $(\mathrm{N}=1,889)$. Individual level predictors were used from the school survey. To collect the institutional level data, census level data were used to ensure the data were accurate and consistent across all neighborhoods. Because this study is examining exclusively the impact of residential segregation, the neighborhoods graded in the original Residential Security map from 1938 were used. After cross-referencing the neighborhoods students identified as where they lived with the census tracts for their respective neighborhoods, census level data such as population, unemployment rates, median income, and poverty rates were collected. Seventy-five census tracts 
were selected from the 201 tracts in Louisville, based on the neighborhoods that received grades in survey. A total of 341 student survey respondents lived within neighborhoods that received grades in the original survey of Louisville.

\section{Individual Level Variables}

Data on individual-level variables include injunctive norms, descriptive norms, exposure to violence, participation in violent behavior, and cultural identity. These data were obtained from the YVPRC 2017 School Survey, which was comprised of validated measures to determine the social norms of youth violence in Louisville, as well as other measures looking at local exposure and participation in violence, cultural identity, and sociopolitical development. Many of the scales can be found in the Centers for Disease Control and Prevention's (CDC) Youth Violence Compendium of Assessment Tools (Dahlberg, Toal, Swahn, \& Behrens, 2005), as well as the Virginia Commonwealth University's Youth Violence Prevention Center (VCU) (Virginia Commonwealth University Clark-Hill Institute for Positive Youth Development, n.d.). Table 8 includes the constructs utilized for this study from the 2017 School Survey. 
Table 8

Selected YVPRC Constructs Included in this Study

\begin{tabular}{|c|c|c|c|c|}
\hline Construct & $\begin{array}{c}\text { Scale/ } \\
\text { Assessment }\end{array}$ & $\underline{\text { Characteristics }}$ & $\frac{\text { Reliability/ }}{\underline{\text { Validity }}}$ & Developer \\
\hline $\begin{array}{l}\text { Descriptive } \\
\text { Norms of } \\
\text { Violence }\end{array}$ & $\begin{array}{l}\text { Peer } \\
\text { Behaviors } \\
\text { Scale; } 10 \\
\text { items }\end{array}$ & $\begin{array}{l}\text { Measure assessing } \\
\text { youth reports of } \\
\text { friends' involvement } \\
\text { in various activities }\end{array}$ & $\begin{array}{l}\text { Peer } \\
\text { Deviance } \\
=.88 ; \text { Peer } \\
\text { Prosocial } \\
\text { Behavior = } \\
.81\end{array}$ & VCU \\
\hline $\begin{array}{l}\text { Injunctive } \\
\text { Norms of } \\
\text { Violence }\end{array}$ & $\begin{array}{l}\text { Peer Support } \\
\text { for } \\
\text { Aggression } \\
\text { and } \\
\text { Nonviolence } \\
\text { Scale; } 6 \\
\text { scenarios }\end{array}$ & $\begin{array}{l}\text { Assesses youth's } \\
\text { expectations for } \\
\text { how their peers } \\
\text { would react to } \\
\text { different ways the } \\
\text { youth might } \\
\text { respond to a difficult } \\
\text { situation }\end{array}$ & $\begin{array}{l}\text { Support for } \\
\text { Aggression } \\
\text { subscale = } \\
.76 ; \\
\text { Support for } \\
\text { Nonviolent } \\
\text { Behavior } \\
\text { subscale = } \\
.77\end{array}$ & VCU \\
\hline $\begin{array}{l}\text { Exposure } \\
\text { to violence }\end{array}$ & $\begin{array}{l}\text { Children's } \\
\text { Exposure to } \\
\text { Community } \\
\text { Violence; } 9 \\
\text { items }\end{array}$ & $\begin{array}{l}\text { Measures } \\
\text { frequency of } \\
\text { exposure (through } \\
\text { sight and sound) to } \\
\text { violence in one's } \\
\text { home and } \\
\text { neighborhood. }\end{array}$ & .84 & $\begin{array}{l}\text { Richters \& } \\
\text { Martinez, } \\
1990\end{array}$ \\
\hline $\begin{array}{l}\text { Violent } \\
\text { Behavior }\end{array}$ & $\begin{array}{l}\text { Victimization; } \\
10 \text { items }\end{array}$ & $\begin{array}{l}\text { Measures exposure } \\
\text { to violence and } \\
\text { victimization in } \\
\text { one's home, school, } \\
\text { and neighborhood }\end{array}$ & $\begin{array}{l}\text { Not } \\
\text { available }\end{array}$ & $\begin{array}{l}\text { Nadel, } \\
\text { Spellmann, } \\
\text { Alvarez- } \\
\text { Canino, } \\
\text { Lausell- } \\
\text { Bryant \& } \\
\text { Landsberg, } \\
1991\end{array}$ \\
\hline $\begin{array}{l}\text { Cultural } \\
\text { Identity }\end{array}$ & $\begin{array}{l}\text { Multigroup } \\
\text { Ethnic } \\
\text { Identity } \\
\text { Measure }\end{array}$ & $\begin{array}{l}\text { Measures ethnic } \\
\text { identity search (a } \\
\text { developmental and } \\
\text { cognitive } \\
\text { component) and } \\
\text { affirmation, } \\
\text { belonging, and } \\
\text { commitment (an } \\
\text { affective } \\
\text { component). }\end{array}$ & .80 & $\begin{array}{l}\text { Phinney, } \\
1992\end{array}$ \\
\hline
\end{tabular}


Dependent Variables. Participation in violent behavior was used to measure violent behavior using the victimization scale from the CDC's Youth Violence Compendium, which measures exposure to violence and victimization in one's home, school, and neighborhood (Dahlberg et al., 2005; Nadel et al., 1991). YVPRC only used 10 of the 14 questions from the original scale, and respondents could choose from the options of never, once or twice, a few times, or many times. The items determine whether violence is direct or vicarious. The mean score for each set of question was calculated, with higher scores indicating participation in violent behaviors many times.

Independent Variables. Injunctive norms (expectations of your peers) were measured using the Peer Support for Aggression and Nonviolence scale, which contains two subscales: Perceived Support for Aggression and Perceived Support for Nonviolent Behavior (Virginia Commonwealth University Clark-Hill Institute for Positive Youth Development, n.d). The 12-item scale determines whether participants believe their peers will have negative, neutral, or positive reactions to six scenarios. A mean score for both scales were calculated for each survey participant. Higher scores for support for aggression indicates more support for aggressive behaviors, while higher scores for nonviolent behavior means their peers support nonviolent reactions.

Descriptive norms (peer behavior) were measured using the Peer Behaviors Scale, which is a 10 -item self-reported school measuring survey participant's friend's participation in various behaviors. The scale includes two 
subscales: Peer Deviance (6 items) and Peer Prosocial Behavior (4 items). To determine peer deviance, the scale ask how many of their friends are involved in a variety of deviant activities, while the prosocial subscale measures "peer behaviors and reactions to potential conflict theorized to have a positive relation to adolescent adjustment outcomes and a negative relation to aggression" (Virginia Commonwealth University Clark-Hill Institute for Positive Youth Development, n.d, p. 24). The mean score for the prosocial and deviant behaviors were calculated. Higher scores represent more of their friends who participate in prosocial or deviant behaviors respectfully.

Cultural Identity was measured using the Multigroup Ethnic Identity Measure. The measure includes two factors: "ethnic identity search (a developmental and cognitive component) and affirmation, belonging, and commitment (an affective component) (Phinney, 1992). A mean score was calculated to determine the sense of cultural identity the participant possess.

Exposure to violence was measured using the Children's Exposure to Community Violence scale. The original scale includes 12-items; however, YVPRC utilized nine of the items within their 2017 School Survey. The items "measure the frequency of exposure (through sight and sound) to violence in one's home and neighborhood" (Dahlberg et al., 2005, p. 331). Frequency was measured based on having heard or seen various crimes and violence: never, once or twice, a few times, or many times. Point values were summed and then divided by the total number of items (9) to determine the range of "frequent exposure to acts of crime and violence" (Dahlberg et al., 2005, p. 332). 
Surveys were also divided based on whether the students are in middle or high school. Demographic data were included such as age, gender, and race. However, these variables were included as control variables that could influence participation in violent behaviors.

\section{Institutional-Level Variables}

Students were asked what neighborhood they lived in, providing information to connect individual-level variables to the institutional-level variables. The grades for each neighborhood were recorded and given a code to represent that grade $(A=1 ; B=2 ; C=3 ; D=4)$. Neighborhoods were connected to census tracts in their respective neighborhoods. Some neighborhoods have multiple census tracts, so respondents identifying a particular neighborhood were randomly divided between the census tracts. Each tract included between one and 18 respondents (average $=4$ ). The census provided data on tract characteristics utilized in the study, poverty rate.

\section{Statistical Analysis}

Behavioral data commonly have a nested structure; for example, these data are from students nested within neighborhoods. Early applications of hierarchical linear models (HLM) addressed three general research purposes: improved estimation of effects within individual units, the formulation and testing of hypotheses about cross-level effects, and the partitioning of variance and covariance components among levels (Raudenbush \& Bryk, 2002). To analyze whether there is a relationship between neighborhood characteristics that would indicate a presence of the impact systemic racism within neighborhoods 
contribute to Louisville youths participation in violent behaviors above and beyond the social norms of violence, HLM7 (Scientific Software International) was used. Multilevel modeling allows a determination of the variance into within(Level 1 model), and between-neighborhood components (Level 2 model) (Raudenbush \& Bryk, 2002).

Using Raudenbush \& Bryk's (2002) model-building strategy, the analysis starts with building an unconditional growth model to estimate the intraclass correlation, then Level-1 random and fixed effects, followed by level-2 random and fixed effects. Based on likelihood ratio tests, the optimal model fit for Level 1 helped determine variables to be included on both the intercept and slope used for Level 2 analysis. The analysis was run using restricted maximum likelihood (REML); REML estimates of variance-components adjust for the uncertainty about the fixed effects (McCoach \& Black, 2008).

\section{Results}

The original YVPRC 2017 School Survey data set included responses from 1,889 students. After removing students who did not live in neighborhoods that received grades from the Louisville Residential Security Maps and students who declined to provide their neighborhood, 341 students were eligible for this study. After entering the data into the HLM software, 93 students were removed for having missing data. The final results include 248 students, nested within 49 neighborhoods. The intraclass correlation (ICC), which "provides a measure of how similar, or homogenous, individuals are within clusters" (McCoach \& Adelson, 2010 , p. 153$)$, for this study is .043 , meaning four percent $(4.3 \%)$ of the 
total variability in violent behavior can be attributed to the neighborhood $(95.7 \%$ within neighborhoods). Table 9 is the unconditional model. The unconditional model equation is whereas, $\mathrm{VB}=$ the mean score of participation of violent behavior measures:

$$
\begin{gathered}
\text { Level-1 Model: } V B_{i j}=\beta_{0 j}+r_{i j}, \\
\text { Level-2 Model: } \beta_{0 j}=\gamma_{00}+u_{0 j} \\
\text { Mixed Model: } V B_{i j}=\gamma_{00}+u_{0 j}+r_{i j}
\end{gathered}
$$

A higher violent behavior score signifies a higher level of participation in violent behaviors.

\begin{tabular}{|c|c|c|c|}
\hline Fixed effects & Coefficient(SE) & $t(\mathrm{df})$ & $p$ \\
\hline \multicolumn{4}{|c|}{ Model for mean violent behavior $\left(\beta_{0}\right)$} \\
\hline Intercept $\left(Y_{00}\right)$ & $.421(0.03)$ & $13.62(48)$ & $<.001$ \\
\hline $\begin{array}{l}\text { Random Effects } \\
\text { (Var. Components) }\end{array}$ & Variance & df & $p$ \\
\hline $\begin{array}{l}\text { Var. in part. In } \\
\text { violent behavior } \\
\text { means }\left(\tau_{00}\right)\end{array}$ & .008 & 48 & 0.208 \\
\hline $\begin{array}{l}\text { Var. within } \\
\text { neighborhoods } \\
\left(\sigma^{2}\right)\end{array}$ & 179 & & \\
\hline
\end{tabular}

Table 9

One-way Random Effects ANOVA Model

The average participation in violent behavior mean is statistically different from zero $\left(Y_{00}\right)$. However, considerable variation in participation in violent behavior means does not exist $\left(\tau_{00}\right)$. Total variability is .187 (between and within). Additional Level-1 variables (student-level) - exposure to violence, positive expectations of peers, negative expectations of peers, deviant peer behavior, prosocial peer behavior, and cultural identity - will be added to try and reduce the 
variation within neighborhoods $\left(\sigma^{2}\right)$. The insignificant variables will be removed to determine best Level 1 fit. Table 3 details the Level-1 model with all variables included. 
Table 10

Random Coefficients (Selected Predictors of Louisville Youth Participation in Violent Behaviors) Model
Fixed effects
Coefficient(SE)
$t(\mathrm{df})$
$p$

Model for mean participation in violent behaviors $\left(\beta_{0}\right)$

$\begin{array}{lccc}\text { Intercept }\left(Y_{00}\right) & 0.193 & 1.448(48) & 0.154\end{array}$

Model for exposure to violence $\left(\beta_{1}\right)$

\begin{tabular}{llll}
\hline Intercept $\left(Y_{10}\right)$ & 0.241 & $6.581(48)$ & $<0.001$
\end{tabular}

Model for expectation of peers 1 slope $\left(\beta_{2}\right)$

\begin{tabular}{llll}
\hline Intercept $\left(Y_{20}\right)$ & -0.102 & $-1.900(48)$ & 0.063
\end{tabular}

Model for expectation of peers 2 Slope $\left(\beta_{3}\right)$

\begin{tabular}{llll}
\hline Intercept $\left(\mathrm{Y}_{30}\right)$ & 0.043 & $0.982(48)$ & 0.331
\end{tabular}

Model for deviant peer behavior Slope $\left(\beta_{4}\right)$

\begin{tabular}{llll}
\hline Intercept $\left(Y_{40}\right)$ & 0.334 & $4.747(48)$ & $<0.001$
\end{tabular}

Model for prosocial peer behavior Slope $\left(\beta_{5}\right)$

\begin{tabular}{llll}
\hline Intercept $\left(Y_{50}\right)$ & -0.066 & $-2.001(48)$ & 0.051
\end{tabular}

Model for cultural identity $\left(\beta_{6}\right)$

\begin{tabular}{llll}
\hline Intercept $\left(\mathrm{Y}_{60}\right)$ & 0.071 & $1.932(48)$ & 0.059 \\
\hline
\end{tabular}

Random Effects

(Var.

Variance

df

$p$

Components)

Var. in

participation

0.337

14

$<0.001$

violent behavior

means $\left(\tau_{00}\right)$

Var. in exposure to

violence slopes

0.013

14

0.117

$\left(\tau_{11}\right)$

Var. in expectation

of peers 1 slopes

$(\tau 12)$

Var. in expectation

of peers 2 slopes

0.034

14

0.098

$\left(\tau_{13}\right)$

Var. in deviant

peer behavior

slopes $\left(\tau_{14}\right)$

Var. in prosocial

peer behavior

slopes $(\tau 15)$

0.027

14

$>0.500$

0.065

14

0.001

0.015

14

0.328 


\begin{tabular}{llll}
\hline $\begin{array}{l}\text { Var. in cultural } \\
\text { identity slopes } \\
(\tau 16)\end{array}$ & 0.011 & 14 & 0.002 \\
\hline $\begin{array}{l}\text { Var. within } \\
\text { neighborhoods } \\
\left(\sigma^{2}\right)\end{array}$ & 0.057 & & \\
\hline
\end{tabular}

\section{Level 1 Model}

After including all the predictors of participation in violent behaviors within neighborhoods, within-neighborhood variability in participation in violent behaviors increased by 37.2 percent. The overall mean participation in violent behaviors across neighborhoods is not statistically different from zero $\left(Y_{00}\right)$ when the predictors were added. The injunctive norms (expectations of your peers) were the only predictors that were not statistically significant, and will be removed from the level-1 model. There are still statistically significant differences (variability) in 15 neighborhoods ( $\tau 00)$. This between-neighborhood variability may be explained by incorporating neighborhood level variables into the model, after determining the best fit. Also, there is statistically significant variability in the effect of deviant peer behavior (slopes) across neighborhoods $\left(\tau_{13}\right)$ and cultural identity $\left(\tau_{16}\right)$, meaning neighborhood-level variables could help to explain these differences as well. Table 11 includes the significant predicators from the original Level-1 model. 
Table 11

Random Coefficients (Selected Predictors to Determine Louisville Youth

Participation in Violent Behaviors) Model
Fixed effects
Coefficient(SE)
$t(\mathrm{df})$
$p$

Model for mean participation in violent behaviors $\left(\beta_{0}\right)$

$\begin{array}{llll}\text { Intercept }\left(Y_{00}\right) & 0.133 & 1.470(48) & 0.148\end{array}$

Model for exposure to violence $\left(\beta_{1}\right)$

\begin{tabular}{llll}
\hline Intercept $\left(Y_{10}\right)$ & 0.257 & $6.904(48)$ & $<0.001$
\end{tabular}

Model for deviant peer behavior Slope $\left(\beta_{2}\right)$

\begin{tabular}{llll}
\hline Intercept $\left(Y_{20}\right)$ & 0.345 & $5.226(48)$ & $<0.001$
\end{tabular}

Model for prosocial peer behavior Slope $\left(\beta_{3}\right)$

\begin{tabular}{lccc}
\hline Intercept $\left(Y_{30}\right)$ & -0.072 & $-2.088(48)$ & 0.042
\end{tabular}

Model for cultural identity $\left(\beta_{4}\right)$

\begin{tabular}{llll}
\hline Intercept $\left(\Upsilon_{40}\right)$ & 0.063 & $1.776(48)$ & 0.082 \\
\hline
\end{tabular}

Random Effects

(Var.

Components)

Var. in

participation

$0.073 \quad 22$

0.016

violent behavior

Variance

df

$p$

means $(\tau 00)$

Var. in exposure to

violence slopes

0.012

22

0.174

$\left(\tau_{10}\right)$

Var. in deviant

peer behavior

0.040

22

0.007

slopes $\left(\tau_{12}\right)$

Var. in prosocial

peer behavior

slopes ( $\tau 13)$

Var. in cultural

identity slopes

$\left(\tau_{14}\right)$

Var. within

neighborhoods

$\left(\sigma^{2}\right)$

0.017

22

0.010

\begin{tabular}{ll}
0.007 \\
\hline
\end{tabular}

$\begin{array}{lll}0.005 & 22 & 0.045\end{array}$ 
four percent (3.5\%). The overall mean participation in violent behaviors across neighborhoods is still not statistically different from zero $\left(Y_{00}\right)$ when the predictors were removed. In this model, cultural identity was the only predictor that was not statistically significant, and will be removed from the Level-1 model. There are still statistically significant differences (variability) in 23 neighborhoods ( $(00)$. This between-neighborhood variability may be explained by incorporating neighborhood level variables into the model, after determining the best fit. Again, there is statistically significant variability in the effect of deviant peer behavior ( $\left.\tau_{12}\right)$ and prosocial behavior $\left(\tau_{13}\right)$, and even cultural identity $\left(\tau_{14}\right)$, meaning neighborhood-level variables could help to explain these differences as well. Table 12 includes the significant predicators from the original Level-1 model and the best fit Level-1 model. 
Table 12

Random Coefficients (Social Norms of Youth Violence in Louisville) Model Fixed effects Coefficient(SE) $t(\mathrm{df})$

Model for mean participation in violent behaviors $\left(\beta_{0}\right)$

\begin{tabular}{|c|c|c|c|}
\hline Intercept $\left(Y_{00}\right)$ & 0.246 & $3.804(48)$ & $<0.001$ \\
\hline \multicolumn{4}{|c|}{ Model for exposure to violence $\left(\beta_{1}\right)$} \\
\hline Intercept (Y10) & 0.250 & $6.626(48)$ & $<0.001$ \\
\hline \multicolumn{4}{|c|}{ Model for deviant peer behavior Slope $\left(\beta_{2}\right)$} \\
\hline Intercept (Y20) & 0.349 & $5.316(48)$ & $<0.001$ \\
\hline \multicolumn{4}{|c|}{ Model for prosocial peer behavior Slope $\left(\beta_{3}\right)$} \\
\hline Intercept $\left(Y_{30}\right)$ & -0.068 & $-1.911(48)$ & 0.062 \\
\hline $\begin{array}{l}\text { Random Effects } \\
\text { (Var. } \\
\text { Components) }\end{array}$ & Variance & df & $p$ \\
\hline $\begin{array}{l}\text { Var. in } \\
\text { participation } \\
\text { violent behavior } \\
\text { means }\left(\tau_{00}\right)\end{array}$ & 0.043 & 26 & 0.058 \\
\hline $\begin{array}{l}\text { Var. in exposure to } \\
\text { violence slopes } \\
(\tau 10)\end{array}$ & 0.013 & 26 & 0.089 \\
\hline $\begin{array}{l}\text { Var. in deviant } \\
\text { peer behavior } \\
\text { slopes }\left(\tau_{12}\right)\end{array}$ & 0.037 & 26 & 0.175 \\
\hline $\begin{array}{l}\text { Var. in prosocial } \\
\text { peer behavior } \\
\text { slopes }\left(\tau_{13}\right)\end{array}$ & 0.019 & 26 & 0.021 \\
\hline $\begin{array}{l}\text { Var. within } \\
\text { neighborhoods } \\
\left(\sigma^{2}\right)\end{array}$ & 0.077 & & \\
\hline
\end{tabular}

Table 12 presents the best level-1 model, with the following formula:

$V B i j=\beta 0 j+\beta 1 j^{*}(E X 2 V i j)+\beta 2 j^{*}\left(P E E R \_D E V i j\right)+\beta 3 j^{*}\left(P E E R \_P R O i j\right)+r i j$

After removing the cultural identity predictor from the model, the within-

neighborhood variability in participation in violent behaviors decreased by 14.8

percent. The overall mean participation in violent behaviors across

neighborhoods is now statistically different from zero $\left(Y_{00}\right)$. There are statistically 
significant differences (variability) in 26 neighborhoods ( $\left.\tau_{00}\right)$. This betweenneighborhood variability may be explained by incorporating neighborhood-level variables into the model in Level 2 . There is statistically significant variability in the effect of prosocial peer behavior $(\tau 13)$, meaning neighborhood-level variables could help to explain these differences as well.

\section{Level 2 Model}

Only two institutional level variables were tested (separately) in the Level2 model: neighborhood poverty rates and HOLC neighborhood grade. The poverty rate for each neighborhood was centered around the grand mean since poverty rate is a continuous variable. Table 13 includes the results from the Level-2 model with neighborhood poverty rate as the institutional level predictor, and Table 14 includes the results with HOLC neighborhood grade as the predictor. The formula for the poverty rate Level-2 model is:

$$
\begin{aligned}
& \beta 0 j=\gamma 00+\gamma 01^{*}(\text { POVERTYRj })+u 0 j \\
& \beta 1 j=y 10+\gamma 11^{*}(\text { POVERTYRj })+u 1 j \\
& \beta 2 j=\gamma 20+\gamma 21^{*}(\text { POVERTYRj })+u 2 j \\
& \beta 3 j=\gamma 30+\gamma 31^{*}(\text { POVERTYRj })+u 3 j
\end{aligned}
$$

Mixed Model: $V B i j=y 00+y 01^{*} P O V E R T Y R j+y 10^{\star} E X 2 V i j+$ $Y 11^{*} P O V E R T Y R j^{*} E X 2 V i j$

$+y 20^{*} P E E R \_D E V i j+y 21^{*} P O V E R T Y R j^{*} P E E R \_D E V i j$

$+y 30^{*} P E E R \_P R O i j+Y 31^{*} P O V E R T Y R j^{*} P E E R \_P R O i j$

$+u 0 j+u 1 j^{\star} E X 2 \overline{V i j}+u 2 j^{\star} P E E R \_D E V i j+u 3 j^{*} P E E R \_P R O i j+r i j$ 
Table 13

Contextual Model with Neighborhood Poverty Rates

Fixed effects Coefficient(SE) $t(\mathrm{df})$

Model for mean participation in violent behaviors $\left(\beta_{0}\right)$

$\begin{array}{llll}\text { Intercept }\left(Y_{00}\right) & 0.242(0.067) & 3.624(47) & <0.001 \\ \text { Poverty Rate }\left(Y_{01}\right) & 0.002(0.001) & 0.517(47) & 0.608\end{array}$

Model for exposure to violence $\left(\beta_{1}\right)$

\begin{tabular}{llll}
\hline Intercept $\left(Y_{10}\right)$ & $0.258(0.038)$ & $6.723(47)$ & $<0.001$
\end{tabular}

$\begin{array}{llll}\text { Poverty Rate }\left(Y_{11}\right) & -0.003(0.002) & -1.361(47) & 0.180\end{array}$

Model for deviant peer behavior Slope $\left(\beta_{2}\right)$

\begin{tabular}{llll}
\hline Intercept $\left(Y_{20}\right)$ & $0.338(0.07)$ & $4.831(47)$ & $<0.001$
\end{tabular}

$\begin{array}{llll}\text { Poverty Rate }\left(Y_{12}\right) & 0.002(0.003) & 0.802(47) & 0.426\end{array}$

Model for prosocial peer behavior Slope $\left(\beta_{3}\right)$

$\begin{array}{llll}\text { Intercept }\left(Y_{30}\right) & -0.063(0.036) & -1.784(47) & 0.081\end{array}$

Poverty Rate $\left(Y_{13)} \quad-0.000(0.002) \quad-0.016(47) \quad 0.987\right.$

Random Effects

Variance

df

$p$

Components)

Var. in

participation

0.049

25

0.036

violent behavior

means $\left(\tau_{00}\right)$

Var. in exposure to

violence slopes

0.108

25

0.126

$\left(\tau_{10}\right)$

Var. in deviant

peer behavior

0.045

25

0.112

slopes $\left(\tau_{12}\right)$

Var. in prosocial

peer behavior

0.14

25

0.015

slopes $\left(\tau_{13}\right)$

Var. within

neighborhoods

$\left(\sigma^{2}\right)$

0.277

(.619)

The formula for the HOLC neighborhood grade level-2 model is:

Level 2 Model: $\beta 0 j=y 00+y 01^{*}(R E D L I N E V j)+u 0 j$

$$
\begin{aligned}
& \beta 1 j=\gamma 10+\gamma 11^{*}(R E D L I N E V j)+u 1 j \\
& \beta 2 j=\gamma 20+\gamma 21^{*}(R E D L I N E V j)+u 2 j \\
& \beta 3 j=\gamma 30+\gamma 31^{*}(\text { REDLINEVj })+u 3 j
\end{aligned}
$$


Mixed Model: VBij $=y 00+y 01^{*} R E D L I N E V j+y 10^{*} E X 2 V i j y 11^{*} R E D L I N E V j^{*} E X 2 V i j$ $+y 20^{*} P E E R \_D E V i j+y_{2} 1^{*} R E D L I N E V j^{*} P E E R \_D E V i j+\gamma 30^{*} P E E R \_P R O i j$

$+\gamma 31^{*} R E D L I N E V j^{*} P E E R \_P R O i j+u 0 j+u 1 j^{*} E X 2 V i j+u 2 j^{*} P E E R \_D E V i j+$ $u 3 j^{*} P E E R \_P R O i j+r i j$ 
Table 14

Contextual Model with Neighborhood HOLC Grade Category

Fixed effects Coefficient(SE) $t(\mathrm{df})$

Model for mean participation in violent behaviors $\left(\beta_{0}\right)$

\begin{tabular}{lccc} 
Intercept $\left(Y_{00}\right)$ & 0.376 & $1.574(47)$ & 0.122 \\
Grade $\left(Y_{01}\right)$ & -0.042 & $-0.570(47)$ & 0.572 \\
\hline Model for exposure to violence $\left(\beta_{1}\right)$ & & \\
\hline Intercept $\left(Y_{10}\right)$ & 0.346 & $2.036(47)$ & 0.047 \\
Grade $\left(Y_{11}\right)$ & -0.032 & $-0.609(47)$ & 0.545 \\
\hline \multicolumn{2}{l}{ Model for deviant peer behavior Slope $\left(\beta_{2}\right)$} & & \\
\hline Intercept $\left(Y_{20}\right)$ & 0.423 & $1.530(47)$ & 0.133 \\
Grade $\left(Y_{12}\right)$ & -0.022 & $-0.258(47)$ & 0.798 \\
\hline \multicolumn{2}{l}{ Model for prosocial peer behavior Slope $\left(\beta_{3}\right)$} & \\
\hline Intercept $\left(Y_{30}\right)$ & -0.190 & $-1.423(47)$ & 0.161 \\
Grade $\left(Y_{13}\right.$ & 0.041 & $0.970(47)$ & 0.337
\end{tabular}

\begin{tabular}{llll}
\hline $\begin{array}{l}\text { Random Effects } \\
\text { (Var. Components) }\end{array}$ & Variance & df & $p$ \\
\hline
\end{tabular}

Var. in

$\begin{array}{llll}\text { participation } & 0.046 & 25 & 0.053\end{array}$

means $\left(\tau_{00}\right)$

Var. in exposure to

violence slopes

$\left(\tau_{10}\right)$

Var. in deviant

peer behavior

slopes $\left(\tau_{12}\right)$

Var. in prosocial

peer behavior

slopes $\left(\tau_{13}\right)$

Var. within

neighborhoods

$\left(\sigma^{2}\right)$

$\begin{array}{lll}0.014 & 25 & 0.095\end{array}$

0.095

$0.039 \quad 25 \quad 0.152$

$0.189 \quad 25 \quad 0.019$

0.078

The Level-2 models show that neighborhood variability is not explained

by either poverty rate or HOLC neighborhood grading categories. However, there is something that does explain these differences, based on the Level-1 predictor of peer prosocial behavior, just not these two predictors. This could be explained 
by the small overall sample size, resulting in a small amount of students within neighborhood clusters.

\section{Discussion}

The purpose of this study was to determine if the impact of systemic racism within neighborhood characteristics contribute to Louisville youths participation in violent behavior above and beyond the social norms of violence. While the social norms of violence and other Level-1 predictors such as cultural identity and exposure to violence are important to understand; looking above and beyond Level-1 predictors at the institutional characteristics help to examine the impact neighborhoods on youth's participation in violent behaviors. The study utilized the impact of residential segregation's racist policies and practices, which were the bases of how neighborhoods were not only formed in Louisville, but also, the impact the HOLC grades have on the neighborhoods currently. Nearly 70 years after the HOLC, Louisville continues to see the impact of residential segregation on the social determinants of health, violence, and overall economic investment throughout the city. As the city has recognized the impact of residential segregation and the extent of the outcomes rooted in racism, it is important to determine how much of an impact the neighborhood has on a youth to participate in violent behaviors.

This study was presented with limitations within its intentions based on the data. The sample size of the students who fit within study criteria, coupled with the neighborhood samples proved to be challenging in determining the impact of neighborhoods on participation in violent behavior. The peer prosocial behavior 
predictor shows that there is significant differences in the effect of the predictor on violent behavior across neighborhood. However, the neighborhood poverty rate and HOLC neighborhood grades in the Level-2 model, did not show significance. The differential effect does not appear to be due to neighborhood poverty or HOLC grade, but some other unidentified neighborhood characteristic.

Since the sample only included data for neighborhoods that received grades in the Residential Survey of 1938, the study did not account for new development within the city. Including newly development neighborhoods can also provide for more variations within neighborhoods and how the city has transformed within the past 70 years. Looking across policies and practices, this can account for the lack of economic development in certain areas, but the development of new communities in other areas. Included students from these neighborhoods can also provide a higher sample size for testing the hypothesis.

There are several factors that can be considered as to why the Level-2 predictors did not confirm what causes variability. As Gee (2002, p. 621) found, "institutional factors may have a weak relationship to individual outcomes but a profound impact on group outcomes, and thus they may drive macro-level racial disparities." Meaning that institutional factors determine individual factors because they are analyzed at lower levels (Gee, 2002). It is challenging to find objective neighborhood characteristics to measure the impact of systemic racism. While the "traditional" measures to determine disparities within communities such as poverty rates, median income, and unemployment rates, these are individual factors that give a look at the impact of institutional factors, but it is a summation 
of individual outcomes. Using the neighborhood grades from the 1938 survey is objective; however, the grading system was subjective to reach a certain outcome during the time. Residential segregation is a complex historical practice that is hard to reflect in one or two variables. Variables such as the number of vacant and abandon properties, home ownership, neighborhood crime rates, and presence of liquor stores, could be potential neighborhood characteristics to utilize in the study.

This exploratory study set out to measure a macro-level impact, with data at the micro-level. To improve the study and models, there is a need for a larger sample size, as well as individual-level predictors that will be able to mirror the institutional-level predictors' impact on youth's participation in violent behavior. Measuring the impact of residential segregation or any other systemically racist policies and practices that were created to subordinate marginalized groups is a large task that will take the creation of measures that will level out individual-level impact and data to institutional-level impact and data. 


\section{CHAPTER VI}

\section{NORMS? SAYS WHO?: A LOOK INTO ADDITIONAL FACTORS OF THE SOCIAL NORMS OF YOUTH VIOLENCE \\ Introduction}

We all ascribe to social rules; however, how often do we stop to evaluate from where these rules derived? Why do we wear different clothes everyday if the clothes are still clean? With advances in technology and electricity, why are typical workdays still between 9 A.M. and 5 P.M. What if someone works better between 12 P.M. and 8 P.M.? Should workers be forced to work within the model that may not coincide with their most productive hours? For many, social norms are not as simple as the ones that are general for "everyone." Social rules may align with the mainstream culture; however, each person has multiple identities, and those identities may not subscribe to the mainstream culture. There are many misperceptions "between actual attitudes or behaviors, and what people think is true about others' attitudes or behaviors" (Berkowitz, 2004, p. 7). There can be many misperceptions about youth from adults that become even more complicated when the identity of the youth is added to their age. A young Black boy in a "certain" part of town may be viewed as "out of place" or "a thug" or "up to no good." Why is it hard to see that he lives in the neighborhood? Or a young Black girl who wears braids or natural hair is seen as distracting or 
unprofessional? Are these rules consistent across all youth groups and identities? No. What makes certain youth different than others, and how are these factors contributing to how youth see themselves as well as engage in "risky" behaviors?

\section{Background}

There are two types of norms: injunctive and descriptive. Injunctive norms "refer to attitudes or what people feel is right based on morals or beliefs," while descriptive norms are "concerned with behavior, i.e. what people actually do" (Berkowitz, 2004, p. 12). The overestimation of "bad" behaviors increases an individual's participation in these behaviors, while the underestimation of healthy behaviors decreases their participation in those behaviors (Berkowitz, 2004). It has been proven that "peer influences have a greater impact on individual behavior than biological, personality, familial, religious, cultural, and other influences" (Berkowitz, 204, p. 5; Berkowitz \& Perkins, 1986a; Borsari \& Carey, 2001; Kandel, 1985; Perkins, 2002).

Youth living in communities with high levels of crime are at greater risk to be involved in violent behavior than those living in communities with low levels of crime (Farrington, 1998; Kelly, 2010; Thornberry et al., 1995). Diminished economic opportunities; high concentrations of poverty; high levels of transiency; high levels of family disruption; low levels of community participation; socially disorganized neighborhoods (CDC, 2016); and communities with a high density of alcohol outlets (Resko et al., 2010) increase the risk of youth participating in violent behaviors. Other researchers have found that neighborhood street culture 
is also a predictor of violent delinquency in Black youth (Anderson, 1999; Stewart \& Simon, 2010). Poverty, political structures, and cultural influences are societal factors that are also associated with youth violence (WHO \& Krug, 2002). Cultural norms that support aggression toward others (WHO \& Krug, 2002); media violence (Anderson et al., 2010); societal income inequity (Fajnzlber, Lederman, \& Loayza, 2002; Kennedy, Kawachi, Prothrow-Stith, Lochner, \& Gupta, 1998; Messner, 1988; Nivette, 2011); and harmful norms around masculinity and femininity (CDC, 2016; Connolly, Pepler, Craig, \& Taradash, 2000; Espelage, Basile, \& Hamburger, 2012; Krug, Mercy, Dahlberg, \& Zwi, 2002) are societal risk factors that create conditions in which youth violence is more likely to occur.

In October 2015, the University of Louisville's Office of Public Health Practice (OPHP) received a Centers for Disease Control and Prevention National Centers of Excellence in Youth Violence Prevention designation for the establishment of a Youth Violence Prevention Center. The University of Louisville's Youth Violence Prevention Research Center (YVPRC) is conducting a research project centered on the creation and evaluation of a three-year social norming campaign to reduce youth violence in WL by influencing the social context of youth in Louisville. The campaign seeks to cultivate positive racial identity and foster community dialogue around difficult issues such as racial and social justice. In doing so, YVPRC aims to raise critical consciousness in an effort to promote racial justice and reduce youth violence. YVPRC is taking a social norms approach to reducing youth violence, which "states that behavior is 
influenced by incorrect perceptions of how other members of our social groups think and act" (Berkowitz, 2004, p. 5). Utilizing data from the YVPRC's 2017 School Survey and Pre-Campaign Focus Groups, the purpose of this study was to determine to what extent perceived norms are representative of the actual behavior of WL youth and to explore what additional factors contribute to WL youth's view on the social norms of youth violence.

West Louisville was the target geographic area for the study. In 2014, 60,749 residents lived in West Louisville, which is made up of nine contiguous neighborhoods (Algonquin, California, Chickasaw, Park DuValle, Park Hill, Parkland, Portland, Russell, and Shawnee), covering 22 census tracts (Kentucky State Data Center [KSDC], 2014; United States [U.S.] Census Bureau, 2012a). Youth comprise about 24 percent $(14,476)$ of the total West Louisville population (KSDC, 2014; U.S. Census Bureau, 2012a). The overall poverty rate of the area is 42.7 percent, nearly three times the rate of all Louisville Metro (16.5\%) (KSDC, 2014). The median household income in West Louisville is $\$ 22,170$ - less than half of LM's median household income of $\$ 46,701$. The overall unemployment rate in $\mathrm{WL}$ is 23.3 percent - more than twice the rate of $\mathrm{LM}(10.0 \%)$ as a whole (KSDC, 2014; U.S. Census Bureau, 2012b).

In WL, violent crime rates for are significantly higher than in surrounding areas. Table 15 shows felony crime rates from Louisville Metro Police Department (LMPD) between 2012 and 2013 for all of Louisville Metro, West Louisville falls within Divisions 1 (Portland, Russell, and Phoenix Hill neighborhoods) and 2 (Shawnee, Chickasaw, and Park DuValle neighborhoods). 
Felony crime rates within West Louisville range between 69.3 and 126 per 1,000 residents. As provided by LMPD, the juvenile arrest/citation rates for WL are higher than LM, ranging from 4.6 to 6.1 per 1,000 residents, compared to 1.1 to 2.3 per 1,000 residents respectively. In 2016, Louisville recorded its highest homicide rate of 113, tying the deadliest single year for homicides, 1971 (Eisenmenger, 2016). From 2009-2013, 280 homicides were reported in Louisville. Approximately, 50 percent of those homicides occurred in WL (LMG: OSHN, 2015).

Table 15

Crime Rates by Division as provided by Louisville Metro Government 2012-2013

\begin{tabular}{|c|c|c|c|}
\hline LMPD Division & $\underline{\text { Total Population }}$ & $\frac{\text { Felony per } 1,000}{\underline{\text { residents }}}$ & $\frac{\text { Juvenile arrest }}{\frac{\text { per } 1,000}{\text { residents }}}$ \\
\hline 1 & 28,621 & 126.0 & 6.1 \\
\hline 2 & 49,544 & 69.3 & 4.6 \\
\hline 3 & 119,781 & 37.7 & 2.2 \\
\hline 4 & 72,838 & 64.3 & 2.3 \\
\hline 5 & 62,938 & 30.5 & 1.1 \\
\hline 6 & 89,015 & 36.9 & 1.6 \\
\hline 7 & 110,728 & 26.5 & 1.9 \\
\hline 8 & 119,860 & 15.6 & 1.6 \\
\hline
\end{tabular}

The reputation of West Louisville is that it is crime infested, dirty, ghetto, where all the Black people live in the city, stricken with poverty, violent, unsafe, bad, ugly, and not a great place to live. To provide context on how the area gained this reputation, it is important to understand the history of the neighborhoods. As enslaved Black people were brought to Louisville, they started to develop communities west and east of downtown (Kleber, 2001). Within these communities, Black people developed their own system of 
leadership, methods of relations with white people, and means that were helpful to fugitive slaves (Kleber, 2001). At the end of slavery, "racial attitudes and the determination to maintain the subordination of African Americans did not change" (Kleber, 2001, p. 15). During Reconstruction, racial segregation evolved "as a means of ensuring a safe status difference between the races; any condition or interaction that implied white subordination to or equality with African Americans was proscribed" (Kleber, 2001, p. 15). Discrimination, poverty, poor housing, crime, and police brutality existed as a norm within the city; however the local Black community continued to develop, but within the limits of "slavery and freedom" in the words of President James A. Garfield (Kleber, 2001, p. 15).

While Black people were developing and sustaining their own communities within these conditions, actual policies began to pass that would distinctly place them in subordination. In 1914, the Louisville Board of Aldermen passed an ordinance that prevented Black residents from moving onto streets that were majority white, and white residents from moving to areas that had been designated Black. In response, the Louisville Chapter of the National Association for the Advancement of Colored People (NAACP) was founded, and two men took Buchanan v. Warley (1917) to the Supreme Court, which ruled the ordinance unconstitutional (Fosl et al., 2013). The city saw an emergence of new Black communities: Smoketown, California, and Little Africa, which were wellorganized and comparatively stable (Kleber, 2001).

Despite this victory, several factors contributed to the continued segregation of Black and white communities in the period that followed. Realtors 
steered white and Black buyers to separate neighborhoods; zoning laws limited multi-family housing; "restrictive covenants" mandated to whom buyers could sell; white community petitions were passed around to keep Black people out of certain neighborhoods; and the federal Home Owner's Loan Corporation "redlining" deemed most Black neighborhoods "low quality" for investment purposes (Aubespin, Clay, \& Hudson, 2011; Fosl et al., 2013). Redlining "is the refusal of lenders to make mortgage loans in certain areas regardless of the creditworthiness of the individual loan applicant" (Holmes \& Horvitz, 1994, p. 81). This public policy which lies within the context of "lack of available credit typically described as due to racial bias or irrational behavior - is cited as a causal factor in neighborhood deterioration" (Lang \& Nakamura, 1993, p. 224). Appendix A includes the redlining maps for Louisville compared to a map of WL.

Urban renewal in Louisville attempted to level Black residential areas both east and west of downtown Louisville during the late 1950s and early 1960s through the creation of new housing developments. According to the U.S. Department of Housing and Urban Development, the Urban Renewal Project is: a project planned and undertaken by an LPA (Local Public Agency) in an urban renewal area with Federal financial and technical assistance under Title I of the Housing Act of 1949. A project may involve slum clearance and redevelopments rehabilitation and conservation, or a combination of both. It may include acquisition of land, relocation of displaced site occupants, site clearance, installation of site improvements rehabilitation of properties and disposition of acquired land for redevelopment in 
accordance with the Urban Renewal Plan (U.S. Department of Housing and Urban Development, n.d.).

Urban renewal in Louisville demolished homes and businesses at Old Walnut Street - the heart of Black life in the city and the thriving business district corridor - and the area has never recovered (Aubespin et al., 2011; Fosl et al., 2013; Kleber, 2001). During the 1960s, more than 15,000 white residents left WL and settled to the east and south ends of Louisville (Fosl et al., 2013). Currently, 45 percent of Louisvillians live in segregated areas, and residents of WL face substantial health, social, education, and economic difficulties compared to the rest of the city (Fosl et al., 2013). Additionally, Louisville's white-Black dissimilarity index is 68.6 , meaning that 68.6 percent of white people would need to move to another neighborhood to make white and Black people evenly distributed across all neighborhoods in Louisville (CensusScope, n.d.). Compared to all U.S. Metro Areas, Louisville is ranked $69^{\text {th }}$ out of $318^{6}$ looking at racial segregation (CensusScope, n.d.). For the purpose of this study, history provides context on how the historical neighborhoods of West Louisville were formed, how they compare to Louisville Metro, and subsequently the conditions within the neighborhood that contribute to the social context in which the youth who participated in the study live.

\section{Data and Methods}

\section{Sample}

The YVPRC research team recruited survey participants from within

\footnotetext{
${ }^{6}$ There are 382 Metropolitan Statistical Areas as delineated by the Office of Management and Budget.
} 
Jefferson County Public School (JCPS) District middle and high schools. JCPS educates more than 100,000 students within 173 schools by over 6,400 teachers (Jefferson County Public Schools, n.d.). The school survey was distributed to middle and high school students from 16 target schools, with a total enrollment of these schools combined at 17,565 (Jefferson County Public Schools, n.d.). These schools were selected to comprise an adequate sample of students who reside in WL as a proportion of the overall sample (approximately 1 in 3 students of these schools combined).

Survey administration was conducted by the Family Resource and Youth Service Center (FRYSC) Coordinator for each school. FRYSC coordinators develop and coordinate the resource center programs within JCPS schools. They develop and maintain contact with business and community representatives throughout Louisville (Jefferson County Public Schools, n.d.). FRYSC Coordinators have contact information (email and/or cell phone) for students and students' parents/guardians in their respective school. Because the school surveys were voluntary and confidential, parents were notified and given the opportunity to inspect the content of the survey before it was deployed to their student. The FRYSC Coordinator for each school sent the University of Louisville's Institutional Review Board-approved parent email on behalf of the study team informing parents about the survey and its contents, and providing a link to the survey for their review if they so desired. The email was disseminated to parents, and a paper copy of the letter was sent home with every student one week prior to survey administration. All students in the 16 target schools were 
invited to participate in the survey; completed surveys were returned to the FRYSC Coordinator, who collected them and returned them to the YVPRC staff. Because the survey was only available in English, students who could not communicate in English were excluded.

In addition to the surveys, the YVPRC research team conducted nine precampaign focus groups with various WL youth age groups (middle schoolers, high schoolers, and post high schoolers), parents, and police officers. The YVPRC research team had existing community partnerships with local organization such as the Mayor's Office, local clinics and hospitals, youth serving organizations, community centers, libraries, etc. The research team recruited WL youth between the ages of 11 and 24 through a variety of methods, but primarily through these community partners. The partner organizations recruited potential participants, who then received a flyer with pre-campaign focus group information. Participants ages 11 to 17 received a parental sign consent form before the scheduled focus group. The pre-campaign focus group facilitator reviewed the assent form with participants prior to the focus group, and assent was obtained before the focus group discussion began. Participants ages 18 and older received the consent form prior to the focus group; the facilitator reviewed the consent form prior to the discussion and obtained consent before beginning the audio-recording. Youth who participated in the focus groups received a $\$ 25$ incentive. Only the middle school and high school pre-campaign focus groups were used for this study, to align with the age of students who participated in the school survey. 


\section{Measures}

The YVPRC 2017 School Survey was comprised of validated measures used in studies across the country. Most of the scales can be found in the Centers for Disease Control and Prevention's Youth Violence Compendium of Assessment Tools (Dahlberg, Toal, Swahn, \& Behrens, 2005), as well as Virginia Commonwealth University's Youth Violence Prevention Center (VCU) (Virginia Commonwealth University Clark-Hill Institute for Positive Youth Development, n.d.). Table 16 includes the constructs utilized for this study from the 2017 School Survey. 
Table 16

Selected YVPRC Constructs Included in this Study

\begin{tabular}{|c|c|c|c|c|}
\hline$\underline{\text { Construct }}$ & $\frac{\text { Scale/ }}{\text { Assessment }}$ & $\underline{\text { Characteristics }}$ & $\frac{\text { Reliability } /}{\text { Validity }}$ & Developer \\
\hline $\begin{array}{l}\text { Descriptive } \\
\text { Norms of } \\
\text { Violence }\end{array}$ & $\begin{array}{l}\text { Peer } \\
\text { Behaviors } \\
\text { Scale; } 10 \\
\text { items }\end{array}$ & $\begin{array}{l}\text { Measure assessing } \\
\text { youth reports of } \\
\text { friends' involvement } \\
\text { in various activities }\end{array}$ & $\begin{array}{l}\text { Peer } \\
\text { Deviance } \\
=.88 ; \text { Peer } \\
\text { Prosocial } \\
\text { Behavior = } \\
.81\end{array}$ & VCU \\
\hline $\begin{array}{l}\text { Injunctive } \\
\text { Norms of } \\
\text { Violence }\end{array}$ & $\begin{array}{l}\text { Peer Support } \\
\text { for } \\
\text { Aggression } \\
\text { and } \\
\text { Nonviolence } \\
\text { Scale; } 6 \\
\text { scenarios }\end{array}$ & $\begin{array}{l}\text { Assesses youth's } \\
\text { expectations for } \\
\text { how their peers } \\
\text { would react to } \\
\text { different ways the } \\
\text { youth might respond } \\
\text { to a difficult situation }\end{array}$ & $\begin{array}{l}\text { Support for } \\
\text { Aggression } \\
\text { subscale = } \\
.76 ; \\
\text { Support for } \\
\text { Nonviolent } \\
\text { Behavior } \\
\text { subscale = } \\
.77\end{array}$ & VCU \\
\hline $\begin{array}{l}\text { Exposure } \\
\text { to violence }\end{array}$ & $\begin{array}{l}\text { Children's } \\
\text { Exposure to } \\
\text { Community } \\
\text { Violence; } 10 \\
\text { items }\end{array}$ & $\begin{array}{l}\text { Measures frequency } \\
\text { of exposure } \\
\text { (through sight and } \\
\text { sound) to violence } \\
\text { in one's home and } \\
\text { neighborhood. }\end{array}$ & .84 & $\begin{array}{l}\text { Richters \& } \\
\text { Martinez, } \\
1990\end{array}$ \\
\hline $\begin{array}{l}\text { Violent } \\
\text { Behavior }\end{array}$ & $\begin{array}{l}\text { Victimization; } \\
10 \text { items }\end{array}$ & $\begin{array}{l}\text { Measures exposure } \\
\text { to violence and } \\
\text { victimization in } \\
\text { one's home, school, } \\
\text { and neighborhood }\end{array}$ & $\begin{array}{l}\text { Not } \\
\text { available }\end{array}$ & $\begin{array}{l}\text { Nadel, } \\
\text { Spellmann, } \\
\text { Alvarez- } \\
\text { Canino, } \\
\text { Lausell- } \\
\text { Bryant \& } \\
\text { Landsberg, } \\
1991\end{array}$ \\
\hline $\begin{array}{l}\text { Cultural } \\
\text { Identity }\end{array}$ & $\begin{array}{l}\text { Multigroup } \\
\text { Ethnic } \\
\text { Identity } \\
\text { Measure }\end{array}$ & $\begin{array}{l}\text { Measures ethnic } \\
\text { identity search (a } \\
\text { developmental and } \\
\text { cognitive } \\
\text { component) and } \\
\text { affirmation, } \\
\text { belonging, and } \\
\text { commitment (an } \\
\text { affective } \\
\text { component). }\end{array}$ & .80 & $\begin{array}{l}\text { Phinney, } \\
1992\end{array}$ \\
\hline
\end{tabular}


The pre-campaign focus group topic guides were created by the YVPRC research team, and focused on uncovering existing norms - descriptive and injunctive - as well as understanding implications of violating the perceived norms. The focus group questions solicited information about what types of media youth are using, for what purposes, how often, and their level of trust in different applications. Responses from the following questions were used to measure the additional factors of youth violence:

- From your viewpoint, what does it mean to be a young person living in your community? From other's point of view?

- How do you think people outside your community view young people living in your community?

- How do you feel about that?

- How would you define violence?

- Do you see violence in your neighborhood? In your school?

- How do you feel about people who use violence? About people who are victims of violence? In what situations are violence necessary? Appropriate? Expected?

These data add important context to the quantitative data from the school surveys.

\section{Analytic Strategy}

School Survey. Quantitative data analysis was completed using IBM SPSS Statistics for Windows, Version 24.0 (IBM Corp., 2013). Frequency statistics were used to determine the frequency of participants who were exposed to various levels of violence; norms related to violence among their peers; injunctive norms related to violence among their peers; and personal engagement in violent behavior. New variables were calculated to determine the 
average peer reactions (negative, neutral, and positive) for injunctive norms; the average perceived participation in descriptive norms (not participated, participated in some behaviors, participated in many behaviors, and participated in all behaviors); the level of their violent behavior (never, once, sometimes, and often); and their level of exposure to violence (no exposure, low, medium, and high exposure). Crosstabs were run for each of the questions to determine the frequency of participation and perceptions for students who reside in $\mathrm{WL}$ and those who live in neighborhoods outside of WL. Additionally, chi square tests were run to determine the significance of differences in responses between students from WL and LM.

Pre-Campaign Focus Groups. Qualitative data include "voices of participants, the reflexivity of the researcher, a complex description, and interpretation of the problem, and its contribution to the literature or a call for change," or in the case of the campaign, inform the design of the campaign (Creswell, 2013, p. 44). To analyze the qualitative data for this study, a constructivist grounded theory approach was utilized. According to Charmaz (2014), constructivism is a social scientific perspective that addresses how realities are made, by including subjectivity into view and assuming that people, including the researchers, construct the realities in which they participate. The researcher explores the person's experiences and includes multiple views of the experience, creating connections, and then constructing an interpretation (Charmaz, 2014). A constructivist approach is a $360^{\circ}$ view of not only how but also why participants place meaning and actions on their experiences (Charmaz, 
2014). Researchers who take a constructivist grounded theory (CGT) approach take into account how the participants view their experience, as well as the researcher's view and how the broader environment affects the experience and situation. Contrary to objectivist grounded theory, CGT links multiple realities that move past traditional approaches that yielded abstract theories, moving grounded theory into interpretive social science (Charmaz, 2014).

Pre-campaign focus group transcripts started with initial coding, or line-byline coding using gerunds (or -ing verbs). Glaser (1978) explains how gerunding helps to not only detect processes but also helps a researcher stick to the data (Charmaz, 2014). After completing initial coding, the researcher went through the data and completed process coding. Process coding or in vivo codes, includes adopting codes directly from the data (Charmaz, 2014). Coding helped to connect the researcher to the data and helped to direct the researcher to concepts for further exploration. Process codes were grouped based on conceptual relationship and read through thoroughly. Broader themes were created based on the process code groupings, leaving block quotes to accompany the process codes to remain true to statements made by participants and to provide context for the themes.

\section{Results}

\section{School Survey}

The survey yielded an 11 percent response rate with 1,889 surveys included in the final data set after cleaning and validation from the YVPRC research team. For this study, none of the responses were extreme outliers to be 
eliminated for analysis, therefore the $N=1,889$. The median age of participants was 13. As research is expanding and recognizing gender as non-binary (Callis, 2014), YVPRC captured gender identities of the participants beyond male and female. Majority of respondents were male (51.1\%), 41.2 percent were female, 0.4 percent identified as transmale, 0.4 percent as transfemale, one percent identified as genderqueer/gender non-conforming, and 0.5 percent as other. The racial demographics of participants also mirror those of the district, with almost three percent (2.5\%) of respondents identifying as Asian or Asian American, including Chinese, Japanese, and others; 13.2 percent Black or African American; almost nine percent (8.9\%) Hispanic or Latino, including Mexican American, Central American, and others; 27.3 percent White, Caucasian, Anglo, European American, not Hispanic; eight percent (8.2\%) American Indian/Native American; almost five percent (4.6\%) identified as mixed, from more two or more different groups; and almost seven percent (6.6\%) as other.

Descriptive Norms (Peer Behavior). The Peer Behaviors Scale is a 10item self-reported measure assessing youth reports of friends' involvement in various activities. The measure has two subscales: Peer Deviance (6 items) and Peer Prosocial Behavior (4 items). Peer deviance asks how many of their friends have been involved in different deviant activities, while the peer prosocial behavior scale measures "peer behaviors and reactions to potential conflict theorized to have a positive relation to adolescent adjustment outcomes and a negative relation to aggression" (Virginia Commonwealth University Clark-Hill Institute for Positive Youth Development, n.d, p. 24). Perceptions of peer 
behaviors mean scores were calculated to determine how many if any of the participants participate in either the deviant or prosocial behaviors. Of the respondents, 56.7 percent reported that have no friends that participate in deviant behaviors, 36.5 percent have none to some friends, nearly six percent $(5.9 \%)$ have some to many friends that participate, 0.8 percent have many to all friends that participate, and 0.2 percent said all of their friends participate in the deviant behaviors. A little over three percent (3.3\%) of the respondents reported that they have no friends that have participated in the prosocial behaviors, nearly seven percent $(6.9 \%)$ have none to some friends, 44.7 percent have some to many friends that participate, 41.4 percent have many to all friends that participate, while nearly four percent (3.7\%) said all of their friends participate in the prosocial behaviors. Table 17 represents the frequency of responses to determining the level of participation their friends have in certain behaviors, with a comparison of students who live within West Louisville and those who live in other areas of Louisville Metro. The table also includes the chi square $\left(X^{2}\right)$ for each individual question denoting if the responses are statistically significant between West Louisville students and students who live in other areas of Louisville Metro. 
Table 17

Descriptive Norms (Peer Behavior) of Louisville Youth to Determine Local Norms of Violence

Sold drugs?

Stolen something worth more than $\$ 10$ ?

Loaned things to people just to be nice? (prosocial) Hit someone with the idea of hurting that person?

Helped out around the house? (prosocial) Used a weapon, force, or strongarm methods to get money or things from people?

Purposely damaged or destroyed property that wasn't theirs.

Tried to do their best in school? (prosocial) Been in a gang fight?

Helped people without expecting something back?

${ }^{*}$ Louisville Metro numbers exclude students residing in West Louisville

Injunctive Norms (Expectations of Your Peers). The Peer Support for Aggression and Nonviolence Scale contains two subscales: Perceived Support for Aggression and Perceived Support for Nonviolent Behavior (Virginia Commonwealth University Clark-Hill Institute for Positive Youth Development, 
n.d). To determine the anticipated reactions of the participants' peers, the questions determining the perceived support for aggression were calculated and averaged to determine if peers would react negatively, neutrally, or positively. For the first scale, Perceived Support for Aggression, three percent said their friends would respond negatively, 22.3 percent responded between negative and neutral, 53 percent responded neutrally, and .7 percent said their friends would respond positively. For the second scale, Perceived Support for Nonviolent Behavior, 0.6 percent said their friends would respond positively, 50.1 percent responded between negative and neutral, 23.1 percent responded neutrally, and 7.9 percent said their friends would respond negatively. Table 18 represents the frequency comparison of expectations of participant peers for students who reside in WL and those who reside in all other neighborhoods. The chi square $\left(X^{2}\right)$ in the table indicates whether there is a statistically significant difference between respondents who reside in West Louisville from those who live in other areas of Louisville Metro. 
Table 18

Injunctive Norms of Louisville Youth to Determine Local Norms of Violence

(Perceived Support for Aggression)

What would your friends think if you cheered on a fight?

What would your friends think if you went to get an adult?

What would your friends think if you started a fight with the person making fun of you?

What would your friends think if you quit playing ball and left? What would your friends think if you tried to talk to the person calmly to settle the argument? What would your friends if you threw the first punch?

(Perceived Support for Nonviolent Behavior)

What would your friends think if you talked it out with the person the rumor was started about and explained that you didn't start it? What would your friends think if you argued and got into a fight with the person who blamed you for starting the rumor?

What would your friends think if you gave them a serious look and told them if they didn't stop you'd fight them?

What would your friends think if you just ignored the other person and didn't let it bother you?

What would your friends think if you asked an adult, like a teacher or someone in your neighborhood, for help?

What would your friends think if you asked them to help you beat those people?

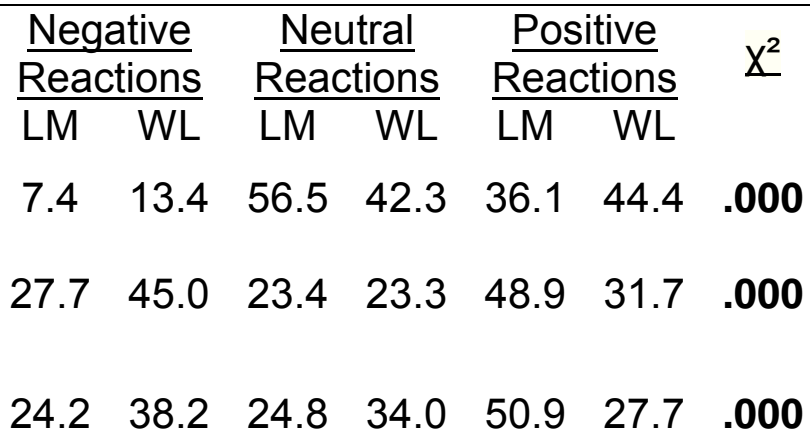

$\begin{array}{lllllll}26.9 & 28.0 & 45.1 & 39.3 & 28.0 & 32.6 & .042\end{array}$

$\begin{array}{lllllll}12.8 & 22.8 & 25.3 & 32.8 & 61.8 & 44.4 & .000\end{array}$

$\begin{array}{lllllll}35.1 & 45.8 & 27.6 & 12.9 & 37.3 & 41.3 & .000\end{array}$

$\frac{\frac{\text { Positive }}{\text { Reactions }}}{\text { LM WL }} \frac{\frac{\text { Neutral }}{\text { Reactions }}}{\text { LM WL }} \frac{\frac{\text { Negative }}{\text { Reactions }}}{\text { LM WL }} \quad \chi^{2}$

$\begin{array}{lllllll}69.8 & 52.7 & 9.2 & 14.2 & 21.0 & 33.1 & .000\end{array}$

$\begin{array}{lllllll}15.1 & 27.8 & 55.7 & 37.1 & 29.2 & 35.0 & .000\end{array}$

$\begin{array}{lllllll}31.3 & 37.7 & 31.6 & 20.9 & 37.1 & 41.4 & .006\end{array}$ $\begin{array}{lllllll}38.9 & 27.7 & 16.5 & 25.1 & 44.7 & 47.2 & .001\end{array}$ $\begin{array}{lllllll}62.7 & 48.3 & 11.9 & 20.6 & 25.4 & 31.1 & .000\end{array}$ $\begin{array}{lllllll}12.0 & 22.7 & 66.2 & 40.3 & 21.8 & 37.0 & .000\end{array}$ 
Exposure to Violence. The items measured the frequency of exposure (through sight and sound) to violence in survey participants home or neighborhood (Dahlberg, Toal, Swahn, \& Behrens, 2005). As advised in the compendium, point values were summed and then divided by the total number of items used in the survey (9) to provide a range. The higher the score indicates the more frequent exposure to acts of crime and violence (Dahlberg et al., 2005). The range for the frequency created is never (0), never to low (>1), low to medium (>2), medium (>3), and high (3) exposure to violence in their home and neighborhood. Of the total participants, 15.5 percent reported never being exposed to violence, while 55.9 percent reported having never to low exposure, 17.1 percent low exposure, 4.7 percent medium exposure, and 0.7 percent reporting high exposure. Table 19 represents the frequency of responses for the exposure to violence questions based on the respondents' neighborhoods, as well as the chi square $\left(X^{2}\right)$ value to determine significance between groups. 
Table 19

Louisville Youth's Exposure to Community Violence

\begin{tabular}{|c|c|c|c|c|c|c|c|c|c|}
\hline \multirow[b]{3}{*}{$\begin{array}{l}\text { I have heard guns } \\
\text { being shot. }\end{array}$} & \multicolumn{2}{|c|}{$\frac{\text { Never }}{(\%)}$} & \multicolumn{2}{|c|}{$\frac{\text { Once or }}{\text { Twice }}$} & \multicolumn{2}{|c|}{$\frac{\text { A Few }}{\text { Times }}$} & \multicolumn{2}{|c|}{$\frac{\text { Many }}{\text { Times }}$} & \multirow[t]{2}{*}{$x^{2}$} \\
\hline & LM & WL & $L \bar{M}$ & $\bar{W} L$ & $\mathrm{LM}$ & $\bar{W} L$ & $\mathrm{LM}$ & $\bar{W} L$ & \\
\hline & 47.8 & 12.6 & 24.6 & 17.6 & 15.1 & 26.5 & 12.5 & 43.3 & .000 \\
\hline $\begin{array}{l}\text { I have seen } \\
\text { somebody arrested. }\end{array}$ & 43.1 & 19.2 & 33.5 & 26.8 & 15.8 & 31.8 & 7.7 & 22.2 & .000 \\
\hline $\begin{array}{l}\text { I hav } \\
\text { deals }\end{array}$ & 73.5 & 47.1 & 12.5 & 19.2 & 7.5 & 15.0 & 6.5 & 18.8 & .000 \\
\hline $\begin{array}{l}\text { som } \\
\text { beat }\end{array}$ & 43.6 & 24.5 & 27.5 & 18.6 & 15.8 & 24.9 & 13.0 & 32.1 & .000 \\
\hline $\begin{array}{l}\text { e has been } \\
\text { to. } \\
\text { en }\end{array}$ & 81.7 & 66.9 & 14.5 & 21.2 & 2.5 & 7.2 & 1.2 & 4.7 & .000 \\
\hline $\begin{array}{l}\text { som } \\
\text { stab }\end{array}$ & 89.0 & 73.9 & 6.3 & 14.3 & 2.9 & 5.9 & 1.8 & 5.9 & .000 \\
\hline $\begin{array}{l}\text { I have seen a gun in } \\
\text { my home. }\end{array}$ & 66.8 & 65.5 & 15.5 & 14.3 & 6.5 & 8.0 & 11.3 & 12.2 & .480 \\
\hline $\begin{array}{l}\text { I have seen gangs } \\
\text { in my neighborhood. } \\
\text { I have seen }\end{array}$ & 81.9 & 39.3 & 8.8 & 21.8 & 5.0 & 16.3 & 4.3 & 22.6 & .000 \\
\hline $\begin{array}{l}\text { somebody pull a } \\
\text { gun on another } \\
\text { person. }\end{array}$ & 85.3 & 66.4 & 8.7 & 12.6 & 2.8 & 9.7 & 3.1 & 11.3 & .000 \\
\hline
\end{tabular}

Violent Behaviors. Survey participants were asked questions regarding their own behavior. A new variable was calculated to determined how often respondents participated in a variety of violent acts. The mean scores were calculated to determine the frequency of which participants engage in violent behaviors. Of the total participants 24.6 percent reported never being violent, participating in behaviors never to once 60.5 percent, sometimes 7.1 percent, and often .3 percent. Table 20 compares the respondents participation in violent behavior based on if they live in $\mathrm{WL}$ or not, along with the chi square $\left(\mathrm{X}^{2}\right)$ values 
to determine if there is significance between the groups.

Table 20

Louisville Youth Engagement in Various Violent Behavior

Hit or kicked

someone.

Never Once Sometimes Often $X^{2}$

LM WL LM WL LM WL LM WL

Pushed or shoved

someone when you

were angry.

$\begin{array}{llllllllll}\text { Beaten someone up. } \quad 80.2 & 54.9 & 11.5 & 14.8 & 6.3 & 21.1 & 2.0 & 9.3 & .000\end{array}$

Carried a knife or

sharp weapon or

other blade.

$\begin{array}{lllllllll}42.7 & 25.1 & 27.1 & 21.3 & 24.5 & 36.8 & 5.8 & 16.7 & .000\end{array}$

$\begin{array}{lllllllll}46.4 & 32.1 & 27.0 & 20.4 & 20.4 & 32.5 & 6.2 & 15.0 & .000\end{array}$

Threatened someone

with a knife or sharp

weapon.

Attacked someone

with a knife or sharp

weapon.

Carried a gun.

Threatened someone

with a gun.

Used a gun on

another person.

$\begin{array}{lllllllll}87.1 & 80.3 & 4.9 & 9.7 & 4.9 & 6.3 & 3.1 & 3.8 & .001\end{array}$

$\begin{array}{lllllllll}95.4 & 86.9 & 2.8 & 6.4 & 1.1 & 5.9 & 0.6 & 0.8 & .000\end{array}$

Said something to someone that made them feel bad about

$\begin{array}{lllllllll}97.1 & 93.3 & 1.5 & 1.7 & 1.0 & 4.2 & .04 & 0.8 & .000\end{array}$

$\begin{array}{lllllllll}92.7 & 88.8 & 3.0 & 5.8 & 2.6 & 3.8 & 1.7 & 1.7 & .000\end{array}$

$\begin{array}{lllllllll}96.8 & 93.3 & 1.4 & 1.7 & 1.1 & 4.6 & 0.6 & 0.4 & .000\end{array}$

$\begin{array}{lllllllll}97.5 & 94.1 & 1.1 & 1.7 & 0.9 & 2.5 & 0.4 & 1.7 & .002\end{array}$ themselves, or afraid.

$\begin{array}{lllllllll}64.2 & 50.0 & 23.3 & 21.7 & 9.6 & 20.4 & 2.9 & 7.9 & .000\end{array}$

Cultural Identity. The cultural identity measure for the YVPRC 2017

School Survey utilized measures from the Multigroup Ethnic Identity Measure, which compares two factors: ethnic identity search (a developmental and cognitive component) and affirmation, belonging, and commitment (an affective component). The preferred score is to use the mean of the item scores, with a range from 0 to 3 , meaning, student with higher averages have a higher sense of cultural identity. A little over one percent (1.3\%) of the students reported having 
no cultural identity, seven percent $(7.1 \%)$ reported no to low cultural identity, 47.8 percent have low cultural identity, while 31.2 percent reported having medium, and two percent of respondents have high cultural identity. Table 21 compares the cultural identity of students from West Louisville to students from other areas of Louisville Metro, along with the chi square value for each individual question. 
Table 21

Cultural Identity of Louisville Students

I have spent time

\begin{tabular}{|c|c|c|c|}
\hline$\frac{\text { Strongly }}{\text { Disagree }}$ & Disagre & $\underline{\text { Agree }}$ & $\frac{\text { Strongly }}{\text { Agree }}$ \\
\hline M $\quad$ W & 10 & & \\
\hline
\end{tabular}

trying to find out

more about my

ethnic group, such

$\begin{array}{lllllllll}8.2 & 10.9 & 33.6 & 29.7 & 46.1 & 44.4 & 12.1 & 15.1 & .103\end{array}$

as its history,

traditions, and

customs.

I am active in

organizations or

social groups that

include mostly

$\begin{array}{lllllllll}10.3 & 12.2 & 41.3 & 37.8 & 39.8 & 34.0 & 8.5 & 16.0 & .000\end{array}$

members of my own

ethnic group.

I have a clear sense

of my ethnic

background and

what it means for

me.

I think a lot about

how my life will be

affected by my

ethnic group

membership.

I am happy that I am

a member of the

group I belong to.

I have a strong

sense of belonging

to my own ethnic

$\begin{array}{lllllllll}6.1 & 8.5 & 19.9 & 26.4 & 58.8 & 46.8 & 15.2 & 18.3 & .020\end{array}$

group.

I understand pretty

well what my ethnic

group membership

$\begin{array}{lllllllll}11.0 & 9.9 & 37.3 & 30.0 & 40.1 & 41.6 & 11.6 & 18.5 & .001\end{array}$

means to me.

$\begin{array}{lllllllll}3.3 & 4.3 & 8.9 & 12.0 & 66.9 & 48.5 & 29.4 & 35.2 & .000\end{array}$

$\begin{array}{lllllllll}4.7 & 6.4 & 17.5 & 15.0 & 54.8 & 50.9 & 23.0 & 27.8 & .005\end{array}$

$\begin{array}{lllllllll}4.6 & 5.6 & 15.9 & 19.0 & 59.8 & 50.2 & 19.6 & 25.1 & .000\end{array}$ 


\begin{tabular}{|c|c|c|c|c|c|c|c|c|c|}
\hline & $\frac{\text { Stro }}{\text { Dise }}$ & $\frac{\text { gly }}{\text { gree }}$ & Disa & gree & $\underline{\mathrm{Ag}}$ & ee & & $\frac{\text { ngly }}{\text { ree }}$ & $x^{2}$ \\
\hline & LM & WL & LM & WL & LM & WL & LM & WL & \\
\hline $\begin{array}{l}\text { In order to learn } \\
\text { more about my } \\
\text { ethnic background, I } \\
\text { have often talked to } \\
\text { other people about } \\
\text { my ethnic group. }\end{array}$ & 10.6 & 11.0 & 35.9 & 32.5 & 40.4 & 39.2 & 13.0 & 17.3 & .044 \\
\hline $\begin{array}{l}\text { I have a lot of pride } \\
\text { in my ethnic group. } \\
\text { I participate in } \\
\text { cultural practices of }\end{array}$ & 4.4 & 6.0 & 16.6 & 13.4 & 53.3 & 49.6 & 25.7 & 31.0 & .005 \\
\hline $\begin{array}{l}\text { my own group, such } \\
\text { as special food, } \\
\text { music, or customs. }\end{array}$ & 11.0 & 9.3 & 27.7 & 32.6 & 43.1 & 40.3 & 18.2 & 17.8 & .074 \\
\hline $\begin{array}{l}\text { attachment towards } \\
\text { my own ethnic } \\
\text { group. }\end{array}$ & 5.3 & 7.8 & 20.5 & 19.5 & 51.9 & 50.2 & 22.3 & 22.5 & .133 \\
\hline $\begin{array}{l}\text { I feel good about my } \\
\text { cultural or ethnic } \\
\text { background. }\end{array}$ & 4.3 & 5.2 & 14.6 & 18.1 & 52.2 & 16.1 & 29.0 & 30.6 & .016 \\
\hline
\end{tabular}

\section{Pre-Campaign Focus Groups}

A total of 60 middle and high school aged WL youth participated in the six focus groups that were analyzed for the qualitative portion of this study.

Participants ranged in age between 11 and 18 . There were 42 males and 18 females who participated in the focus groups, and all 60 youth were Black. These demographic data were captured by YVPRC staff members who recorded notes during focus groups. Four themes arose during qualitative analysis: What's it like in my community; This is how they see us; Racism: Everyday-Everywhere; and This is how we see ourselves. 
Life in My Community is Complicated. All focus group participants lived in West Louisville or participate in programs in West Louisville and there was consensus that many norms or stereotypes are placed on them by not only people outside of their community, but also people within their community, and their families. While most of the survey respondents said that there was not much violence in their communities (majority live outside of West Louisville), focus group participants experience violence within their community and in school. When asked to define violence one participant said 'it's just an everyday thing. From the time you wake up there's going to be some violence. You go to sleep, there's going to be some violence. Somebody getting killed, somebody's killing somebody." Violence to the participants is a cycle. One participant provided an analogy to define violence:

"I put it in the context and my knowledge here, it's kind of like a dog and cat analogy like you shoot my dog or you shoot my cat, so l'm going to shoot your dog. Kind of like you shot my homeboy, so I'm going to shoot your homeboy, and it keep building up and going on and on and continue. That's how I look at it."

Participants see gun violence, fights (in and outside school), drug abuse and selling, domestic violence, gang violence, and bullying. Most had been directly or indirectly impacted by violence. Violence is seen as a way to survive. When asked how they feel about a person that engages in violence someone responded, "They living their life. They got to survive." The norm is to react when something is not only done to you, but someone close to you. A participant 
shared a story of her brother being killed and then his friend retaliating. For many youth living in West Louisville, this is a reality of everyday life. Not only did they describe seeing violence, they also mentioned poverty, the lack of economic investment, vacant and abandon homes, mixed with a lack of opportunities for youth to engage in positive recreational activities. Many of the things the youth describe as a part of their neighborhood are community risk factors of violence. They have recognized their neighborhood is a socially disorganized community, which is also a cause for high rates of violence. Being a youth in their community is hard and many are looking for things to change for not only themselves but for future generations.

They See Us as Bad. When asked how people outside of their community viewed youth from their community, overall, the view of youth from West Louisville was that they were bad. "They would think that we're bad but really we're not." For them, just walking down the street is not so simple. "Most people, if you were to walk down the street, they'll think you're up to something." They mention that this comes from police that patrol their community or that see them around the city in places, such as the mall. With a lack of recreational activities or fun things to do in their community (movies, mall, skating rink, etc.), participants described traveling outside of their community to experience fun things; however, they are then seen as out of place or up to no good. "People think we going to steal their cars. But you can't always suspect somebody who's walking the street is going to steal your car. Everybody don't steal cars." In this particular focus group, some participants admitted to hanging with other youth who may steal 
cars, but that does not mean they are stealing cars or the entire group should be seen a particular way. Participants mentioned that the media (local and national) play a major part in shaping the way people outside of their community view them. They feel that their community is highlighted for the negative instances of things that happen rather than the positive aspects that transpire.

We See Racism Every day, Everywhere. A major theme that emerged from the focus groups was racism (discrimination and structural). While racism was the major theme, two subthemes emerged: racism within school and racism within the city. With students spending more than eight hours a day within schools, their perspective on how racism impacts their learning spaces is telling.

Racism within school. Participants mentioned that their schools may be diverse; however, within the schools, they are separated by race. Students reported experiencing racism within their schools in terms of how teachers treat them, curriculum, and inequity in discipline reoccurred throughout the focus groups. When asked how would you describe your school, some participants answered, "Racist. Ain't equal opportunities in our schools. They be lying." Another student put it this way:

"I was just saying everybody ain't the same in our school. When you catch a couple of white kids who's caught skipping up, they set them aside and they get a couple of lectures. A couple of Black kids get caught skipping, we get kicked out. The next day it goes on and on and on and so on." The participants did not feel that the teachers as well as the curriculum in schools were culturally competent and they felt lied to about not only where they 
come from but the contributions people of their racial background have made to the country. In the city, many students have been advocating for the local school district to incorporate accurate Black history throughout the curriculum, and this was echoed in the focus groups. The participants would learn history on their own and want to know why they did not learn it in school. Lack of cultural competence is also evident in some school policy. In the summer of 2016, one of the local high schools created a hair policy that would directly impact Black students. Participants in one focus group attended the school and talked about how this made them feel and their act of resistance to the system changes that oppressed them. "For the African American males or whatever, they thought you know how cornrows are part of our nature, culture whatever; so it was more offensive to African American males, the females and males, so instead we did like a protest, and we got the rule changed." The local school held a meeting in regards to the rule, not allowing anyone to speak on the rule, and essentially reserving the rule. In response to this and many other actions within local high schools, a growth in Black Student Unions (BSUs) formed locally (Ross, 2016). Racism within the city. The theme of racism did not just cover practices within the school, but also practices within the city. They linked lack of access to services, programs, jobs, and fun things in their community to the city not caring about their neighborhood. Participants discussed the judgment and racist comments that are made towards them when they travel outside of their neighborhood for recreational activities. "They don't think that I hear what they are saying behind my back but I do" explained one participant when talking about 
encounters with white youth in the city. The perception of the community that has been created is all the Black people live in West Louisville and that bad things happen there. The "9th Street Divide," which separates West Louisville from East Louisville is a barrier created during Urban Renewal to physically separate the city, and as a result, many of the conditions faced in WL are a direct result of the environment created through policies.

We Want to Make Change Happen. Regardless of how others view them, the majority of youth who participated noted that being a young person in their community means that they can be active and helpful. They want to make a change and help others and not live or play into the stereotype that they are all up to something. One male participant stated that: "being a young person in your community is someone to keep the traditions going...like if your community has a tradition that it's your responsibility to make sure it continues or to look out for the elder. Make sure they're okay. Just take care of your community." They have a positive sense of self and want to contribute to making the community better despite the conditions or things that are put upon them.

\section{Discussion}

The purpose of this study was to determine to what extent perceived norms are representative of the actual behavior of West Louisville youth and to explore what additional factors contribute to West Louisville youth's view on the social norms of youth violence. While many of the survey measures show variation between students who reside in areas of Louisville Metro outside of West Louisville and students who reside within West Louisville, some are 
particularly important to examine as the discussion focuses on neighborhood and the environment in which many of the students live. It is clear that students who live in West Louisville are exposed to more violence such as having heard gunshots, seen someone beaten up, or seen gangs in their neighborhood. Students who live in West Louisville are also more likely to be involved in violent behavior such as hit or kicked someone, beaten someone up, or said something to someone that made them feel bad about themselves or afraid. Additionally, the norms surrounding support of nonviolent behavior varies amongst the groups. Data from the school survey provide a picture on how students from different areas of the city differ regarding norms and experiences. Additionally, most of the students have a sense of their cultural identity. Compared to students in Louisville Metro, more West Louisville students reported being happy to be a member of their ethnic group, with an understanding of what it means to be a member of their ethnic group. They also have pride in their ethnic group.

The peer behaviors and the students' own behaviors can be linked back to their exposure and the things around them. Neighborhood culture has a great influence on individual behavior (Anderson, 1999). It has been found that neighborhoods that suffer from the impact of unequal structures oppose the mainstream norms and create a culture that keeps them in survival mode (Bruce, Roscigno, \& McCall, 1998; Hughes \& Short, 2005; Kubrin \& Weitzer, 2003; Melynk et al., 2010). This culture is complicated through local systems (political, justice, and educational), which has for decades discriminated against Black people (Unnever, 2008). A sense of hopelessness is created within the 
community and defeat when they are constantly harassed or labeled, creating the cycle the students were able to describe in the focus groups, such using violence to survive.

While being able to recognize the norm of violence being a tactical mode of survival, the recurring theme of racism across all the focus groups grew to be an additional factor to the norms of violence. Most of the responses to questions surrounding descriptions of their neighborhood align with demographic data: poverty, lack of jobs, lack of resources, high rates of violence, and neighborhood physical disorder. The participants discussed experiencing racism on the individual and systemic level. A continued source of stress for Black youth as they transition into adulthood is racial discrimination (Caldwell, Kohn-Wood, Schmeelk-Cone, Chavous, \& Zimmerman, 2004; Krieger, 1990; Sellers, Caldwell, Schmeelk-Cone \& Zimmerman, 2003.) Substantial evidence indicates that racial discrimination is a fundamental part of the social structure in the lives of Black people (Cross, Parham, \& Helms, 1998; Jackson, Brown, Williams, Torres, Sellers, \& Brown, 1996; Williams, Spencer, \& Jackson, 1999). However, the experience of racial discrimination varies over the life course (Caldwell et al., 2004). Romero and Roberts (1998) found that older youth are more likely than younger youth to perceive racial discrimination; however, youth may not yet fully understand the concept. Which was evident in the middle school focus groups compared to the high school focus groups. High school participants were able to identify and state the impact of racism on their everyday life in school as well as their community. They also found that Black youth reported higher levels of 
perceived racial discrimination than other youth (Romero \& Roberts, 1998).

Youth who perceive that society does not value their racial group may engage in violent behaviors as a way to cope with stressful racial experiences (Caldwell et al., 2004). An example of using violent behaviors to cope with stressful racial experiences was described when the youth talked about their friends stealing cars when perceived as people who steal cars because they were in the "wrong neighborhood."

Interesting to note is that the JCPS system currently operates with a busing system. Nearly 42 years after a court order to desegregate schools in Louisville to "remedy to inequalities between poor, predominantly black schools and the mostly white and wealthy schools in Jefferson County," JCPS continues to battle inequity within schools (Clark, 2015). Students may not necessarily attend schools in their neighborhood; however, much of the performance of school reflects that in which the neighborhood the school is located. While it may not seem like "traditional" busing, JCPS' method includes assigning students to schools based not only on race, but also their socioeconomic status, and adult educational attainment. While the method JCPS uses works for them, as students mentioned in the pre-campaign focus groups, they experience problems that make their learning environment complex. Regardless of school, their residing neighborhood has a major impact on not only their norms of violence, but participation in violent behavior as well. The focus groups also shed light on the actual impact of busing from the perspective of the students. Even though the policy was created to promote diverse schools, students are still segregated 
within the school, and see an erasure of their culture within the curriculum and school space. This frustration is that West Louisville students report having pride in their ethnic group, it may be expected that they desire this to be reflected within all of their spaces, especially school.

Though for the purpose of this study, responses from the focus groups that focused on participants' social identity and norms and attitudes toward violence were used, it revealed an additional factor to the norms of violence and why they think people are violent: racism. Looking from the systemic level, many of the conditions created in West Louisville such as high poverty rates, lack of jobs, food deserts, and schools that lack proper educational resources can be traced back to the actual creation of the neighborhoods through policies, specifically Louisville's Residential Security Maps, redlining, and the local housing ordinance. Though the ordinance was overturned, generations of families had established their foundation in the community, and the impact of the creation and separation of residents by race are still impacting the city today. It is important to address race and racism when moving forward to creating solutions that will help reduce youth violence. The root of the problem does not solely fall on the people. Everyone needs to take responsibility, but it would be premature to give the burden of youth violence to youth, when they have little power in decision-making and the conditions in which they live.

\section{Limitations}

Threats to internal and external validity were reduced by using valid and reliable instruments from samples similar to the students who were recruited for 
the proposed study. Response bias from students is a limitation of this study. Sometimes participants are not honest in their survey responses or respond how they think they should respond because of "consequences," or how they will be perceived for participating in certain behaviors. The survey also asks about some "unfavorable" behaviors. Students with prosocial norms are more likely to attend school, complete the survey, and return surveys to the school. Therefore, it is more likely that students in the sample are exposed to protective factors. A low response rate is also a limitation of the data, a higher response rate could provide a stronger sense of the norms as well as exposure and participation in violent behaviors.

\section{Conclusion}

Youth have a unique perspective on what is going on in their community and provide context and a bridge between quantitative data and how they are interpreted and put into practice to change things for their future. While violence is a large issue within the community, they see the violence as a cycle, and the behavior as a reaction to the conditions in which West Louisville residents live. In the context of youth violence, the youth mention not being able to access certain resources, which within the literature, positive youth development programs, and opportunities to grow are protective factors against youth violence. As public health professionals, we need to in conjunction with addressing youth violence from a behavioral perspective need to push towards changing the systems and structures such as economics, justice, education, health, food, and political to change the conditions in which the youth live and use violence as a means to 
survive. The systemic inequalities that produce schools that lack proper educational resources, lack of opportunities for jobs, recreational activities, or enough healthy food options for the area contribute to the high rates of violence. Public health has taken a behavioral approach to youth violence for almost 30 years with an increase as years have progressed. There is a need to shift our focus from the behavior of the people at the moment and focus on the environment in which the people live. If we examine the social environment and address issues at the macro-level in the form of a policy and procedure reform, we then shift our focus to changing the norm in which people have to survive and subsequently a change in behaviors. Then we will start to see a in decrease youth violence as well as other health outcomes and move towards creating communities where the youth can continue traditions and help those around them.

It is equally important that in the process of changing the social conditions for youth, youth are included in the decision-making. An equitable process requires the addition of youth from a variety of backgrounds but those who live directly in the neighborhood, affected by youth violence, and those engaged in programs that serve as protective factors. Equity looks like youth who have different identities and experiences participating alongside those in positions of power to create change. Youth may not have much political power; however, their perspective and input provide a view that the adults in their life may not be able to understand. They can also rally other youth in the process of changing the environment and continuing the fight as they grow older. They understand 
what is realistic and how certain things will impact them immediately. This is important to creating change for their future and the future of the youth to come. 


\section{CHAPTER VII}

\section{DISCUSSION}

The purpose of this study was to examine how the field of public health addresses systemic racism, and further, how public health's approach to systemic racism informs youth violence prevention. The study further examined how systemic racism impacts West Louisville youth's participation in violent behaviors. Expanding on Krieger's (2003) ideal of recognizing systemic racism as a determinant of population health, this study recognized systemic racism as a determinant of youth violence and utilized history to contextualize the environment in which violence is pervasive in West Louisville. It sought to challenge the typical approach of examining an issue through the typically root causes of the social determinants of health in neighborhoods such: as lack of educational opportunities, lack of jobs, poverty, and the risk and protective factors of youth violence. While disparities between racial groups within these determinants are consistently pervasive, disparities are often discussed in terms of behavioral factors rather than the structural determinants that create the environment for which these disparities are persistent in certain racial groups.

With there being little to no discussion on the impact of systemic racism on health disparities and subsequently, youth violence within the literature, it was first important to understand the concepts of race and racism and how that impacts research and practice. Drawing upon traditional racial-realism founders 
of critical race theory and institutional racism research of critical researchers such as Ture and Hamilton (1967), Joe Feagin (2012; 2013), and Eduardo Bonilla Silva (2010; 2017), as well as taking a Critical Race Theory approach, it was important to understand these concepts before approaching the topic. Additionally, it was important to understand my racial and cultural positionality first within the field of public health and then my approach to this research topic. Utilizing Milner's (2007) framework, I first researched myself, then self in relation to others, and lastly, a shift from self to system. In order for this study to truly shift from self (behavior) to system, it was important to understand how historical policies and practices created the social environment in which we live and practice and specifically for this study, the social environment in Louisville. Examining the external powers that contribute to Louisville youth participating in violent behaviors was important since youth have little to no control over the conditions in which they are born. Often times, the narrative of youth violence surrounds behaviors and is framed around youth fulfilling certain stereotypes and images that play into how many minorities are seen within mainstream culture. This is not seen only within youth violence, but many health "disparities" within the U.S.

While racism is widely recognized as a problem within how Blacks are treated within this country, research within the field of public health is white racially framed (Feagin \& Bennefield, 2014), giving us language of racial disparities and that certain diseases are apparent in Black communities due to their behaviors. Utilizing a Critical Race Theory (CRT) approach during the 
conceptualization, execution, analysis, and summation, helped to examine the relationship among race, racism, and power within how research is conducted with the field of public health (Delgado \& Stefancic, 2001). Race being a social construct, should provide the way in which practitioners discuss disparities, from the context of the social environment. As public health continues to operate within this frame, it became challenging to counter the narrative, especially in writing, to ensure that the experiences of the marginalized community of interest were centered. Being able to incorporate theories and frameworks from the fields of Sociology and Education, provided the foundation for shifting from self to system and "taking into consideration historic, political, social, economic, racial, and cultural realities" (Milner, 2007, p. 397) of why youth violence is pervasive.

Generally, the field of Public Health does not explicitly link many health disparities or root causes of health issues to racism, they are linked to behaviors. Racism being a newly recognized social determinant of health (Brondolo, Gallo, \& Myers, 2009; Brondolo, Ver Halen, Pencille, Beatty, \& Contrada, 2009; Dressler, Oths, \& Gravlee, 2005; Ford \& Airhihenbuwa, 2010a, 2010b; Gee \& Ford, 2011; Jee-Lyn García \& Sharif, 2015; Jones, 2000, 2001, 2002; Krieger, 2003; Marmot et al., 2008; McKenzie, 2003; Nuru-Jeter et al., 2009; Paradies et al., 2013; David R Williams, 1999), existing literature supports this gap. There are allusions to something greater that impacts the health of marginalized groups; however, there is a hesitancy to call out racism. The socioecological model provides public health professionals with an opportunity to hypothesize how multiple levels influence health of an individual and are concerned with improving 
population health. However, there is an inequity in how this operates at the societal and policy level. Many issues are contextualized from the individual level perspective; therefore, there is an overwhelming focus of both theory and intervention on psychosocial factors and health behavior. This is even true for the racism work that has been conducted within the field. Much focus is focused on perceived racism and discrimination on the individual level (Brondolo, Rieppi, Kelly, \& Gerin, 2003; Calvin et al., 2003; Krieger, 1999, 2003; Krieger, Rowley, Herman, \& Avery, 1993; Paradies, 2006; Williams, Neighbors, \& Jackson, 2003; Williams \& Williams-Morris, 2000). And yet disparities persist, and in many cases widen. If we know conceptually that macro-level factors have the greatest influence on health, our theories and practice should reflect that if we truly want to alleviate inequity. Looking at the outset of public health and John Snow identifying the Broad Street pump being the problem (Schneider, 2016), he addressed an environmental issue, less a behavior of the people. The people's behaviors were in reaction to the social environment. Once the social environment was changed, there was a decrease in cholera. As violence has been a public health issue since the 1980 s, there is a need to revisit the behavioral approach only, in reducing youth violence.

The systematic literature review provides a baseline assessment of public health's current standing on the topics of systemic (structural and institutional) racism. Numerous articles and studies examining the impact of individual-level racism in the forms of discrimination and bias were present. Additionally, behavioral implications to the reactions of individual-level racism are well- 
documented throughout the literature. As the field is recently recognizing racism as a social determinant, it is accurate to assume that the findings from the systematic literature review reveal the lack of discussion within the field of public health on the acknowledgment of the impact of racism within systems and structures and its effect on health outcomes. As public health practitioners, there is a responsibility to advocate for the entire population. As an advocate with an understanding of policy and practices, it is important to bring the scientific evidence to the impact of systems and structures to improving the health of the population. Not just one part of the population, but ensuring that we are advocating for the minoritized populations, which fall deeper into the gaps of many health outcomes. There is a need in the field to shift the discussion and research from behaviors only to examining the social environment. Taking a macro-level approach, where policies and systems are racially equitable are necessary for a drastic reduction of health and racial disparities. An acknowledgement of how systemic racism has and continues to impact health is equally important in the shift, and needs to be incorporated in the understanding of different racial groups. Incorporating the contextualization of important historical policies and procedures will help to understand the conditions in which we all live in the U.S., but more specifically, for the use of working within communities. It is important to understand the impact historical policies and practices have had on communities of interest when working to improve the individual as well as population health. 
With residential and racial segregation being a major theme within the systematic literature review, as well as the city of Louisville's acknowledgment of its impact, this was an opportune time to review its impact on West Louisville youth's participation in violent behaviors. Understanding not only the history of how Louisville and subsequently, West Louisville were formed, helps to understand the social environment for youth in the city. Contextualizing the issue from the perspective of historical policies and practices shifts the view from the typical root causes, and provides a view of why there is a high concentration of people living in one area that face many of the same disparities. While, there are multiple programs within the community that are seeking to reduce youth violence, and the city has numerous efforts to complement those of community organizations. The homicide rates continue to increase. Instead of approaching youth violence from the lens of youth behavior, it was important to dig deeper to understand why youth violence is more pervasive in some neighborhoods compared to others. As the typically root causes of violence are always the cause for concern, it is evident that it is about more than just poverty rates, median household income, lack of educational achievement and opportunities, as well as lack of economic development, especially with the findings in Chapter V.

In Chapter V, the impact of the Home Owners Loan Corporation (HOLC) grading system, which was the bases for redlining discriminatory practices within the city and neighborhood poverty rates in relation to youth participating in violent behaviors were examined. Utilizing Hierarchical Linear Modeling to determine if 
there is an institutional effect on the nested behavioral data to account for both levels, this study examined the variance within and between neighborhoods. As the sample size used were not large enough to yield an accurate representation of the effect of neighborhood on the participation in violent behaviors, there are implications that other neighborhood characteristics may be able to explain those differences with a larger sample size. Characteristics such as neighborhood crime rates, the number of vacant and abandoned properties, and other objective neighborhood characteristics should further be explored to determine what neighborhood characteristic determines a youths participation in violent behaviors. Additionally, there are weak relationships between institutional factors and individual factors because many of the institutional factors produce group outcomes. Racist policies and practices are intertwined into a number of systems, making it difficult to measure the impact of one characteristic without considering numerous factors and without adding subjectivity to the equation.

While there was a need for a larger sample size within the Hierarchal Linear Models, the YVPRC 2017 School Survey revealed that students who reside in West Louisville have higher exposure to violence and friends who promote deviant behaviors. There is a difference between students in neighborhoods, but where that difference comes from needs further exploration beyond descriptive statistically analysis. The pre-campaign focus group participants discussed that they see violence and that violence is necessary to survive. Connecting the root causes to high rates of violence, many of the people living in the neighborhood use violence as a way to not only survive through the 
norms of violence, but to survive as a reaction to not having access to similar opportunities as those in other Louisville Metro areas. Socially disorganized neighborhoods tend to see higher rates of violence. As a socially disorganized neighborhood, West Louisville residents have little to no other options than to do what they need to survive. With evidence that the neighborhoods need more resources and not just the dumping of resources, but resources with the intentions of providing residents with the tools to sustain and live past the provision of services is necessary for an overall rebirth of the area.

Further, it was evident throughout the pre-campaign focus groups that racism is not only acknowledged by youth of West Louisville, but they experience it in a variety of spaces. Often times, youth's opinions or views are not necessarily taken into account, nor do adults think they know what is going on. The pre-campaign focus group attendees not only recognized racism on the individual level, but also were able to connect it to the systemic level and how it impacts their neighborhoods. As the youth were able to link the city not caring about them and where they live to provide enough resources or just fun activities for them to do, they feel that they have to channel their energy into other things. And just live to survive, by any means necessary. They question why they have to go to other parts of town for certain things, and can tell when youth from other parts of the city judge them because of where they are from. The youth are impacted by the bussing system within the city and describe how the policy meant to diversify the school, has them segregated within the school. As the survey revealed that many West Louisville students have pride in their ethnicity, it 
showed by their expression of wanting more accurate Black history incorporated into their curriculum, instead of what they considered being "lied too" about historical events.

Together, the findings show that while racism is not explicitly stated within the field of public health and that it is not addressed in the approach to preventing youth violence. Much of the findings from the systematic literature review provide a bases for understanding how the field has acknowledged something greater, but not pushed towards uncovering its impact on health outcomes. The acknowledgement of the city of Louisville of the impact of racism on the residential and racial segregation present, connects to the finding of the impact of racial and residential segregation on a variety of health outcomes. It is movement in the direction of connecting historical policies and procedures to the social environment in which many disparities are prevalent in neighborhoods that look similar in many different states. Now with the acknowledgement comes the task of pinpointing characteristics that actually provide evidence of the neighborhood impact on participation in violent behaviors. While neighborhood poverty rates and Home Owners Loan Corporation grades were not found to have an impact in this study, there is a need to uncover other characteristics that may contribute to the differences between neighborhoods. There are differences in the cultural identity, perceived and actual norms, exposure, and participation in violent behavior between Louisville youth. As the specific neighborhood characteristics that account for these differences is unknown, at the individual level, students identity the difference based on what there community has (or the 
lack there of), how people outside of their neighborhood characterize them, and racism on the individual and systemic level. While West Louisville youth are ready and willing to make a change in their community to pass down the traditions and culture to future generations, it will take those with power to listen to what burdens them to make a change.

Youth are born into the conditions in which they have to respond. Many respond with violence, because that is what they feel they have to respond. They are hopeless and hopeful, but understand that they have to contribute and work towards making their neighborhood and conditions better. It should not solely be on them, because that it is a heavy burden to bear. It is one-sided to say that the behavior of all youth who reside in West Louisville is the same, therefore the approach to addressing violence, cannot be the same. A macro-level approach to preventing youth violence takes an equitable approach. Equity in the decision makers, and not decision makers to appeal to a look with borrowed power. Actually including youth and those who live in West Louisville to work alongside those in positions of power to create system and policy level changes that will truly change the social environment. There is a need for drastic policy and practice reform to create solutions for sustainable economic investment, improved educational opportunities, access to health and human services, as well as transportation. Policy makers should review the impact of the ordinances and policies that were overturned and how to rectify the outcome, instead of moving on without a proper solution. A neighborhood cannot rebuild its self 
without the proper planning and execution of rehabilitation to get to where there is no difference between the East and West.

This dissertation contributes to the field evidence of the current stance Public Health literature that takes steps towards addressing and acknowledging systemic/structural/institutional racism. It provides to the growing ideal of racism being a social determinant of health and how the mere lack of acknowledgement continues to yield the same results. It provides a look at how history of the neighborhoods and the inequity in the distribution of resources created many of the disparities and concentrations of individuals with high rates of poverty and unemployment, and low median income. Instead of framing the issue of youth violence in terms of the lack within the community, it looks at what caused the lack and attempted to see if those characteristics contribute to youth participating in violent behaviors. It will take a macro-level approach through the eradication of historically racist policies and procedures to address the issue of youth violence. It further calls for Public Health professionals to lead the way in addressing the impact of race and racism in improving population health and to take an intersectional look of how new policies and procedures will impact multiple identities. Further, they should also work towards equity in not only the policies, but making sure that the solutions are equitable in decision makers, decisions, and intentions of sustainability for generations to come. Public Health professionals can start by centering the margins in their research and practice and acknowledge the part history has played into the creation and execution of the social environment. 


\section{REFERENCES}

Abroms, L. \& Maibach, E. (2008). The effectiveness of mass communication to change public behavior. Annual Reviews of Public Health, 29: 219-234.

Acevedo-Garcia, D., \& Lochner, K. A. (2003). Residential segregation and health. Neighborhoods and health, 265-287.

Acevedo-Garcia, D., Lochner, K. A., Osypuk, T. L., \& Subramanian, S. V. (2003). Future directions in residential segregation and health research: a multilevel approach. American Journal of Public Health, 93(2), 215-221.

Aisenberg, E., \& Herrenkohl, T. (2008). Community violence in context: Risk and resilience in children and families. J Interpers Violence, 23(3), 296-315.

Alejandro-Wright, M. A. (1998). I'm Chocolate, You're Vanilla: Raising Healthy Black and Biracial Children in a Race-Conscious World. Jossey-Bass Inc., Publishers, 350 Sansome Street, San Francisco, CA 94104.

Anderson, E. (1999). Code of the Street: New York: Norton.

Anderson, C. A., Shibuya, A., Ihori, N., Swing, E. L., Bushman, B. J., Sakamoto, A., ... Saleem, M. (2010). Violent video game effects on aggression, empathy, and prosocial behavior in eastern and western countries: a meta-analytic review. Psychological bulletin, 136(2), 151.

Ansley, F. L. (1991). Race and the Core Curriculum in Legal Education. California Law Review, 1511-1597.

Arbona, C., Jackson, R. H., McCoy, A., \& Blakely, C. (1999). Ethnic identity predictor of attitudes of adolescents toward fighting. The Journal of Early Adolescence, 19(3), 323-340.

Arias E. Changes in life expectancy by race and Hispanic origin in the United States, 2013-2014. NCHS data brief, no 244. Hyattsville, MD: National Center for Health Statistics. 2016.

Aubespin, M., Clay, K., \& Hudson, J. B. (2011). Two Centuries of Black Louisville: A Photographic History. Louisville, KY: Butler Books.

Baeza, M. L. (1985). Telecommunications Reregulation and Deregulation: The Impact on IOpportunities for Minorities. Blackletter J., 2, 7.

Bartholet, E. (1991). Where do black children belong? The politics of race matching in adoption. University of Pennsylvania Law Review, 139(5), 1163-1256. 
Belgrave, F. Z., Cherry, V. R., Cunningham, D., Walwyn, S., Letdaka-Rennert, K., \& Phillips, F. (1994). The influence of Africentric values, self-esteem, and Black identity on drug attitudes among African American fifth graders: A preliminary study. Journal of Black Psychology, 20(2), 143156.

Bell, D. (1989). And we are not saved: The elusive quest for racial justice: Basic Books.

Berkowitz, A. D. (2004). An overview of the social norms approach. Changing the culture of college drinking: A socially situated health communication campaign, 193-214.

Berkowitz, A. D., \& Perkins, H. W. (1986). Problem drinking among college students: A review of recent research. Journal of American College Health, 35(1), 21-28.

Bhopal, R., \& Donaldson, L. (1998). White, European, Western, Caucasian, or what? Inappropriate labeling in research on race, ethnicity, and health. American Journal of Public Health, 88(9), 1303-1307.

Bliss, D., Mishra, M., Ayers, J., \& Lupi, M. V. (2016). Cross-Sectoral Collaboration: The State Health Official's Role in Elevating and Promoting Health Equity in All Policies in Minnesota. J Public Health Manag Pract, 22 Suppl 1, S87-93. doi:10.1097/phh.0000000000000330

Blumenbach, J. F., \& Bendyshe, T. (1865). The Anthropological Treatises of Johann Friedrich Blumenbach: Anthropological Society.

Bonilla-Silva, E. (2010). Racism without racists: Color-blind racism and racial inequality in contemporary America: Rowman \& Littlefield.

Bonilla-Silva, E. (2017). Racism without racists: Color-blind racism and the persistence of racial inequality in America: Rowman \& Littlefield.

Borsari, B., \& Carey, K. B. (2001). Peer influences on college drinking: A review of the research. Journal of substance abuse, 13(4), 391-424.

Bowleg, L. (2012). The Problem With the Phrase Women and Minorities: Intersectionality - an Important Theoretical Framework for Public Health. American Journal of Public Health, 102(7), 1267-1273. doi:10.2105/AJPH.2012.300750

Bowling, C. (2017, February 14). Louisville debuts map that examines lasting impacts of redlining. Retrieved June 27, 2017, from https://insiderlouisville.com/metro/louisville-debuts-map-that-examineslasting-impacts-of-redlining/ 
Bowsher, C. A. (1990). Immigration Reform: Employer Sanctions and the Question of Discrimination: United States General Accounting Office.

Braveman, P. A., Kumanyika, S., Fielding, J., LaVeist, T., Borrell, L. N., Manderscheid, R., \& Troutman, A. (2011). Health disparities and health equity: the issue is justice. American Journal of Public Health, 101(S1), S149-S155.

Brewer, M. B., \& Gardner, W. (1996). Who is this" We"? Levels of collective identity and self representations. Journal of personality and social psychology, 71(1), 83.

Brondolo, E., Gallo, L. C., \& Myers, H. F. (2009). Race, racism and health: disparities, mechanisms, and interventions. Journal of Behavioral Medicine, 32(1), 1.

Brondolo, E., Rieppi, R., Kelly, K. P., \& Gerin, W. (2003). Perceived racism and blood pressure: a review of the literature and conceptual and methodological critique. Annals of Behavioral Medicine, 25(1), 55-65.

Brondolo, E., Ver Halen, N. B., Pencille, M., Beatty, D., \& Contrada, R. J. (2009). Coping with racism: A selective review of the literature and a theoretical and methodological critique. Journal of Behavioral Medicine, 32(1), 64-88.

Brook, J. S., Balka, E. B., Brook, D. W., Win, P. T., \& Gursen, M. D. (1998). Drug use among African Americans: Ethnic identity as a protective factor. Psychological reports, 83(3_suppl), 1427-1446.

Brown, D. L., \& Tylka, T. L. (2010). Racial discrimination and resilience in African American young adults: Examining racial socialization as a moderator. Journal of Black Psychology, 0095798410390689.

Browne, T., Pitner, R., \& Freedman, D. A. (2013). When identifying health disparities as a problem is a problem: pedagogical strategies for examining racialized contexts. J Prev Interv Community, 41(4), 220-230. doi:10.1080/10852352.2013.818481

Bruce, M. A., Roscigno, V. J., \& McCall, P. L. (1998). Structure, context, and agency in the reproduction of black-on-black violence. Theoretical criminology, 2(1), 29-55.

Buckner-Brown, J., Tucker, P., Rivera, M., Cosgrove, S., Coleman, J. L., Penson, A., \& Bang, D. (2011). Racial and ethnic approaches to community health: reducing health disparities by addressing social determinants of health.

Fam Community Health, 34 Suppl 1, S12-22.

doi:10.1097/FCH.0b013e318202a720 
Caldwell, C. H., Kohn-Wood, L. P., Schmeelk-Cone, K. H., Chavous, T. M., \& Zimmerman, M. A. (2004). Racial discrimination and racial identity as risk or protective factors for violent behaviors in African American young adults. American journal of community psychology, 33(1-2), 91-105.

Caldwell, C. H., Zimmerman, M. A., Bernat, D. H., Sellers, R. M., \& Notaro, P. C. (2002). Racial identity, maternal support, and psychological distress among African American adolescents. Child development, 73(4), 13221336.

Callis, A. S. (2014). Bisexual, pansexual, queer: Non-binary identities and the sexual borderlands. Sexualities, 17(1-2), 63-80.

Calvin, R., Winters, K., Wyatt, S. B., Williams, D. R., Henderson, F. C., \& Walker, E. R. (2003). Racism and cardiovascular disease in African Americans. The American journal of the medical sciences, 325(6), 315-331.

Came, H., \& Griffith, D. (2017). Tackling racism as a "wicked" public health problem: Enabling allies in anti-racism praxis. Soc Sci Med. doi:10.1016/j.socscimed.2017.03.028

Carr, P. J., Napolitano, L., \& Keating, J. (2007). We never call the cops and here is why: A qualitative examination of legal cynicism in three Philadelphia neighborhoods. Criminology, 45(2), 445-480.

Casas, J. M. (1984). Policy, training, and research in counseling psychology: The racial/ethnic minority perspective. Handbook of counseling psychology, 785-831.

Centers for Disease Control and Prevention. (2016). 10 Leading Causes of Death by Age Group, United States 2014. Retrieved February 1, 2017, from https://www.cdc.gov/injury/images/lccharts/leading_causes_of_death_age_group_2014_1050w760h.gif

Centers for Disease Control and Prevention, National Center for Injury Prevention and Control. Webbased Injury Statistics Query and Reporting System (WISQARS) [online]. (2014). [cited 2017 Jan 16] Available from www.cdc.gov/injury.

Centers for Disease Control and Prevention, National Center for Injury Prevention and Control. (2009). Web-based Injury Statistics Query and Reporting System (WISQARS) [Retrieved from http://www.cdc.gov/ncipc/wisqars.

Centers for Disease Control and Prevention, National Center for Health Statistics, Division of Violence Prevention. (n.d.). Leading Causes of death, 1900-1998. [Press release]. Retrieved from http://www.cdc.gov/nchs/data/dvs/lead1900_98.pdf 
Centers for Disease Control and Prevention, National Center for Injury Prevention and Control. Webbased Injury Statistics Query and Reporting System (WISQARS) [online]. (2014). [cited 2016 Nov 8] Available from www.cdc.gov/injury.

Centers for Disease Control and Prevention. (2016, August 30). Frequently Asked Questions. Retrieved February 01, 2017, from https://www.cdc.gov/violenceprevention/nvdrs/faqs.html

Centers for Disease Control and Prevention, Sexual Violence: Risk and Protective Factors. Available at: http://www.cdc.gov/ViolencePrevention/sexualviolence/riskprotectivefactor s.html Accessed January 13, 2017.

Centers for Disease Control and Prevention. (2015) Youth Risk Behavior Survey. Available at: www.cdc.gov/yrbs. Accessed on 20 March 2016.

Centers for Disease Control and Prevention (CDC) (2012). Youth Violence: Facts at a Glance. Retrieved from http://www.cdc.gov/violenceprevention/pdf/yvdatasheet-a.pdf

Centers for Disease Control and Prevention (CDC) (2013). Youth Violence: State Statistics. Retrieved from http://www.cdc.gov/violenceprevention/youthviolence/stats ata glance/ky.html

Centers for Disease Control and Prevention. (2016, May 11). Youth Violence: Risk and Protective Factors. Retrieved January 25, 2017, from https://www.cdc.gov/violenceprevention/youthviolence/riskprotectivefactor s.html

CensusScope. (n.d.). CensusScope -- Segregation: Dissimilarity Indices. Retrieved January 30, 2017, from http://www.censusscope.org/us/m4520/chart_dissimilarity.html

Clark, K. (2015, September 04). JCPS battling inequity 40 years after busing.

Clark, V. R. (2001). The perilous effects of racism on blacks. Ethn Dis, 11(4), 769-772.Retrieved June 26, 2017, from http://www.courierjournal.com/story/news/education/2015/09/03/jcps-battling-inequity-40years-after-busing/32432257/

Connolly, J., Pepler, D., Craig, W., \& Taradash, A. (2000). Dating experiences of bullies in early adolescence. Child Maltreat, 5(4), 299-310.

Corp, I. B. M. (2013). IBM SPSS statistics for windows, version 22.0. Armonk, NY: IBM Corp. 
Creswell, J. W. (2013). Research design: Qualitative, quantitative, and mixed methods approaches. Sage publications.

Cross, W. E., Parham, T. A., \& Helms, J. E. (1998). Nigrescence revisited: Theory and research. African American identity development, 3-71.

Cummings, J. R., Wen, H., \& Ko, M. (2016). Decline In Public Substance Use Disorder Treatment Centers Most Serious In Counties With High Shares Of Black Residents. Health Aff (Millwood), 35(6), 1036-1044. doi:10.1377/hlthaff.2015.1630

Dahlberg, L. L., \& Mercy, J. A. (2009). History of violence as a public health problem. Virtual Mentor, 11(2), 167.

Dahlberg, L. L., Toal, S. B., Swahn, M. H., \& Behrens, C. B. (2005). Measuring violence-related attitudes, behaviors, and influences among youths: $A$ compendium of assessment tools. Centers for Disease Control and Prevention.

David-Ferdon, C., \& Simon, T. R. (2014). Preventing Youth Violence: Opportunities for Action. Centers for Disease Control and Prevention.

Demo, D. H., \& Hughes, M. (1990). Socialization and racial identity among Black Americans. Social Psychology Quarterly, 364-374.

DeNavas-Walt, C., \& Proctor, B. D. (2015). Income and Poverty in the United States: 2014, Current Population Reports P60-252: Washington, DC: US Census Bureau.

Department of Health and Human Services (2001). Youth violence: a report of the Surgeon General. Retrieved from www.surgeongeneral.gov/library/youthviolence/toc.html

Dressler, W. W., Oths, K. S., \& Gravlee, C. C. (2005). Race and ethnicity in public health research: models to explain health disparities. Annu. Rev. Anthropol., 34, 231-252.

Eisenmenger, S. (2016, December 2). Louisville's Deadliest Year: Shooting death in Algonquin neighborhood brings city's homicide count to 111. Retrieved February 01, 2017, from http://www.wave3.com/story/33857184/1-shot-in-algonquin-neighborhood

Elliott, D. S., \& Ageton, S. S. (1980). Reconciling race and class differences in self-reported and official estimates of delinquency. American Sociological Review, 95-110. 
Elliott, D. S., Huizinga, D., \& Menard, S. (2012). Multiple problem youth: Delinquency, substance use, and mental health problems: Springer Science \& Business Media.

Espelage, D. L., Basile, K. C., \& Hamburger, M. E. (2012). Bullying perpetration and subsequent sexual violence perpetration among middle school students. Journal of Adolescent Health, 50(1), 60-65.

Exworthy, M., \& Washington, A. E. (2006). Organizational strategies to tackle health-care disparities in the USA. Health Serv Manage Res, 19(1), 44-51. doi:10.1258/095148406775322043

Fabio, A., Li, W., Strotmeyer, S., \& Branas, C. C. (2004). Racial segregation and county level intentional injury in Pennsylvania: analysis of hospital discharge data for 1997-1999. Journal of Epidemiology \& Community Health, 58(4), 346-351.

Fabiano, P. M., Perkins, H. W., Berkowitz, A., Linkenbach, J., \& Stark, C. (2003). Engaging men as social justice allies in ending violence against women: Evidence for a social norms approach. Journal of American College Health, 52(3), 105-112.

Fajnzlber, P., Lederman, D., \& Loayza, N. (2002). Inequality and violent crime. JL \& Econ., 45, 1.

Farrington, D. P. (1998). Predictors, causes, and correlates of male youth violence. Crime andjustice, 421-475.

Feagin, J. (2013). Systemic racism: A theory of oppression: Routledge.

Feagin, J. R. (2013). The white racial frame: Centuries of racial framing and counter-framing: Routledge.

Feagin, J. R. (2014). Racist America: Roots, current realities, and future reparations: Routledge.

Feagin, J., \& Bennefield, Z. (2014). Systemic racism and US health care. Social science \& medicine, 103, 7-14.

Felson, R. B., Liska, A. E., South, S. J., \& McNulty, T. L. (1994). The subculture of violence and delinquency: Individual vs. school context effects. Soc. F., 73, 155.

Flanagan, C. A. (2004). Volunteerism, leadership, political socialization, and civic engagement. 
Foshee, V., Bauman, K., Arriaga, X., Helms, R., Koch, G. \& Linder, G.F. (1998). An evaluation of Safe Dates, an adolescent dating violence prevention program. American Journal of Public Health, 88(1): 45-50.

Ford, C. L., \& Airhihenbuwa, C. O. (2010a). Critical Race Theory, race equity, and public health: toward antiracism praxis. Am J Public Health, $100 \mathrm{Suppl}$ 1, S30-35. doi:10.2105/ajph.2009.171058

Ford, C. L., \& Airhihenbuwa, C. O. (2010b). The public health critical race methodology: praxis for antiracism research. Social science \& medicine, 71(8), 1390-1398.

Fosl, C., Hinko, C., Cissell, N., Duke, A., Stauffer, C., Poe, J., . . K'Meyer, T. (2013). Making Louisville Home For Us All: A 20 Year Action Plan for Fair Housing. Retrieved from Louisville, KY: https://louisvilleky.gov/sites/default/files/human relations/reports publicati ons/louisville metro 20-year action plan.pdf

Fowler, F. J. (2009). Survey research methods (4th ed.). Thousand Oaks, CA: Sage.

Franzini, L., Caughy, M., Spears, W., \& Eugenia Fernandez Esquer, M. (2005). Neighborhood economic conditions, social processes, and self-rated health in low-income neighborhoods in Texas: A multilevel latent variables model. Social science \& medicine, 61(6), 1135-1150. doi:http://doi.org/10.1016/j.socscimed.2005.02.010

Frye, V., Egan, J. E., Tieu, H. V., Cerdá, M., Ompad, D., \& Koblin, B. A. (2014). "I didn't think I could get out of the fucking park." Gay men's retrospective accounts of neighborhood space, emerging sexuality and migrations. Social Science \& Medicine, 104, 6-14. doi:http://doi.org/10.1016/j.socscimed.2013.12.002

Fullilove, M. T. (1998). Comment: abandoning" race" as a variable in public health research--an idea whose time has come. American Journal of Public Health, 88(9), 1297-1298.

Gee, G. C. (2002). A multilevel analysis of the relationship between institutional and individual racial discrimination and health status. American Journal of Public Health, 92(4), 615-623.

Gee, G. C., \& Ford, C. L. (2011). STRUCTURAL RACISM AND HEALTH INEQUITIES: Old Issues, New Directions. Du Bois Review: Social Science Research on Race, 8(1), 115-132. doi:10.1017/S1742058X1100013. 
Gee, G. C., \& Ford, C. L. (2011). STRUCTURAL RACISM AND HEALTH INEQUITIES: Old Issues, New Directions. Du Bois Review: Social Science Research on Race, 8(1), 115-132. doi:10.1017/S1742058X11000130

Gee, G. C., \& Ford, C. L. (2011). STRUCTURAL RACISM AND HEALTH INEQUITIES: Old Issues, New Directions. Du Bois Review: Social Science Research on Race, 8(1), 115-132. doi:10.1017/S1742058X11000130

Gehlert, S., Sohmer, D., Sacks, T., Mininger, C., McClintock, M., \& Olopade, O. (2008). Targeting health disparities: A model linking upstream determinants to downstream interventions. Health Affairs, 27(2), 339-349.

Ginwright, S. (2003). Youth organizing: Expanding possibilities for youth development. Occasional Papers Series on Youth Organizing, 1.

Goldstein, J., and Cialdini, R.. "Using social norms as a lever of social influence." The science of social influence: Advances and future progress (2007): 167-192.

Gonzales, N. A., \& Cauce, A. M. (1995). Ethnic identity and multicultural competence: Dilemmas and challenges for minority youth.

Green, D. P., Strolovitch, D. Z., \& Wong, J. S. (1998). Defended neighborhoods, integration, and racially motivated Crime 1 . American Journal of Sociology, 104(2), 372-403.

Haines, M. P., Perkins, H. W., Rice, R. M., \& Barker, G. (2005). A guide to marketing social norms for health promotion in schools and communities. East Lansing MI: National Social Norms Resource Center.

Hammond, W. R., \& Yung, B. (1986). Psychology's role in the public healthresponse to assaultive violence among young African-American men. Health, 1990(1992).

Havens, B. E., Yonas, M. A., Mason, M. A., Eng, E., \& Farrar, V. D. (2011). Eliminating inequities in health care: understanding perceptions and participation in an antiracism initiative. Health Promot Pract, 12(6), 848857. doi:10.1177/1524839910370423

Helms, J. E. (1990). Black and white racial identity: Theory, research, and practice. Greenwood Press.

Herrenkohl, T. I., Maguin, E., Hill, K. G., Hawkins, J. D., Abbott, R. D., \& Catalano, R. F. (2000). Developmental risk factors for youth violence. Journal of Adolescent Health, 26(3), 176-186.

Hillier, A. E. (2003). Redlining and the home owners' loan corporation. Journal of Urban History, 29(4), 394-420. 
Hindelang, M. J., Hirschi, T., \& Weis, J. G. (1981). Measuring delinquency: Sage Publications Beverly Hills.

Holmes, A., \& Horvitz, P. (1994). Mortgage redlining: Race, risk, and demand. The Journal of Finance, 49(1), 81-99.

Hughes, D. (2003). Correlates of African American and Latino parents' messages to children about ethnicity and race: A comparative study of racial socialization. American journal of community psychology, 31(1-2), 15-33.

Hughes, L. A., \& Short, J. F. (2005). Disputes involving youth street gang members: Micro-social contexts. Criminology, 43(1), 43-76.

Iguchi, M., Bell, J., Ramchand, R., \& Fain, T. (2005). How criminal system racial disparities may translate into health disparities. $J$ Health Care Poor Underserved, 16(4), 48-56.

IBM Corp (2013). IBM SPSS statistics for windows, version 22.0. Armonk, NY: IBM Corp.Jefferson County Public Schools (n.d.) About. Retrieved July 26, 2016, from https://www.jefferson.kyschools.us/about

Jackson, J. S., Williams, D. R., \& Torres, M. (1997). Perceptions of discrimination: The stress process and physical and psychological health. Washington, DC: National Institute of Mental Health.

Jee-Lyn García, J., \& Sharif, M. Z. (2015). Black lives matter: a commentary on racism and public health. American Journal of Public Health, 105(8), e27e30.

Jefferson County Public Schools (n.d.) About. Retrieved July 26, 2016, from https://www.jefferson.kyschools.us/about

Jefferson County Public Schools. (n.d.). Data Books 2017-High School. Retrieved January 20, 2017, from https://www.jefferson.kyschools.us/node/1193

Jefferson County Public Schools. (n.d.). Coordinator Family Resource/Youth Service Center. Retrieved January 10, 2017, from https://www.jefferson.kyschools.us/department/human-resources/jobdescriptions/199

Jessor, R., Van Den Bos, J., Vanderryn, J., Costa, F. M., \& Turbin, M. S. (1995). Protective factors in adolescent problem behavior: Moderator effects and developmental change. Developmental Psychology, 31(6), 923.

Jones, C. P. (2000). Levels of racism: a theoretic framework and a gardener's tale. American Journal of Public Health, 90(8), 1212-1215. 
Jones, C. P. (2001). Invited commentary:"race," racism, and the practice of epidemiology. American Journal of Epidemiology, 154(4), 299-304.

Jones, C. P. (2002). Confronting institutionalized racism. Phylon (1960-), 7-22.

Kahne, J., \& Westheimer, J. (2003). Teaching democracy: What schools need to do. Phi Delta Kappan, 85(1), 34-66.

Kandel, D. B. (1985). On processes of peer influences in adolescent drug use: A developmental perspective. Advances in Alcohol \& Substance Abuse, 4(34), 139-162.

Kelly, S. (2010). The psychological consequences to adolescents of exposure to gang violence in the community: an integrated review of the literature. Journal of Child and Adolescent Psychiatric Nursing, 23(2), 61-73.

Kennedy, B. P., Kawachi, I., Prothrow-Stith, D., Lochner, K., \& Gupta, V. (1998). Social capital, income inequality, and firearm violent crime. Social science \& medicine, 47(1), 7-17.

Kennedy, D. (1990). A cultural pluralist case for affirmative action in legal academia. Duke Law Journal, 1990(4), 705-757.

Kennedy, R. L. (1988). McCleskey v. Kemp: Race, capital punishment, and the Supreme Court. Harvard Law Review, 101(7), 1388-1443.

Kentucky State Data Center(KSDC) (2014). Comparing Demographics of West Louisville Neighborhoods with those of Louisville Metro. Unpublished Report Prepared for Louisville Metro Government Promise Zone Initiative, compiled from American Community Survey 2010-2012 and U.S. Census estimates.

Kleber, J. E. (2001). The encyclopedia of Louisville: University Press of Kentucky.

Klonoff, E. A., \& Landrine, H. (1999). Acculturation and alcohol use among Blacks: The benefits of remaining culturally traditional. The Western Journal of Black Studies, 23(4), 211.

Kochanek, K. D., Murphy, S. L., Xu, J., \& Tejada-Vera, B. (2016). Deaths: final data for 2014. National vital statistics reports: from the Centers for Disease Control and Prevention, National Center for Health Statistics, National Vital Statistics System, 65(4), 1.

Krieger, N. (1999). Embodying inequality: a review of concepts, measures, and methods for studying health consequences of discrimination. International journal of health services, 29(2), 295-352. 
Krieger, N. (2003). Does racism harm health? Did child abuse exist before 1962? On explicit questions, critical science, and current controversies: an ecosocial perspective. American Journal of Public Health, 93(2), 194-199.

Krieger, N., Rowley, D. L., Herman, A. A., \& Avery, B. (1993). Racism, sexism, and social class: implications for studies of health, disease, and wellbeing. Am J Prev Med.

Krogman, W. M. (1945). The concept of race. The science of man in world crisis, 38-62.

Krug, E. G., Mercy, J. A., Dahlberg, L. L., \& Zwi, A. B. (2002). The world report on violence and health. The Lancet, 360(9339), 1083-1088.

Krug, E. G., Sharma, G. K., \& Lozano, R. (2000). The global burden of injuries. American Journal of Public Health, 90(4), 523.

Krug, E., Dahlberg, L., Mercy, J., Zwi, A., \& Lozano, R. (2002). Violence-a global public health approach. World report on violence and health: Geneva, Switz: World Health Organization.

Kruger, D. J., Carty, D. C., Turbeville, A. R., French-Turner, T. M., \& Brownlee, S. (2015). Undoing Racism Through Genesee County's REACH Infant Mortality Reduction Initiative. Prog Community Health Partnersh, 9(1), 5763. doi:10.1353/cpr.2015.0004

Kubrin, C. E., \& Weitzer, R. (2003). New directions in social disorganization theory. Journal of research in crime and delinquency, 40(4), 374-402.

Lang, W. W., \& Nakamura, L. I. (1993). A model of redlining. Journal of Urban Economics, 33(2), 223-234.

Laub, J. H., \& Lauritsen, J. L. (1998). The interdependence of school violence with neighborhood and family conditions. Violence in American schools: A new perspective, 127-155.

LaVeist, T. A., Sellers, R., \& Neighbors, H. W. (2001). Perceived racism and self and system blame attribution: consequences for longevity. Ethn Dis, 11(4), 711-721.

Lewis-Charp, H., Yu, H. C., \& Soukamneuth, S. (2006). Civic activist approaches for engagingyouth in social justice. Beyond resistance: Youth activism and community change, 21-35.

Liberati, A., Altman, D. G., Tetzlaff, J., Mulrow, C., Gøtzsche, P. C., Ioannidis, J. P., . . . Moher, D. (2009). The PRISMA statement for reporting systematic reviews and meta-analyses of studies that evaluate health care interventions: explanation and elaboration. PLoS Med, 6(7), e1000100. 
Lin-Fu, J. S. (1987). Special health concerns of ethnic minority women. Public Health Rep, 102(4 Suppl), 12-14.

Liu, S., Chen, J., \& Glymour, M. M. (2011). DECREASE TREND IN COMMONCAUSE ADOLESCENT MORTALITY RATES FOLLOWING SCHOOL DESEGREGATION LEGISLATION, US 1968-1988. Paper presented at the American Journal of Epidemiology.

Lipsey, M. W., \& Derzon, J. H. (1998). Predictors of violent or serious delinquency in adolescence and early adulthood: a synthesis of longitudinal research.

Logan, J. R., \& Messner, S. F. (1987). Racial residential segregation and suburban violent crime. Social Science Quarterly, 68(3), 510.

Lopez, I. F. H. (1994). The social construction of race: Some observations on illusion, fabrication, and choice. Harv CR-CLL Rev., 29, 1.

Lösel, F., \& Farrington, D. P. (2012). Direct protective and buffering protective factors in the development of youth violence. Am J Prev Med, 43(2), S8S23.

Louisville Metro Government (LMG): Office for Safe and Healthy Neighborhoods (OSHN) (2015). One Love Louisville: Louisville's Blueprint for Safe and Healthy Neighborhoods. Retrieved from https://louisvilleky.gov/sites/default/files/safe neighborhoods/1-3015 one love action plan.pdf

Major, B., Levin, S., Schmader, T., \& Sidanius, J. (1999). Implications of justice ideology, group identification, and ethnic group for perceptions of discrimination. Unpublished manuscript.

Marmot, M., Friel, S., Bell, R., Houweling, T. A., Taylor, S., \& Health, C. o. S. D. o. (2008). Closing the gap in a generation: health equity through action on the social determinants of health. The Lancet, 372(9650), 1661-1669.

Mays, V. M., Cochran, S. D., \& Barnes, N. W. (2007). Race, race-based discrimination, and health outcomes among African Americans. Annu. Rev. Psychol., 58, 201-225.

McCoach, D. B., \& Adelson, J. L. (2010). Dealing with dependence (Part I): Understanding the effects of clustered data. Gifted Child Quarterly, 54(2), 152-155.

McCoach, D. B., \& Black, A. C. (2008). Evaluation of model fit and adequacy. Multilevel modeling of educational data, 245-272. 
McKenzie, K. (2003). Racism and health. BMJ: British Medical Journal, 326(7380), 65.

McMahon, S. D., \& Watts, R. J. (2002). Ethnic identity in urban African American youth: Exploring links with self-worth, aggression, and other psychosocial variables. Journal of Community Psychology, 30(4), 411-431.

McLeroy, K. R., Bibeau, D., Steckler, A., \& Glanz, K. (1988). An ecological perspective on health promotion programs. Health Education \& Behavior, 15(4), 351-377.

Melynk, V., van Herpen, E., \& van Trijp, H. C. (2010). The Influence of Social Norms in Consumer Behavior: A Meta-Analysis. Advances in Consumer Research, 1-3.

Menefee, L. T. (1996). Are black Americans entitled to equal health care? a new research paradigm. Ethn Dis, 6(1-2), 56-68.

Mercy J., Butchart A., Farrington D., \& Cerdá M. (2002). Youth violence. In Krug E., Dahlberg L.L., Mercy J.A., Zwi A.B., \& Lozano R., (Eds.), World report on violence and health (pp.25-56). Geneva, Switzerland: World Health Organization.

Messner, S. F. (1988). Research on cultural and socioeconomic factors in criminal violence. Psychiatric Clinics of North America.

Miles, M. B., \& Huberman, A. M. (1994). Qualitative data analysis: A sourcebook. Beverly Hills: Sage Publications.

Milner IV, H. R. (2007). Race, culture, and researcher positionality: Working through dangers seen, unseen, and unforeseen. Educational researcher, 36(7), 388-400.

Morgan, R. (2003). Sisterhood is forever. The Women's Anthology for a New Millenium.

Morin, S., Sengupta, S., Cozen, M., Richards, T. A., Shrivera, M. D., Palacio, H., \& Kahn, J. (2002). Responding to racial and ethnic disparities in use of HIV drugs: analysis of state policies. Public Health Reports, 117, 263.

Nadel, H., Spellmann, M., Alvarez-Canino, T., Lausell- Bryant, L., Landsberg, G. The cycle of violence and victimization: a study of the school-based intervention of a multidisciplinary youth violence prevention program. American Journal of Preventive Medicine 1996;12(5 Supply):109-119.

National Center for Health Statistics. Health, United States, 2015: With Special Feature on Racial and Ethnic Health Disparities. Hyattsville, MD. 2016. 
National Center for Injury Prevention and Control. (2013). Understanding and preventing violence: Summary of research activities. Retrieved from: https://www.cdc.gov/violenceprevention/pdf/dvp-research-summary-a.pdf

Neblett, E. W., Smalls, C. P., Ford, K. R., Nguyên, H. X., \& Sellers, R. M. (2009). Racial socialization and racial identity: African American parents' messages about race as precursors to identity. Journal of Youth and Adolescence, 38(2), 189-203.

Nivette, A. E. (2011). Cross-national predictors of crime: A meta-analysis. Homicide Studies, 15(2), 103-131.

Noonan, A. S., Velasco-Mondragon, H. E., \& Wagner, F. A. (2016). Improving the health of African Americans in the USA: An overdue opportunity for social justice. Public Health Reviews, 37(1). doi:10.1186/s40985-016-0025-4

Nuru-Jeter, A., Dominguez, T. P., Hammond, W. P., Leu, J., Skaff, M., Egerter, S., . . Braveman, P. (2009). "It's the skin you're in": African-American women talk about their experiences of racism. An exploratory study to develop measures of racism for birth outcome studies. Maternal and child health journal, 13(1), 29-39.

Office of the Surgeon General. (2001). Chapter 4-Risk Factors for Youth Violence. Youth violence: A report of the Surgeon General.

Oliver, W. (1989). Black males and social problems: Prevention through Afrocentric socialization. Journal of Black Studies, 20(1), 15-39.

Operario, D., \& Fiske, S. T. (2001). Ethnic identity moderates perceptions of prejudice: Judgments of personal versus group discrimination and subtle versus blatant bias. Personality and Social Psychology Bulletin, 27(5), 550-561.

Osborne, J. W. (2016). Regression \& Linear Modeling: Best Practices and Modern Methods.

Paradies, Y. (2006). A systematic review of empirical research on self-reported racism and health. International Journal of Epidemiology, 35(4), 888-901. doi:10.1093/ije/dyl056

Paradies, Y., Ben, J., Denson, N., Elias, A., Priest, N., Pieterse, A., ... Gee, G. (2015). Racism as a Determinant of Health: A Systematic Review and Meta-Analysis. PLoS ONE, 10(9), e0138511. http://doi.org/10.1371/journal.pone.0138511

Paradies, Y., Priest, N., Ben, J., Truong, M., Gupta, A., Pieterse, A., . . Gee, G. (2013). Racism as a determinant of health: a protocol for conducting a systematic review and meta-analysis. Systematic reviews, 2(1), 85. 
Paschall, M. J., \& Hubbard, M. L. (1998). Effects of neighborhood and family stressors on African American male adolescents' self-worth and propensity for violent behavior. Journal of Consulting and Clinical Psychology, 66(5), 825.

Perkins, H. W. (2002). Social norms and the prevention of alcohol misuse in collegiate contexts. Journal of Studies on Alcohol, supplement, (14), 164172.

Perry, T. L. (1990). Race and Child Placement: The Best Interests Test and the Cost of Discretion. J. Fam. L., 29, 51.

Pestronk, R. M., \& Franks, M. L. (2003). A partnership to reduce African American infant mortality in Genesee County, Michigan. Public Health Rep, 118(4), 324-335. doi:10.1093/phr/118.4.324

Peterson, N. A., Peterson, C. H., Agre, L., Christens, B. D., \& Morton, C. M. (2011). Measuring youth empowerment: Validation of a sociopolitical control scale for youth in an urban c ommunity context. Journal of Community Psychology, 39(5), 592-605.

Peterson, R. D., \& Krivo, L. J. (1993). Racial segregation and black urban homicide. Social Forces, 71(4), 1001-1026.

Phillips J, Springer F. Extended National Youth Sports Program 1991-92 evaluation highlights, part two: Individual Protective Factors Index (IPFI) and risk assessment study. Report prepared for the National Collegiate Athletic Association. Sacramento, CA: EMT Associates, 1992. (Unpublished)

Phinney, J. (1992). The Multigroup Ethnic Identity Measure: A new scale for use with adolescents and young adults from diverse groups. Journal of Adolescent Research, 7, 156-176.

Phinney, J. S., \& Chavira, V. (1995). Parental ethnic socialization and adolescent coping with problems related to ethnicity. Journal of research on adolescence, 5(1), 31-53.

Poe, J. (2017, February 14). Redlining Louisville: The History of Race, Class, and Real Estate. Retrieved July 05, 2017, from https://lojic. maps.arcgis.com/apps/MapSeries/index.html?appid=e4d29907 953c4094a17cb9ea8f8f89de

Pollard, J. A., Hawkins, J. D., \& Arthur, M. W. (1999). Risk and protection: Are both necessary to understand diverse behavioral outcomes in adolescence? Social work research, 23(3), 145-158. 
Race. (1989). In Oxford English dictionary online, Retreived from: https://en.oxforddictionaries.com/definition/race

Randolph, W. \& Viswanath, K. (2004). Lessons learned from public health mass media campaigns: Marketing health in a crowded media world. Annual Reviews of Public Health, 25: 419-437.

Raudenbush, S., \& Bryk, A. (2002). Hierarchical linear models (2nd ed.). Newbury Park, CA:

Rencher, W. C., \& Wolf, L. E. (2013). Redressing Past Wrongs: Changing the Common Rule to Increase Minority Voices in Research. American Journal of Public Health, 103(12), 2136-2140. doi:10.2105/AJPH.2013.301356

Resko, S. M., Walton, M. A., Bingham, C. R., Shope, J. T., Zimmerman, M., Chermack, S. T., . . . Cunningham, R. M. (2010). Alcohol availability and violence among inner-city adolescents: A multi-level analysis of the role of alcohol outlet density. American Journal of Community Psychology, 46(34), 253-262.

Resnick, M. D., Ireland, M., \& Borowsky, I. (2004). Youth violence perpetration: what protects? What predicts? Findings from the National Longitudinal Study of Adolescent Health. Journal of Adolescent Health, 35(5), 424. e421-424. e410.

Resnik, J. (1989). Dependent sovereigns: Indian tribes, states, and the federal courts. The University of Chicago Law Review, 56(2), 671-759.

Rice, L. J., Hughes, B., Briggs, V., Delmoor, E., Jefferson, M., Johnson, J. C., \& Halbert, C. H. (2016). Perceived Efficacy and Control for Neighborhood Change: the Cross-Cutting Role of Collective Efficacy. J Racial Ethn Health Disparities, 3(4), 667-675. doi:10.1007/s40615-015-0185-9

Rich, J. A., \& Grey, C. M. (2005). Pathways to recurrent trauma among young black men: traumatic stress, substance use, and the "code of the street". American Journal of Public Health, 95(5), 816-824.

Richters, J.E., Martinez, P. Things I Have Seen and Heard: a structured interview for assessing youth children's violence exposure. Rockville, MD: National Institute of Mental Health, 1990. (Unpublished)

Romero, A. J., \& Roberts, R. E. (1998). Perception of discrimination and ethnocultural variables in a diverse group of adolescents. Journal of adolescence, 21(6), 641-656.

Ross, A. (2016, December 29). Black Student Unions rise on JCPS campuses. Retrieved June 26, 
2017, from http://www.courier-

journal.com/story/news/education/2016/12/29/black-student-unions-riseicps-campuses/95354800/

Rotheram-Borus, M. J., Lightfoot, M., Moraes, A., Dopkins, S., \& LaCour, J. (1998). Developmental, ethnic, and gender differences in ethnic identity among adolescents. Journal of Adolescent Research, 13(4), 487-507.

Rowley, S. J., Sellers, R. M., Chavous, T. M., \& Smith, M. A. (1998). The relationship between racial identity and self-esteem in African American college and high school students. Journal of personality and social psychology, 74(3), 715.

Ryan, W. (1976). Blaming the victim (Vol. 226): Vintage.

Ryan, C. L., \& Bauman, K. (2016). Educational Attainment in the United States: 2015: Current Population Reports, P20-xxx. Washington, DC: US Census Bureau.

Sampson, R. J., \& Wilson, W. J. (1995). Toward a theory of race, crime, and urban inequality (Vol. 1995).

Sampson, R. J., Morenoff, J. D., \& Raudenbush, S. (2005). Social Anatomy of Racial and Ethnic Disparities in Violence. American Journal of Public Health, 95(2), 224-232. doi:10.2105/AJPH.2004.037705

Scheier, L. M., Botvin, G. J., Diaz, T., \& Ifill-Williams, M. (1997). Ethnic identity as a moderator of psychosocial risk and adolescent alcohol and marijuana use: Concurrent and longitudinal analyses. Journal of Child \& Adolescent Substance Abuse, 6(1), 21-47.

Schneider, M. J. (2016). Introduction to public health. Jones \& Bartlett Publishers.

Schultz, P. W., Nolan, J. M., Cialdini, R. B., Goldstein, N. J., \& Griskevicius, V. (2007). The constructive, destructive, and reconstructive power of social norms. Psychological science, 18(5), 429-434.

Sellers, R. M., Caldwell, C. H., Schmeelk-Cone, K. H., \& Zimmerman, M. A. (2003). Racial identity, racial discrimination, perceived stress, and psychological distress among African American young adults. Journal of Health and Social Behavior, 302-317.

Sellers, R. M., Rowley, S. A., Chavous, T. M., Shelton, J. N., \& Smith, M. A. (1997).Multidimensional Inventory of Black Identity: A preliminary investigation of reliability and construct validity. Journal of personality and social psychology, 73(4), 805. 
Sellers, R. M., Smith, M. A., Shelton, J. N., Rowley, S. A., \& Chavous, T. M. (1998). Multidimensional model of racial identity: A reconceptualization of African American racial identity. Personality and Social Psychology Review, 2(1), 18-39.

Seymour-Smith, C. (1986). Macmillan dictionary of anthropology.

Shavers, V. L., Fagan, P., Jones, D., Klein, W. M., Boyington, J., Moten, C., \& Rorie, E. (2012). The state of research on racial/ethnic discrimination in the receipt of health care. Am J Public Health, 102(5), 953-966. doi:10.2105/ajph.2012.300773

Shelton, J. N., \& Sellers, R. M. (2000). Situational stability and variability in African American racial identity. Journal of Black Psychology, 26(1), 2750.

Shihadeh, E. S., \& Flynn, N. (1996). Segregation and crime: The effect of black social isolation on the rates of black urban violence. Social Forces, 13251352.

Smedley, B. D. (2012). The Lived Experience of Race and Its Health Consequences. American Journal of Public Health, 102(5), 933-935. doi:10.2105/AJPH.2011.300643

Smedley, B. D., \& Myers, H. F. (2014). Conceptual and Methodological Challenges for Health Disparities Research and Their Policy Implications. Journal of Social Issues, 70(2), 382-391. doi:10.1111/josi.12065

Smith, E. P., Walker, K., Fields, L., Brookins, C. C., \& Seay, R. C. (1999). Ethnic identity and its relationship to self-esteem, perceived efficacy and prosocial attitudes in early adolescence. Journal of adolescence, 22(6), 867-880.

Smith, D. A., \& Jarjoura, G. R. (1988). Social structure and criminal victimization. Journal of Research in Crime and Delinquency, 25(1), 27-52.

Spencer, M. B., Cunningham, M., \& Swanson, D. P. (1995). Identity as coping: Adolescent African-American males' adaptive responses to high-risk environment.

Stevenson, H. C. (1994). Validation of the scale of racial socialization for African American adolescents: Steps toward multidimensionality. Journal of Black Psychology, 20(4), 445-468.

Stewart, E. A., \& Simons, R. L. (2010). Race, code of the street, and violent delinquency: A multilevel investigation of neighborhood street culture and individual norms of violence. Criminology, 48(2), 569-605. 
Stewart, E. A., \& Simons, R. L. Race, Code of the Street, and Violent Delinquency: A Multilevel Investigation of Neighborhood Street Culture and Individual Norms of Violence. Criminology, 48(2), 569-605.

Stouthamer-Loeber, M., Loeber, R., Wei, E., Farrington, D. P., \& Wikström, P.-O. $\mathrm{H}$. (2002). Risk and promotive effects in the explanation of persistent serious delinquency in boys. Journal of consulting and clinical psychology, 70(1), 111.

Subramanian, S. V., Acevedo-Garcia, D., \& Osypuk, T. L. (2005). Racial residential segregation and geographic heterogeneity in black/white disparity in poor self-rated health in the US: a multilevel statistical analysis. Social science \& medicine, 60(8), 1667-1679.

Sunstein, C. R. (1996). Social norms and social roles. Columbia law review, 96(4), 903-968.

Thomas, S. B., Quinn, S. C., Butler, J., Fryer, C. S., \& Garza, M. A. (2011). Toward a fourth generation of disparities research to achieve health equity. Annu Rev Public Health, 32, 399-416. doi:10.1146/annurevpublhealth-031210-101136

Thompson, V. L. S. (1994). Socialization to race and its relationship to racial identification among African Americans. Journal of Black Psychology, 20(2), 175-188.

Thornberry, T., Huizinga, D., \& Loeber, R. (1995). Prevention of Serious Delinquency and Violence: Implications From the Program of Research on the Causes and Correlates of Delinquency (From Sourcebook on Serious, Violent, and Chronic Juvenile Offenders, P 213-237, 1995, James C. Howell, Barry Krisberg, et. al., eds).

Trevelyan, E., Gambino, C., Gryn, T., Larsen, L., Acosta, Y., Grieco, E., . . . Walters, N. (2016). The Characteristics of the US Population by Generational Status: 2013: US Government Printing Office, Washington, DC.

Ture, K. \& Hamilton, C., (1967). Black power: Politics of liberation in America. Vintage.

United States Census Bureau (2012a). 2012 Population Estimates. Retrieved from: http://www.census.gov/popest/index.html

United States Bureau of Labor Statistics. (2016, September). Labor force characteristics by race and ethnicity, 2015. Retrieved January 13, 2017, from https://www.bls.gov/opub/reports/race-andethnicity/2015/pdf/home.pdf 
United States Census Bureau (2012b). 2008-2012 American Community Survey 5-year Estimates. Retrieved from http://www.census.gov/acs/www/

United States Census Bureau (2012b). 2008-2012 American Community Survey 5-year IEstimates. Retrieved from http://www.census.gov/acs/www/

United States Census Bureau. (2017). Quickfacts. Retrieved February 10, 2017, from http://www.census.gov/quickfacts/table/RHI125215/00

United States Department of Health and Human Services. Office of Disease Prevention and Health Promotion. Healthy People 2020, November 2010. Available at: http://www.healthypeople.gov/2020/ about/disparitiesAbout.aspx. Accessed February 7, 2017.

United States Department of Housing and Urban Development. (n.d.). Resources. Retrieved February 01, 2017, from https://www.huduser.gov/portal/glossary/glossary all.html\#u

United States Department of Health and Human Services. The Secretary's Advisory Committee on National Health Promotion and Disease Prevention Objectives for 2020. Phase I report: Recommendations for the framework and format of Healthy People 2020 [Internet]. Section IV: Advisory Committee findings and recommendations [cited 2017 May 2]. Available

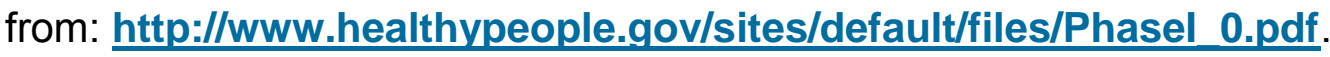

Unnever, J. D. (2008). Two worlds far apart: black-white differences in beliefs about why African-American men are disproportionately imprisoned. Criminology, 46(2), 511-538.

Verba, S., Schlozman, K. L., \& Brady, H. E. (1995). Voice and equality: Civic voluntarism in American politics. Harvard University Press.

Viner, R. M., Ozer, E. M., Denny, S., Marmot, M., Resnick, M., Fatusi, A., \& Currie, C. (2012). Adolescence and the social determinants of health. The Lancet, 379(9826), 1641-1652.

Virginia Commonwealth University Clark-Hill Institute for Positive Youth Development. (n.d) Promoting Positive Development in Adolescence HM13300. Appendix A - Measures.

Von Linné, C. (1956). A Photographic Facsmile of the First volume of the 10th Edition. London: British Museum of Natural History, 1956, 20-22.

Wakefield, M., Loken, B. \& Hornik, R. (2010). Use of mass media campaigns to change health behavior. Lancet, 376: 1261-1271. 
Wallington, S. F., Blake, K. D., Taylor-Clark, K., \& Viswanath, K. (2010). Challenges in covering health disparities in local news media: an exploratory analysis assessing views of journalists. J Community Health, 35(5), 487-494. doi:10.1007/s10900-009-9217-x

Walters, K. L., Mohammed, S. A., Evans-Campbell, T., Beltrán, R. E., Chae, D. H., \& Duran, B. (2011). BODIES DON'T JUST TELL STORIES, THEY TELL HISTORIES: Embodiment of Historical Trauma among American Indians and Alaska Natives. Du Bois Review: Social Science Research on Race, 8(1), 179-189. doi:10.1017/S1742058X1100018X

Watts, R. J., \& Guessous, O. (2006). Sociopolitical development: The missing link in research and policy on adolescents. Beyond resistance, 59-80.

Watts, R. J., Williams, N. C., \& Jagers, R. J. (2003). Sociopolitical development. American Journal of Community Psychology, 31(1-2), 185194.

World Health Organization (2017) What are social determinants of health? Retrieved January 20, 2017, from http://www.who.int/social determinants/sdh definition/en/

Widome, R., Sieving, R. E., Harpin, S. A., \& Hearst, M. O. (2008). Measuring neighborhood connection and the association with violence in young adolescents. Journal of Adolescent Health, 43(5), 482-489.

Wilkins, N., Tsao, B., Hertz, M., Davis, R., \& Klevens, J. (2014). Connecting the dots: an overview of the links among multiple forms of violence.

Wilkins, N., Tsao, B., Hertz, M., Davis, R., Klevens, J. (2014). Connecting the Dots: An Overview Pratkanis (Ed). The Science of Social Influence: Advances \& Future Progress. New York, NY: Psychology Press.

Williams, D. R. (1999). Race, socioeconomic status, and health the added effects of racism and discrimination. Annals of the New York Academy of Sciences, 896(1), 173-188.

Williams, Jr, R. A. (1989). Documents of barbarism: The contemporary legacy of European racism and colonialism in the narrative traditions of federal Indian law. Ariz. L. Rev., 31, 237.

Williams, D. R., \& Collins, C. (2001). Racial residential segregation: a fundamental cause of racial disparities in health. Public Health Reports, 116(5), 404-416.

Williams, J. R., \& Gold, M. (1972). From delinquent behavior to official delinquency. Social Problems, 20(2), 209-229. 
Williams, D. R., \& Mohammed, S. A. (2009). Discrimination and racial disparities in health: evidence and needed research. Journal of Behavioral Medicine, 32(1), 20-47. doi:10.1007/s10865-008-9185-0

Williams, D. R., \& Williams-Morris, R. (2000). Racism and mental health: The African American experience. Ethnicity and health, 5(3/4), 243.

Williams, D. R., Mohammed, S. A., Leavell, J., \& Collins, C. (2010). Race, socioeconomic status, and health: complexities, ongoing challenges, and research opportunities. Annals of the New York Academy of Sciences, 1186(1), 69-101.

Williams, D. R., Neighbors, H. W., \& Jackson, J. S. (2003). Racial/ethnic discrimination and health: findings from community studies. American Journal of Public Health, 93(2), 200-208.

Williams, D. R., Spencer, M. S., \& Jackson, J. S. (1999). Race, stress, and physical health: the role of group identity.

Williams, P. J. (1991). The alchemy of race and rights: Harvard University Press.

Witt, W. P., Park, H., Wisk, L. E., Cheng, E. R., Mandell, K., Chatterjee, D., \& Zarak, D. (2015). Neighborhood Disadvantage, Preconception Stressful Life Events, and Infant Birth Weight. American Journal of Public Health, 105(5), 1044-1052. doi:10.2105/AJPH.2015.302566

Witzig, R. (1996). The medicalization of race: scientific legitimization of a flawed social construct. Annals of internal medicine, 125(8), 675-679.

World Health Oranization (WHO), \& Krug, E. (2002). World report on violence and health. 2002.

Yonas, M. A., Jones, N., Eng, E., Vines, A. I., Aronson, R., Griffith, D. M., .. . DuBose, M. (2006). The art and science of integrating Undoing Racism with CBPR: challenges of pursuing NIH funding to investigate cancer care and racial equity. $J$ Urban Health, 83(6), 1004-1012. doi:10.1007/s11524006-9114-x 
APPENDIX A: Redlining Maps for Louisville, Kentucky

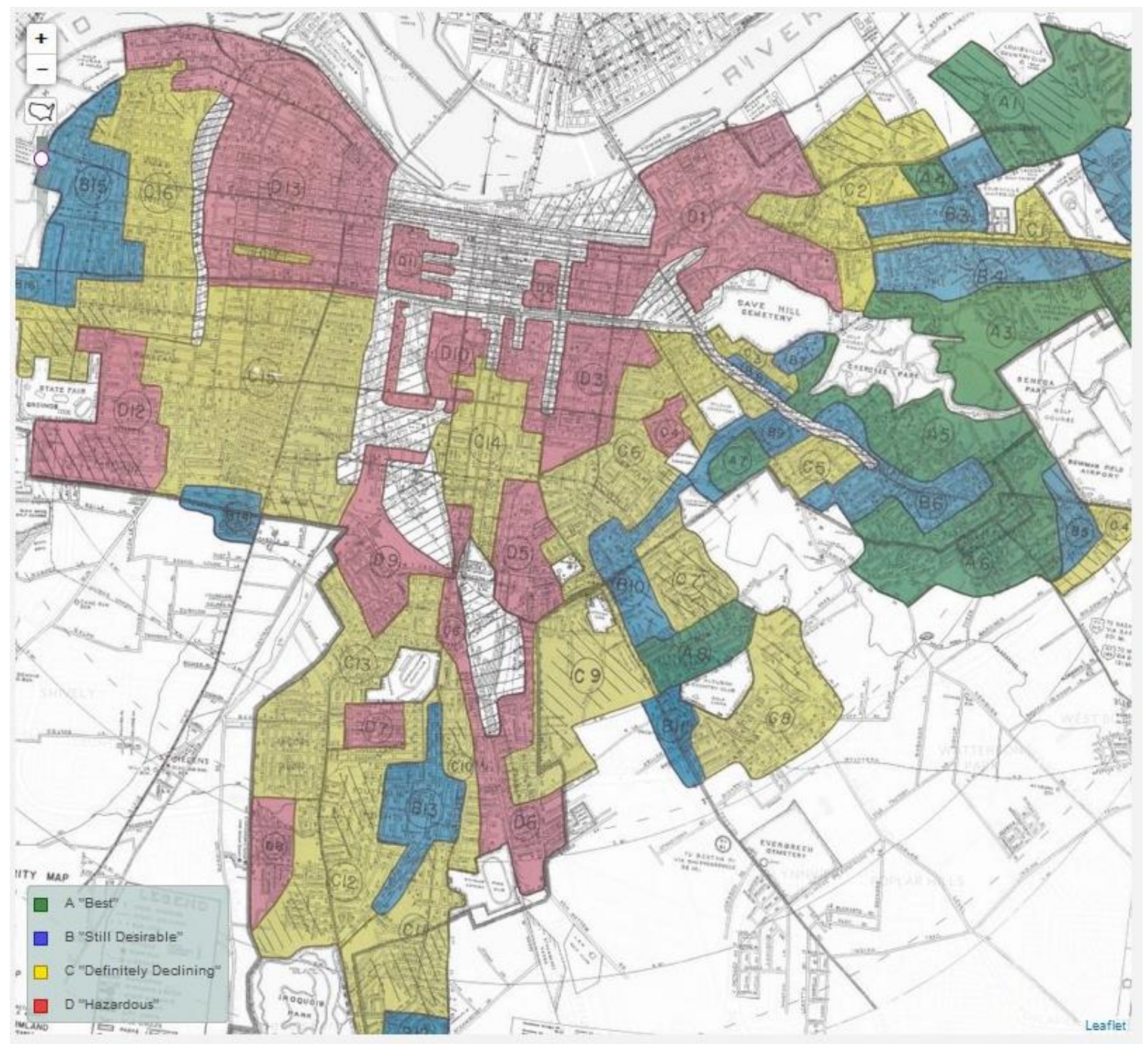




\section{Appendix B: YVPRC 2017 School Survey}

\section{Part I: Behavior of Your Peers}

We would like to ask you about the behavior of your closest friends. In particular, we want to know how many of them, as far as you know, have done any of these things in the last 3 months.

As far as you know, in the last $\mathbf{3}$ months how many of your close friends have...

\begin{tabular}{|c|c|c|c|c|}
\hline & None & Some & Many & All \\
\hline Sold drugs? & $\mathrm{O}$ & $\mathrm{O}$ & $\mathrm{O}$ & $\mathrm{O}$ \\
\hline Stolen something worth more than $\$ 10$ ? & O & $\mathrm{O}$ & $\mathrm{O}$ & O \\
\hline Loaned things to people just to be nice? & O & O & O & $\mathrm{O}$ \\
\hline Hit someone with the idea of hurting that person? & $\mathrm{O}$ & $\bigcirc$ & O & O \\
\hline Helped out around the house? & $\mathrm{O}$ & O & O & $\mathrm{O}$ \\
\hline $\begin{array}{l}\text { Used a weapon, force, or strong-arm methods to get } \\
\text { money or things from people? }\end{array}$ & O & O & O & O \\
\hline $\begin{array}{l}\text { Purposely damaged or destroyed property that } \\
\text { wasn't theirs. }\end{array}$ & O & O & O & $\mathrm{O}$ \\
\hline Tried to do their best in school? & $\mathrm{O}$ & O & O & O \\
\hline Been in a gang fight? & O & O & O & O \\
\hline Helped people without expecting something back? & O & O & O & 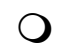 \\
\hline
\end{tabular}

\section{Part II: Expectations of Your Peers}

We're interested in you think your friends might react to different ways of trying to deal with difficult situations.

For the next two questions, imagine you see two people about to start a fight.

What would your friends think if you cheered on the fight?

They would think that I was cool.

They would think I should have stayed out of it.

They would not care.

What would your friends think if you went to get an adult? 
They would think I was being a snitch.

They would not care.

They would think I did the right thing.

For the next two questions, imagine you and your friends are playing ball. Another person close to your age who's watching the game keeps making of the way you are playing.

What would your friends think if you started a fight with the person making fun of you?

They would think I was tough.

They would not care.

They would think I did the wrong thing.

What would your friends think if you quit playing ball and left?

$O$ They would think I was being a punk.

They would think I'm ok.

They would not care.

For the next two questions, imagine that you and another teen get into an argument. Others are there boosting it up saying, "Fight, fight, fight."

What would your friends think if you tried to talk to the person calmly to settle the argument?

They would think I was a punk.

They would not care.

They would think I was smart.

What would your friends think if you threw the first punch?

$O$ They would think that I'm hard.

They would think I was lame.

They would not care.

For the next two questions, imagine that somebody is spreading a rumor about another teen and you got blamed for it. Now you have a big problem with this person who thinks you were talking about them behind their back.

What would your friends think if you talked it out with the person the rumor was started about and explained that you didn't start it? 
They would think that I did the right thing.

They would think I was weak.

They would not care.

What would your friends think if you argued and got into a fight with the person who blamed you for starting the rumor?

They would think that I'm hard.

They would think I was being dramatic.

They would not care.

For the next two questions, imagine that another teen says something to you that is disrespectful about your family.

What would your friends think if you gave them a serious look and told them if they didn't stop you'd fight them?

They would think that I did the right thing.

O They would think I was lame.

They would not care.

What would your friends think if you just ignored the other teen and didn't let it bother you?

They would think that I'm cool.

They would think I was being lame.

They would not care.

For the next two questions, imagine that there's a group of teens that tease and pick on you. They call you names and make fun of you.

What would your friends think if you asked an adult, like a teacher or someone in your neighborhood, for help?

teacher or someone in your neighborhood, for help? $</$ span $></$ span $></$ span $>$

$O$ They would think that I did the right thing.

They would think I was a punk.

They would not care.

What would your friends think if you asked them to help you beat up the other teens?

O They would think that I'm cool.

They would think it was a bad idea.

They would not care. 


\section{Part III: Identity}

In this country, people come from many different countries and cultures, and there are many different words to describe the different backgrounds or ethnic groups that people come from. Some examples of the names of ethnic groups are Hispanic or Latino, Black or African American, Asian American, Chinese, Filipino, American Indian, Mexican American, Caucasian or White, Italian American, and many others. These questions are about your ethnicity or your ethnic group and how you feel about it or react to it.

Please fill in: In terms of ethnic group, I consider myself to be

How much do you agree or disagree with the following statements? 


\begin{tabular}{|c|c|c|c|c|}
\hline & $\begin{array}{l}\text { Strongly } \\
\text { Disagree }\end{array}$ & $\begin{array}{l}\text { Disagre } \\
\mathrm{e}\end{array}$ & Agree & $\begin{array}{l}\text { Strongly } \\
\text { Agree }\end{array}$ \\
\hline $\begin{array}{l}\text { I have spent time trying to find out more about } \\
\text { my ethnic group, such as its history, traditions, } \\
\text { and customs. }\end{array}$ & 0 & 0 & 0 & 0 \\
\hline $\begin{array}{l}\text { I am active in organizations or social groups } \\
\text { that include mostly members of my own ethnic } \\
\text { group. }\end{array}$ & 0 & 0 & 0 & 0 \\
\hline $\begin{array}{l}\text { I have a clear sense of my ethnic background } \\
\text { and what it means for me. }\end{array}$ & 0 & 0 & 0 & 0 \\
\hline $\begin{array}{l}\text { I think a lot about how my life will be affected } \\
\text { by my ethnic group membership. }\end{array}$ & 0 & 0 & 0 & 0 \\
\hline $\begin{array}{l}\text { I am happy that I am a member of the group I } \\
\text { belong to. }\end{array}$ & 0 & 0 & 0 & 0 \\
\hline $\begin{array}{l}\text { I have a strong sense of belonging to my own } \\
\text { ethnic group. }\end{array}$ & 0 & 0 & 0 & 0 \\
\hline $\begin{array}{l}\text { I understand pretty well what my ethnic group } \\
\text { membership means to me. }\end{array}$ & 0 & 0 & 0 & 0 \\
\hline $\begin{array}{l}\text { In order to learn more about my ethnic } \\
\text { background, I have often talked to other } \\
\text { people about my ethnic group. }\end{array}$ & 0 & 0 & 0 & 0 \\
\hline I have a lot of pride in my ethnic group. & O & $\bigcirc$ & $\bigcirc$ & $\bigcirc$ \\
\hline $\begin{array}{l}\text { I participate in cultural practices of my own } \\
\text { group, such as special food, music, or customs. }\end{array}$ & 0 & 0 & 0 & 0 \\
\hline $\begin{array}{l}\text { I feel a strong attachment towards my own } \\
\text { ethnic group. }\end{array}$ & 0 & 0 & 0 & 0 \\
\hline $\begin{array}{l}\text { I feel good about my cultural or ethnic } \\
\text { background. }\end{array}$ & 0 & 0 & 0 & 0 \\
\hline
\end{tabular}

My father's race/ethnicity is:

Asian or Asian American, including Chinese, Japanese, and others

O Black or African American

O Hispanic or Latino, including Mexican American, Central American, and others

O White, Caucasian, Anglo, European American; not Hispanic

American Indian/Native American

Mixed; Parents are from two or more different groups

Other: 
My mother's race/ethnicity is:

Asian or Asian American, including Chinese, Japanese, and others

Black or African American

Hispanic or Latino, including Mexican American, Central American, and others

White, Caucasian, Anglo, European American; not Hispanic

American Indian/Native American

Mixed; Parents are from two or more different groups

Other:

\section{Part IV: Social Support}

For each of the following sentences, please select the response that is closest to how you feel about what the sentence says. Check "Strongly Agree" if you believe very strongly that the sentence is true for you, or that it is the way you feel almost all of the time. Check "Agree" if you sort of agree that the sentence is true for you, or that it is the way you feel most of the time. Check "Disagree" if you sort of believe the sentence is false for you, or that you do not feel that way most of the time. Check "Strongly Disagree" If you believe very strongly that the sentence is false, or that you almost never feel this way.

\begin{tabular}{|c|c|c|c|c|}
\hline & $\begin{array}{l}\text { Strongly } \\
\text { Agree }\end{array}$ & Agree & Disagree & $\begin{array}{l}\text { Strongly } \\
\text { Disagree }\end{array}$ \\
\hline $\begin{array}{l}\text { There are people I can depend on to help me if } \\
\text { I really need it. }\end{array}$ & 0 & 0 & $\mathrm{O}$ & $\mathrm{O}$ \\
\hline $\begin{array}{l}\text { There is not an adult I can turn to for guidance } \\
\text { in times of stress. }\end{array}$ & 0 & O & 0 & 0 \\
\hline $\begin{array}{l}\text { If something went wrong, no one would come } \\
\text { to my assistance. }\end{array}$ & 0 & O & 0 & 0 \\
\hline $\begin{array}{l}\text { There is an adult I could talk to about } \\
\text { important decisions in my life. }\end{array}$ & O & 0 & O & O \\
\hline $\begin{array}{l}\text { There is a trustworthy adult I could turn to for } \\
\text { advice if I were having problems. }\end{array}$ & 0 & 0 & 0 & 0 \\
\hline $\begin{array}{l}\text { There is no one I can depend on for help if I } \\
\text { really need it. }\end{array}$ & 0 & 0 & O & 0 \\
\hline $\begin{array}{l}\text { There is no adult I can feel comfortable talking } \\
\text { about my problems with. }\end{array}$ & $\mathrm{O}$ & 0 & 0 & 0 \\
\hline $\begin{array}{l}\text { There are people I can count on in an } \\
\text { emergency. }\end{array}$ & 0 & 0 & O & O \\
\hline $\begin{array}{l}\text { There is a special person in my life who cares } \\
\text { about my feelings. }\end{array}$ & 0 & 0 & 0 & 0 \\
\hline
\end{tabular}




\section{Part V: Resilience}

For each of item, check the box that best indicates how much you agree with the following statements as they apply to you over the last month. If a particular situation has not occurred recently, answer how you think you would have felt.

\begin{tabular}{|l|c|c|c|c|c|}
\hline & $\begin{array}{c}\text { Not at } \\
\text { All }\end{array}$ & $\begin{array}{c}\text { Rarely } \\
\text { True }\end{array}$ & $\begin{array}{c}\text { Sometimes } \\
\text { True }\end{array}$ & $\begin{array}{c}\text { Often } \\
\text { True }\end{array}$ & $\begin{array}{c}\text { True } \\
\text { Nearly All } \\
\text { the Time }\end{array}$ \\
\hline $\begin{array}{l}\text { I am able to adapt when } \\
\text { changes occur. }\end{array}$ & O & O & 0 & 0 & 0 \\
$\begin{array}{l}\text { I tend to bounce back after } \\
\text { illness, injury, or other } \\
\text { hardships. }\end{array}$ & O & O & 0 & 0 & 0 \\
\hline
\end{tabular}

\section{Part VI: Exposure to Violence}

Please indicate how often you have seen or heard these things around your home and neighborhood (not counting TV shows, movies, or on the internet, etc.).

\begin{tabular}{|c|c|c|c|c|}
\hline & Never & $\begin{array}{l}\text { Once or } \\
\text { twice }\end{array}$ & $\begin{array}{l}\text { A Few } \\
\text { Times }\end{array}$ & $\begin{array}{l}\text { Many } \\
\text { Times }\end{array}$ \\
\hline I have heard guns being shot. & $\mathrm{O}$ & O & $\mathrm{O}$ & $\mathrm{O}$ \\
\hline I have seen somebody arrested. & $\mathrm{O}$ & $\mathrm{O}$ & $\mathrm{O}$ & $\mathrm{O}$ \\
\hline I have seen drug deals go down. & $\bigcirc$ & O & $\bigcirc$ & O \\
\hline I have seen someone being beaten up. & O & $\mathrm{O}$ & $\bigcirc$ & $\mathrm{O}$ \\
\hline My house has been broken into. & $\mathrm{O}$ & $\mathrm{O}$ & $\mathrm{O}$ & $\mathrm{O}$ \\
\hline $\begin{array}{l}\text { I have seen somebody get stabbed or } \\
\text { shot. }\end{array}$ & $\mathrm{O}$ & $\mathrm{O}$ & ○ & $\mathrm{O}$ \\
\hline I have seen a gun in my home. & $\mathrm{O}$ & $\mathrm{O}$ & O & $\mathrm{O}$ \\
\hline $\begin{array}{l}\text { I have seen gangs in my } \\
\text { neighborhood. }\end{array}$ & $\mathrm{O}$ & $\mathrm{O}$ & ○ & $\mathrm{O}$ \\
\hline $\begin{array}{l}\text { I have seen somebody pull a gun on } \\
\text { another person. }\end{array}$ & $\bigcirc$ & O & $\bigcirc$ & O \\
\hline $\begin{array}{l}\text { I have seen someone in my home get } \\
\text { shot or stabbed. }\end{array}$ & $\mathrm{O}$ & O & $\mathrm{O}$ & $\mathrm{O}$ \\
\hline
\end{tabular}

\section{Part VII: Violent Behavior}


The next set of questions ask about your own behavior. Remember that your answers are confidential.

In the past 12 months, how often have you done these things?

\begin{tabular}{|c|c|c|c|c|}
\hline & Never & Once & $\begin{array}{c}\text { Sometime } \\
\mathrm{s}\end{array}$ & Often \\
\hline Hit or kicked someone. & $\mathrm{O}$ & $\mathrm{O}$ & $\mathrm{O}$ & $\mathrm{O}$ \\
\hline $\begin{array}{l}\text { Pushed or shoved someone when you were } \\
\text { angry. }\end{array}$ & $\mathrm{O}$ & $\mathrm{O}$ & $\mathrm{O}$ & $\mathrm{O}$ \\
\hline Beaten someone up. & $\mathrm{O}$ & $\mathrm{O}$ & $\mathrm{O}$ & $\mathrm{O}$ \\
\hline Carried a knife or sharp weapon or other blade. & $\mathrm{O}$ & $\mathrm{O}$ & $\mathrm{O}$ & $\mathrm{O}$ \\
\hline $\begin{array}{l}\text { Threatened someone with a knife or sharp } \\
\text { weapon. }\end{array}$ & O & O & $\mathrm{O}$ & $\mathrm{O}$ \\
\hline Attacked someone with a knife or sharp weapon. & $\mathrm{O}$ & $\mathrm{O}$ & $\mathrm{O}$ & O \\
\hline Carried a gun. & O & $\mathrm{O}$ & O & O \\
\hline Threatened someone with a gun. & $\mathrm{O}$ & $\mathrm{O}$ & O & O \\
\hline Used a gun on another person. & $\mathrm{O}$ & $\mathrm{O}$ & O & 0 \\
\hline $\begin{array}{l}\text { Said something to someone that made them feel } \\
\text { bad about themselves, or afraid. }\end{array}$ & 0 & 0 & 0 & 0 \\
\hline
\end{tabular}

\section{Part VIII: My Thoughts and Attitudes}

The next questions ask about your thoughts about violence?

How much do you agree or disagree with the following statements? 


\begin{tabular}{|c|c|c|c|c|}
\hline & $\begin{array}{l}\text { Strongly } \\
\text { Disagree }\end{array}$ & $\begin{array}{l}\text { Somewhat } \\
\text { Disagree }\end{array}$ & $\begin{array}{l}\text { Somewhat } \\
\text { Agree }\end{array}$ & $\begin{array}{l}\text { Strongly } \\
\text { Agree }\end{array}$ \\
\hline Fighting usually causes more problems than it solves. & $\mathrm{O}$ & $\mathrm{O}$ & $\mathrm{O}$ & $\mathrm{O}$ \\
\hline $\begin{array}{l}\text { It's okay to use physical force to get someone to do } \\
\text { what you want. }\end{array}$ & O & $\mathrm{O}$ & $\mathrm{O}$ & $\mathrm{O}$ \\
\hline $\begin{array}{l}\text { It's okay to fight someone if they do something to } \\
\text { make you mad. }\end{array}$ & $\mathrm{O}$ & $\mathrm{O}$ & O & $\mathrm{O}$ \\
\hline $\begin{array}{l}\text { It's okay to fight someone if they call you names or } \\
\text { tease you. }\end{array}$ & $\mathrm{O}$ & $\mathrm{O}$ & $\mathrm{O}$ & $\mathrm{O}$ \\
\hline Fighting is just wrong; it's a bad thing to do. & $\mathrm{O}$ & $\mathrm{O}$ & $\mathrm{O}$ & $\mathrm{O}$ \\
\hline $\begin{array}{l}\text { It's okay to fight someone if they spread a rumor } \\
\text { about you. }\end{array}$ & $\mathrm{O}$ & $\mathrm{O}$ & O & $\mathrm{O}$ \\
\hline $\begin{array}{l}\text { If you don't fight some people, they'll just keep } \\
\text { messing with you. }\end{array}$ & $\mathrm{O}$ & $\mathrm{O}$ & $\mathrm{O}$ & $\mathrm{O}$ \\
\hline $\begin{array}{l}\text { If people do something to make you really mad, they } \\
\text { deserve to be beaten up. }\end{array}$ & $\mathrm{O}$ & $\mathrm{O}$ & O & $\mathrm{O}$ \\
\hline $\begin{array}{l}\text { It's okay to threaten someone if they won't do what } \\
\text { you want. }\end{array}$ & $\mathrm{O}$ & $\mathrm{O}$ & $\mathrm{O}$ & $\mathrm{O}$ \\
\hline $\begin{array}{l}\text { Sometimes you have only two choices-get punched } \\
\text { or punch the other person first. }\end{array}$ & $\mathrm{O}$ & $\mathrm{O}$ & $\mathrm{O}$ & $\mathrm{O}$ \\
\hline $\begin{array}{l}\text { It's okay to fight someone if they have something } \\
\text { you want. }\end{array}$ & $\mathrm{O}$ & $\mathrm{O}$ & $\mathrm{O}$ & O \\
\hline Fighting mostly just leads to more fighting. & $\mathrm{O}$ & $\mathrm{O}$ & $\mathrm{O}$ & $\mathrm{O}$ \\
\hline $\begin{array}{l}\text { If you back down from a fight, people will think you } \\
\text { are a coward. }\end{array}$ & $\mathrm{O}$ & $\mathrm{O}$ & $\mathrm{O}$ & $\mathrm{O}$ \\
\hline $\begin{array}{l}\text { Sometimes a person doesn't have any choice but to } \\
\text { fight. }\end{array}$ & $\mathrm{O}$ & O & O & $\mathrm{O}$ \\
\hline $\begin{array}{l}\text { Most of the things people fight over aren't worth } \\
\text { fighting about. }\end{array}$ & $\mathrm{O}$ & O & O & $\mathrm{O}$ \\
\hline $\begin{array}{l}\text { It's okay to yell at someone to get them to do things } \\
\text { for you. }\end{array}$ & O & O & O & $\mathrm{O}$ \\
\hline $\begin{array}{l}\text { It's okay for you to hit someone to get them to do } \\
\text { what you want. }\end{array}$ & $\mathrm{O}$ & O & O & O \\
\hline $\begin{array}{l}\text { There are better ways to solve most problems than } \\
\text { by fighting. }\end{array}$ & $\mathrm{O}$ & $\mathrm{O}$ & $\mathrm{O}$ & $\mathrm{O}$ \\
\hline $\begin{array}{l}\text { If you don't fight someone who picks on you, others } \\
\text { will never let you hear the end of it. }\end{array}$ & $\mathrm{O}$ & $\mathrm{O}$ & $\mathrm{O}$ & O \\
\hline If someone pushes you, you should push them back. & O & O & O & O \\
\hline $\begin{array}{l}\text { If you don't fight when someone messes with you, } \\
\text { other people will pick on you. }\end{array}$ & $\mathrm{O}$ & $\mathrm{O}$ & O & O \\
\hline $\begin{array}{l}\text { You should fight someone if they say something bad } \\
\text { about someone in your family. }\end{array}$ & $\mathrm{O}$ & $\mathrm{O}$ & $\mathrm{O}$ & $\mathrm{O}$ \\
\hline
\end{tabular}




\section{IX: Thoughts about Society}

How much do you agree or disagree with the following statements.

\begin{tabular}{|l|c|c|c|c|}
\hline & $\begin{array}{c}\text { Strongly } \\
\text { Disagree }\end{array}$ & Disagree & Agree & $\begin{array}{c}\text { Strongly } \\
\text { Agree }\end{array}$ \\
\hline $\begin{array}{l}\text { Unemployed poor people could find jobs if } \\
\text { they tried harder. }\end{array}$ & 0 & 0 & 0 & 0 \\
$\begin{array}{l}\text { People are poor due to circumstances } \\
\text { beyond their control. }\end{array}$ & 0 & 0 & 0 & 0 \\
$\begin{array}{l}\text { People who are poor should not be blamed } \\
\text { for their misfortune. }\end{array}$ & 0 & 0 & 0 & 0 \\
$\begin{array}{l}\text { Society has a responsibility to help poor } \\
\text { people. }\end{array}$ & 0 & 0 & 0 & 0 \\
\hline Poor people are discriminated against. & 0 & 0 & 0 & 0 \\
\hline
\end{tabular}

\section{X: Color Blind Racial Attitudes}

How much do you agree or disagree with the following statements. 


\begin{tabular}{|c|c|c|c|c|}
\hline & $\begin{array}{l}\text { Strongly } \\
\text { Disagree }\end{array}$ & Disagree & Agree & $\begin{array}{l}\text { Strongly } \\
\text { Agree }\end{array}$ \\
\hline $\begin{array}{l}\text { Race is very important in determining who } \\
\text { is successful and who is not }\end{array}$ & 0 & $\mathrm{O}$ & 0 & 0 \\
\hline $\begin{array}{l}\text { Race plays an important role in who gets } \\
\text { sent to prison. }\end{array}$ & 0 & 0 & O & 0 \\
\hline $\begin{array}{l}\text { Racial and ethnic minorities do not have the } \\
\text { same opportunities as white people in the } \\
\text { US. }\end{array}$ & 0 & 0 & 0 & 0 \\
\hline $\begin{array}{l}\text { Racial and ethnic minorities in the US have } \\
\text { certain advantages because of the color of } \\
\text { their skin. }\end{array}$ & $\mathrm{O}$ & $\mathrm{O}$ & 0 & $\mathrm{O}$ \\
\hline $\begin{array}{l}\text { It is important for public schools to teach } \\
\text { about the history and contributions of racial } \\
\text { and ethnic minorities. }\end{array}$ & 0 & 0 & 0 & 0 \\
\hline $\begin{array}{l}\text { Racial problems in the US are rare and } \\
\text { isolated situations. }\end{array}$ & 0 & $\mathrm{O}$ & 0 & 0 \\
\hline $\begin{array}{l}\text { Everyone who works hard, no matter what } \\
\text { race they are, has an equal chance to } \\
\text { become rich }\end{array}$ & 0 & 0 & 0 & 0 \\
\hline $\begin{array}{l}\text { Racism may have been a problem in the } \\
\text { past, it is not an important problem today. }\end{array}$ & 0 & 0 & 0 & 0 \\
\hline $\begin{array}{l}\text { It is important that people begin to think of } \\
\text { themselves as American and not as African } \\
\text { American, Mexican American, etc. }\end{array}$ & 0 & 0 & 0 & 0 \\
\hline $\begin{array}{l}\text { White people in the US have certain } \\
\text { advantages because of the color of their } \\
\text { skin. }\end{array}$ & 0 & $\mathrm{O}$ & O & $\mathrm{O}$ \\
\hline
\end{tabular}




\section{$\mathrm{XI}$ : Community Activity}

In the past 12 months, how often have you done these things?

\begin{tabular}{|c|c|c|c|c|}
\hline & Never & Once & Sometimes & Often \\
\hline Participated in a political party or club. & $\mathrm{O}$ & $\mathrm{O}$ & $\mathrm{O}$ & $\mathrm{O}$ \\
\hline Participated in church-sponsored group. & O & O & $\mathrm{O}$ & $\mathrm{O}$ \\
\hline Participated in a school academic club or team. & $\mathrm{O}$ & $\mathrm{O}$ & $\mathrm{O}$ & $\mathrm{O}$ \\
\hline $\begin{array}{l}\text { Helped to organize neighborhood or } \\
\text { community events. }\end{array}$ & $\mathrm{O}$ & $\mathrm{O}$ & $\mathrm{O}$ & $\mathrm{O}$ \\
\hline $\begin{array}{l}\text { Gave help (e.g., money, food, clothing, rides) to } \\
\text { friends or classmates who needed it. }\end{array}$ & $\mathrm{O}$ & $\mathrm{O}$ & $\mathrm{O}$ & $\mathrm{O}$ \\
\hline Collected signatures for a petition drive. & $\mathrm{O}$ & O & $\mathrm{O}$ & O \\
\hline $\begin{array}{l}\text { Contacted a public official by phone, mail, or } \\
\text { email to tell him/her how you felt about a } \\
\text { particular issue. }\end{array}$ & O & O & O & $\mathrm{O}$ \\
\hline $\begin{array}{l}\text { Joined a protest march, meeting or } \\
\text { demonstration. }\end{array}$ & O & O & O & $\mathrm{O}$ \\
\hline Volunteered at a school event or function. & $\mathrm{O}$ & $\mathrm{O}$ & $\mathrm{O}$ & $\mathrm{O}$ \\
\hline $\begin{array}{l}\text { Helped people who were new to your } \\
\text { community. }\end{array}$ & $\mathrm{O}$ & O & O & O \\
\hline Visited or helped out people who were sick. & O & O & $\mathrm{O}$ & O \\
\hline $\begin{array}{l}\text { Wrote a letter/email to a school or community } \\
\text { newspaper or publication. }\end{array}$ & $\mathrm{O}$ & $\mathrm{O}$ & $\mathrm{O}$ & O \\
\hline
\end{tabular}




\section{XII: Perception of My Community (Middle School)}

Please indicate how strongly you disagree or agree with each statement.

\begin{tabular}{|c|c|c|c|c|c|c|}
\hline & $\begin{array}{c}\text { Strongly } \\
\text { Disagre } \\
\text { e }\end{array}$ & $\begin{array}{l}\text { Disagre } \\
\mathrm{e}\end{array}$ & $\begin{array}{c}\text { Slightly } \\
\text { Disagre } \\
\mathrm{e}\end{array}$ & $\begin{array}{l}\text { Strongl } \\
\text { y Agree }\end{array}$ & $\begin{array}{l}\text { Agre } \\
\mathrm{e}\end{array}$ & $\begin{array}{l}\text { Strongl } \\
\text { y Agree }\end{array}$ \\
\hline I feel like I am part of a community. & $\mathrm{O}$ & $\mathrm{O}$ & $\mathrm{O}$ & $\mathrm{O}$ & $\mathrm{O}$ & $\mathrm{O}$ \\
\hline $\begin{array}{l}\text { I pay attention to news events that affect } \\
\text { the community. }\end{array}$ & $\mathrm{O}$ & $\mathrm{O}$ & $\mathrm{O}$ & $\mathrm{O}$ & $\mathrm{O}$ & $\mathrm{O}$ \\
\hline $\begin{array}{l}\text { Doing something that helps others is } \\
\text { important to me. }\end{array}$ & O & $\mathrm{O}$ & O & O & $\mathrm{O}$ & $\mathrm{O}$ \\
\hline $\begin{array}{l}\text { I like to help other people, even if it is } \\
\text { hard work. }\end{array}$ & $\mathrm{O}$ & $\mathrm{O}$ & $\mathrm{O}$ & $\mathrm{O}$ & $\mathrm{O}$ & $\mathrm{O}$ \\
\hline $\begin{array}{l}\text { I know what I can do to help make the } \\
\text { community a better place. }\end{array}$ & O & $\mathrm{O}$ & $\mathrm{O}$ & $\mathrm{O}$ & $\mathrm{O}$ & O \\
\hline $\begin{array}{l}\text { Helping other people is something } \\
\text { everyone should do, including myself. }\end{array}$ & $\mathrm{O}$ & $\mathrm{O}$ & $\mathrm{O}$ & O & $\mathrm{O}$ & O \\
\hline $\begin{array}{l}\text { I know a lot of people in the community, } \\
\text { and they know me. }\end{array}$ & $\mathrm{O}$ & $\mathrm{O}$ & $\mathrm{O}$ & $\mathrm{O}$ & $\mathrm{O}$ & $\mathrm{O}$ \\
\hline $\begin{array}{l}\text { I feel like I can make a difference in the } \\
\text { community. }\end{array}$ & $\mathrm{O}$ & $\mathrm{O}$ & $\mathrm{O}$ & $\mathrm{O}$ & $\mathrm{O}$ & $\mathrm{O}$ \\
\hline $\begin{array}{l}\text { I try to think of ways to help other } \\
\text { people. }\end{array}$ & $\mathrm{O}$ & $\mathrm{O}$ & $\mathrm{O}$ & $\mathrm{O}$ & $\mathrm{O}$ & $\mathrm{O}$ \\
\hline $\begin{array}{l}\text { Everyone should pay attention to the } \\
\text { news, including myself. }\end{array}$ & $\mathrm{O}$ & $\mathrm{O}$ & $\mathrm{O}$ & $\mathrm{O}$ & $\mathrm{O}$ & $\mathrm{O}$ \\
\hline
\end{tabular}

\section{XII: Perception of My Community (High School)}

Please indicate how strongly you disagree or agree with each statement. 


\begin{tabular}{|c|c|c|c|c|c|c|}
\hline & $\begin{array}{l}\text { Strongly } \\
\text { Disagree }\end{array}$ & Disagree & $\begin{array}{l}\text { Slightly } \\
\text { Disagree }\end{array}$ & $\begin{array}{l}\text { Slightly } \\
\text { Agree }\end{array}$ & Agree & $\begin{array}{l}\text { Strongly } \\
\text { Agree }\end{array}$ \\
\hline $\begin{array}{l}\text { I have a strong and personal } \\
\text { attachment to a particular } \\
\text { community. }\end{array}$ & $\mathrm{O}$ & $\mathrm{O}$ & $\mathrm{O}$ & $\mathrm{O}$ & $\mathrm{O}$ & 0 \\
\hline $\begin{array}{l}\text { I often discuss and think about } \\
\text { how political, social, local, or } \\
\text { national issues affect the } \\
\text { community. }\end{array}$ & 0 & 0 & O & 0 & 0 & 0 \\
\hline $\begin{array}{l}\text { I participate in political or social } \\
\text { causes in order to improve the } \\
\text { community. }\end{array}$ & 0 & 0 & 0 & $\mathrm{O}$ & 0 & $\mathrm{O}$ \\
\hline $\begin{array}{l}\text { It is my responsibility to help } \\
\text { improve the community. }\end{array}$ & 0 & 0 & 0 & 0 & $\mathrm{O}$ & 0 \\
\hline $\begin{array}{l}\text { I benefit emotionally from } \\
\text { contributing to the community, } \\
\text { even if it is hard and } \\
\text { challenging work. }\end{array}$ & 0 & O & 0 & $\mathrm{O}$ & 0 & $\mathrm{O}$ \\
\hline $\begin{array}{l}\text { I am aware of the important } \\
\text { needs in the community. }\end{array}$ & $\mathrm{O}$ & 0 & $\mathrm{O}$ & $\mathrm{O}$ & 0 & 0 \\
\hline $\begin{array}{l}\text { I feel a personal obligation to } \\
\text { contribute in some way to the } \\
\text { community. }\end{array}$ & $\mathrm{O}$ & 0 & $\mathrm{O}$ & 0 & 0 & 0 \\
\hline
\end{tabular}




\begin{tabular}{|c|c|c|c|c|c|c|}
\hline & $\begin{array}{l}\text { Strongly } \\
\text { Disagree }\end{array}$ & Disagree & $\begin{array}{l}\text { Slightly } \\
\text { Disagree }\end{array}$ & $\begin{array}{l}\text { Slightly } \\
\text { Agree }\end{array}$ & Agree & $\begin{array}{l}\text { Strongly } \\
\text { Agree }\end{array}$ \\
\hline $\begin{array}{l}\text { I am aware of what can be } \\
\text { done to meet the important } \\
\text { needs in the community. }\end{array}$ & $\mathrm{O}$ & $\mathrm{O}$ & $\mathrm{O}$ & $\mathrm{O}$ & $\mathrm{O}$ & $\mathrm{O}$ \\
\hline $\begin{array}{l}\text { Providing service to the } \\
\text { community is something I } \\
\text { prefer to let others do. }\end{array}$ & 0 & 0 & 0 & 0 & 0 & 0 \\
\hline $\begin{array}{l}\text { I have a lot of personal contact } \\
\text { with people in the community. }\end{array}$ & $\mathrm{O}$ & O & $\mathrm{O}$ & $\mathrm{O}$ & 0 & $\mathrm{O}$ \\
\hline $\begin{array}{l}\text { Helping other people is } \\
\text { something that I am personally } \\
\text { responsible for. }\end{array}$ & $\mathrm{O}$ & 0 & $\mathrm{O}$ & 0 & O & $\mathrm{O}$ \\
\hline $\begin{array}{l}\text { I feel I have the power to make } \\
\text { a difference in the community. }\end{array}$ & 0 & 0 & 0 & 0 & O & 0 \\
\hline $\begin{array}{l}\text { I often try to act on solutions } \\
\text { that address political, social, } \\
\text { local, or national problems in } \\
\text { the community. }\end{array}$ & 0 & 0 & 0 & 0 & 0 & 0 \\
\hline $\begin{array}{l}\text { It is easy for me to put aside } \\
\text { my self-interest in favor of a } \\
\text { greater good. }\end{array}$ & 0 & 0 & $\mathrm{O}$ & 0 & 0 & 0 \\
\hline $\begin{array}{l}\text { I participate in activities that } \\
\text { help to improve the } \\
\text { community, even if I am new to } \\
\text { them. }\end{array}$ & 0 & 0 & 0 & 0 & 0 & O \\
\hline $\begin{array}{l}\text { I try to encourage others to } \\
\text { participate in community } \\
\text { service. }\end{array}$ & O & $\mathrm{O}$ & O & O & O & O \\
\hline $\begin{array}{l}\text { Becoming involved in political } \\
\text { or social issues is a good way to } \\
\text { improve the community. }\end{array}$ & 0 & O & 0 & 0 & 0 & 0 \\
\hline $\begin{array}{l}\text { I believe that I can personally } \\
\text { make a difference in the } \\
\text { community. }\end{array}$ & 0 & 0 & $\mathrm{O}$ & 0 & 0 & 0 \\
\hline $\begin{array}{l}\text { I believe that I can have enough } \\
\text { influence to impact community } \\
\text { decisions. }\end{array}$ & 0 & 0 & 0 & 0 & 0 & 0 \\
\hline $\begin{array}{l}\text { I am or plan to become actively } \\
\text { involved in issues that } \\
\text { positively affect the } \\
\text { community. }\end{array}$ & O & $\mathrm{O}$ & O & O & $\mathrm{O}$ & 0 \\
\hline $\begin{array}{l}\text { Being concerned about state } \\
\text { and local issues is an important } \\
\text { responsibility for everybody. }\end{array}$ & $\mathrm{O}$ & O & $\mathrm{O}$ & $\mathrm{O}$ & $\mathrm{O}$ & 0 \\
\hline
\end{tabular}




\begin{tabular}{|c|c|c|c|c|c|c|}
\hline $\begin{array}{l}\text { Being actively involved in } \\
\text { community issues is everyone's } \\
\text { responsibility, including mine. }\end{array}$ & 0 & 0 & 0 & 0 & 0 & 0 \\
\hline $\begin{array}{l}\text { I try to find time or a way to } \\
\text { make a positive difference in } \\
\text { the community. }\end{array}$ & 0 & 0 & 0 & 0 & 0 & 0 \\
\hline $\begin{array}{l}\text { I understand how political and } \\
\text { social policies or issues affect } \\
\text { members in the community. }\end{array}$ & 0 & 0 & 0 & 0 & O & O \\
\hline
\end{tabular}

\section{XIII: Thoughts on Youth Violence}

Please indicate how strongly you disagree or agree with each statement.

\begin{tabular}{|c|c|c|c|c|}
\hline & $\begin{array}{l}\text { Strongly } \\
\text { Disagree }\end{array}$ & Disagree & Agree & $\begin{array}{l}\text { Strongly } \\
\text { Agree }\end{array}$ \\
\hline It is possible to reduce youth violence. & $\mathrm{O}$ & $\mathrm{O}$ & O & O \\
\hline Reducing youth violence is important to me. & $\mathrm{O}$ & O & O & O \\
\hline $\begin{array}{l}\text { People important to me think we should reduce } \\
\text { youth violence. }\end{array}$ & O & $\mathrm{O}$ & $\mathrm{O}$ & O \\
\hline $\begin{array}{l}\text { I'd like to know more about how I can help to } \\
\text { reduce youth violence. }\end{array}$ & $\mathrm{O}$ & $\mathrm{O}$ & $\mathrm{O}$ & O \\
\hline $\begin{array}{l}\text { I'm likely to do something in the efforts to reduce } \\
\text { youth violence. }\end{array}$ & O & O & $\mathrm{O}$ & $\mathrm{O}$ \\
\hline
\end{tabular}


Reminder: Individual Responses will not be linked to specific respondents.

Tell us a little about yourself:

How old are you:

$\begin{array}{ll}\text { O } & 11 \\ \text { O } & 12 \\ \text { O } & 13 \\ \text { O } & 14 \\ \text { O } & 15\end{array}$

What grade are you in:

6th

7th

8th

What is your current gender identity? (Check all that apply)

O Male

Female

Trans male/Trans man

O Trans female/Trans woman

Genderqueer/Gender non-forming

Other identity (please state)

What neighborhood do you live in: 


\section{Appendix C: Focus Group Topic Guide}

\section{[INTRODUCTION]}

Hi. How are you doing? My name is [NAME] and I'm part of the Changing the Narrative project that is focused on youth violence prevention. Thanks for agreeing to participate in this focus group. Before we get started, let me review some information about this conversation with you to make sure you are comfortable participating.

\section{[CONSENT PROCESS + Turn on recorder once consented]}

I'd like to talk to today about life in your community for you and people your age. You don't have to answer any questions that make you uncomfortable.

Let's start by talking about your community.

\section{[BEING A YOUNG PERSON]:}

What is your neighborhood like? [If in school:] How would you describe your school? What kinds of things do you/people your age like to do?

\section{[MEDIA USE]:}

Do people your age watch TV?

[If yes:] What TV shows do you like to watch? [If yes:] How do you watch TV shows? (e.g., on a computer, a phone, or on a TV at home)

What kind of music do you listen to?

[If yes:] Who are some of your favorite artists? [If yes:] How do you listen to music (e.g., computer, ipod, radio/stations)?

Outside of school, do you like to read? What? What are your favorite phone apps? Do you use social media (e.g., Facebook, Twitter, Instagram, Tumblr, YouTube, Vine, or Snapchat)?

[If yes:] Which ones? [If yes:] How do you go on social media? (E.g. on a computer, tablet app, or phone app)

What do you use social media for? Who do you talk to? How often do you use it? How much time do you typically spend on it in a given day?

[SOCIAL IDENTITY]: 
From your point of view, what does it mean to be a young person living in your community? From others' point of view?

Who do you look up to as a role model? (probe: teachers? Faith leaders?)

How do you think people outside your community view young people living in your community?

How do you feel about that?

\section{[DEFINITIONS OF VIOLENCE]:}

How would you define violence?

Do you see violence in your neighborhood? In your school? (probe: bullying? Gang activity?)

\section{[NORMS \& ATTITUDES TOWARD VIOLENCE]:}

Not speaking about anyone specifically, but what kinds of people are violent in your neighborhood? In your school?

How do you feel about people who use violence? About people who are victims of violence? In what situations is violence necessary? Appropriate? Expected?

What happens if someone is in that situation and they don't use violence? How do people react? What do they say about the person? How do they treat the person?

\section{[PERSONAL ENGAGEMENT IN VIOLENCE]:}

How big of a problem are guns in your neighborhood? If someone your age wanted to get a gun, is it difficult/expensive?

What do you think might help stop violence in your neighborhood? What is the best way to reach you and your peers with messages about youth violence?

Any other thoughts?

\section{[CONCLUDE and TURN OFF RECORDER]}

Thank you so much for taking time to talk with me today. As I mentioned, I have a form for you to sign, and then I can give you the incentive we discussed.

[GET FORM SIGNED. COMPLETE LOG. GIVE INCENTIVE. EVERYTHING BACK IN MEETING BOX AND LOCKED.] 


\title{
CURRICULUM VITAE
}

NAME: $\quad$ Billie Castle

ADDRESS: Health Promotion and Behavioral Sciences

485 E. Gray Street

University of Louisville

Louisville, Kentucky 40202

DOB: $\quad$ New Iberia, Louisiana - December 1, 1989

EDUCATION

\& TRAINING:

\author{
B.S., Health Sciences \\ Howard University \\ 2008-12 \\ M.P.H., Health Policy and Management \\ Texas A\&M University \\ 2012-14 \\ Ph.D., Public Health Sciences \\ University of Louisville \\ 2014-17
}

AWARDS: University of Louisville Diversity Fellow, 2014-2016

Howard University College of Nursing and Allied Health Sciences

Community Service and Student Leadership Award, 2012

Circle K International Carthage-Pullman Society, 2012

Kiwanis International Leadership Society, 2012

Who's Who Among College Students, 2012

Howard University College of Nursing and Allied Health Sciences

Dean's List 2010-2012

Circle K International Distinguished Lieutenant Governor, 2011 
Capital District, Circle K International Distinguished Board Member, 2011

Lifetime Member of Girl Scouts of America

PROFESSIONAL SOCITIES: American Public Health Association

PUBLICATIONS:

Peer Reviewed Journal Articles:

Castle, B., Wendel, M., Kelly Pryor, B., \& Ingram, M. (2017) Assessing community leadership: Understanding community capacity for health improvement. Journal of Public Health Management and Practice.

Garney, W. R., Wendel, M., McLeroy, K., Alaniz, A., Cunningham, G., Castle, B., ... Burdine, J. (2017). Using a Community Health Development Framework to Increase Community Capacity: A Multiple Case Study. Family \& Community Health, 40(1), 18-23.

Garney, W. R., Beaudoin, C. E., Clark, H. R., Drake, K. N., Wendel, M. L., McLeroy, K. R., . . . Shaw, R. L. (2015). Using Community-Based Participatory Research to Disseminate a Mass Media Campaign Into Rural Communities. Journal of health communication, 20(7), 799-806.

\section{Technical Reports:}

Garney, W. R., Castle, B., Wendel, M. \& Alaniz, A. (2014). Grimes county physical activity and community engagement project overview. College Station, TX: Center for Community Health Development.

Garney, W. R., Castle, B., Wendel, M. \& Alaniz, A. (2014). Leon county physical activity and community engagement project overview. College Station, TX: Center for Community Health Development.

Garney, W. R., Castle, B., Wendel, M. \& Alaniz, A. (2014). Madison county physical activity and community engagement project overview. College Station, TX: Center for Community Health Development.

Garney, W. R., Castle, B., Wendel, M. \& Alaniz, A. (2013). Madison Outreach and Services through Telehealth (MOST) Preliminary Evaluation: Executive Summary. College Station, TX: Center for Community Health Development.

Alaniz, A., Catanach, C., Clark, H., Drake, K., Garney, W., Nimmons, K,...\& Moser, A. (2013). RHP 17 health status assessment 2013: Regional report. College Station, TX: Center for Community Health Development. 
Alaniz, A., Catanach, C., Clark, H., Drake, K., Garney, W., Nimmons, K,...\& Moser, A. (2013). 2013 RHP 17 health status assessment 2013 supplemental report: Brazos Valley region. College Station, TX: Center for Community Health Development.

Alaniz, A., Catanach, C., Clark, H., Drake, K., Garney, W., Nimmons, K,...\& Moser, A. (2013). 2013 RHP 17 health status assessment 2013 supplemental report: Brazos County. College Station, TX: Center for Community Health Development.

Alaniz, A., Catanach, C., Clark, H., Drake, K., Garney, W., Nimmons, K,...\& Moser, A. (2013). 2013 RHP 17 health status assessment 2013 supplemental report: Burleson County. College Station, TX: Center for Community Health Development.

Alaniz, A., Catanach, C., Clark, H., Drake, K., Garney, W., Nimmons, K,...\& Moser, A. (2013). 2013 RHP 17 health status assessment 2013 supplemental report: Grimes County. College Station, TX: Center for Community Health Development.

Alaniz, A., Catanach, C., Clark, H., Drake, K., Garney, W., Nimmons, K,...\& Moser, A. (2013). 2013 RHP 17 health status assessment 2013 supplemental report: Leon County. College Station, TX: Center for Community Health Development.

Alaniz, A., Catanach, C., Clark, H., Drake, K., Garney, W., Nimmons, K,...\& Moser, A. (2013). 2013 RHP 17 health status assessment 2013 supplemental report: Madison County. College Station, TX: Center for Community Health Development.

Alaniz, A., Catanach, C., Clark, H., Drake, K., Garney, W., Nimmons, K,...\& Moser, A. (2013). 2013 RHP 17 health status assessment 2013 supplemental report: Montgomery County. College Station, TX: Center for Community Health Development.

Alaniz, A., Catanach, C., Clark, H., Drake, K., Garney, W., Nimmons, K,...\& Moser, A. (2013). 2013 RHP 17 health status assessment 2013 supplemental report: Robertson County. College Station, TX: Center for Community Health Development. 
Alaniz, A., Catanach, C., Clark, H., Drake, K., Garney, W., Nimmons, K,...\& Moser, A. (2013). 2013 RHP 17 health status assessment 2013 supplemental report: Washington County. College Station, TX: Center for Community Health Development.

Alaniz, A., Catanach, C., Clark, H., Drake, K., Garney, W., Nimmons, K,...\& Moser, A. (2013). 2013 RHP 17 health status assessment 2013 supplemental report: Walker County. College Station, TX: Center for Community Health Development.

\section{NATIONAL MEETING PRESENTATIONS:}

\section{6}

Wendel, M., Jackson, T., Ingram, M., Ali, N., Castle, B., Combs, R., Jones, G., Rogers, W., \& Carthan, Q., Smith, A. (Presented on May 11 - 14, 2016). West Louisville photovoice project: local perspectives on justice, safety, hope, and racial equity. Panel presentation presented at Community-Campus Partnerships for Health 14th International Conference in New Orleans, Louisiana.

Jackson, T., Wendel, M., Ingram, M., Castle, B., \& Jones, G. (Presented on May $11-14,2016)$. Louisville Listens to Ferguson in Order to Sow Justice, Safety, Hope, and Racial Equity. Poster presentation at Community-Campus

Partnerships for Health 14th International Conference in New Orleans, Louisiana.

\section{5}

Castle, B.F., Wendel, M., Ingram, M., Ali, N., Jackson, T, \& Combs, R. (Presented on October 31 - November 4, 2015). A partnership approach to addressing violence in West Louisville, Kentucky. Poster presented at the American Public Health Association (APHA) 143 ${ }^{\text {nd }}$ Annual Meeting. Chicago, Illinois.

Ingram, M., Jackson, T., Wendel, M., Ali, N., Castle, B., \& Combs, R. (Presented on October 31 - November 4, 2015). Addressing social determinants of health through photovoice. Round table discussion presented at the American Public Health Association (APHA) 143nd Annual Meeting. Chicago, Illinois.

Ali, N., Wendel, M., Ingram, M., Castle, B., Jackson, T., \& Combs, R. (Presented on October 31 - November 4, 2015). United we stand: The role of an urban university in strengthening community capacity. Oral presentation presented at the American Public Health Association (APHA) 143 ${ }^{\text {nd }}$ Annual Meeting. Chicago, Illinois.

Castle, B. F., Yuen, M. Calhoun, D., Nyquist, B., Kash, B. (Presented on June 14-16, 2015). Social Marketing Activities by Health Systems in Texas. Poster presented at Academy Health Annual Research Meeting. Minneapolis, Minnesota. 
Castle, B. F., Yuen, M. Calhoun, D., Nyquist, B., Kash, B. (Presented on April 14-17, 2015). Social Marketing Activities by Health Systems in Texas. Poster presented at National Rural Health Association $38^{\text {th }}$ Annual Rural Health Conference. Philadelphia, Pennsylvania.

\section{4}

Castle, B.F., Garney, W.R., Wendel, M.L., Alaniz, A., Ingram, M., Jackson, V. \& Meece, L. (Presented on November 15-19, 2014). Grimes County Physical Activity and Community Engagement (PACE) Project: Increasing Access to Physical Activity in Rural Populations. Poster presented at the American Public Health Association (APHA) 142 ${ }^{\text {nd }}$ Annual Meeting. New Orleans, Louisiana.

Castle, B. F., Calhoun, D., Nyquist, B., Yuen, M., Kash, B. (Presented on November 15-19, 2014). Social Marketing Activities by Health Systems in Texas. Poster presented at the American Public Health Association (APHA) $142^{\text {nd }}$ Annual Meeting \& Expo. New Orleans, Louisiana.

Garney, W.R., Nimmons, K., McLeroy, K, Castle, B.F., \& Wendel, M.L. (Presented on November 15-19, 2014). Using Structural Equation Modeling to Explore Relationships between Access, Accessibility, and Health Status. Oral presentation presented at the American Public Health Association (APHA) 142nd Annual Meeting. New Orleans, Louisiana.

Garney, W.R., Nimmons, K., Castle, B.F., Roach, A., Allen, B., St. John, J., Alaniz, A. \& Wendel, M.L. (Presented on November 17- 19, 2014). Using Community Health Workers to Increase Awareness about the Affordable Care Act in a Rural Community. Oral presentation presented at the American Public Health Association (APHA) 142nd Annual Meeting. New Orleans, Louisiana.

Garney, W.R., Wendel, M.L., Castle, B.F., Young, A., Cunningham, G.B., Ingram, M., \& Alaniz, A. (Presented on November 15-19, 2014). Exergame Options for Physical Activity: Geocaching for Exercise and Activity Research. Poster presented at the American Public Health Association (APHA) 142nd Annual Meeting. New Orleans, Louisiana.

Wendel, M.L., Garney, W.R., Castle, B.F., Alaniz, A., Ingram, M., McLeroy, K., \& Burdine, J. (Presented on November 17-19, 2014). Community capacity dimensions influencing success of local initiatives: The importance of reflexivity. Oral presentation presented at the American Public Health Association (APHA) $142^{\text {nd }}$ Annual Meeting. New Orleans, Louisiana.

Alaniz, A., Garney, W.R., Young, A., Castle, B.F., Wendel, M.L., Elliott, T., \& McCord, C. (Presented on November 17-19, 2014). MOST: A partnership approach for expanding mental health care. Poster presented at the American 
Public Health Association (APHA) 142 ${ }^{\text {nd }}$ Annual Meeting. New Orleans, Louisiana.

Garney, W.R., Patterson, M., Wendel, M., Cunningham, G. \& Castle, B. (March 16-19, 2014). A New Option for Physical Activity: The Geocaching for Exercise and Activity (GEAR) Study. Poster presented at the 14th Annual American Academy of Health Behavior Meeting. Charleston, South Carolina.

Garney, W.R., Wendel, M.L., Castle, B.F., Alaniz, A. B., McLeroy, K. R. \& Cunningham, G.B. (March 16-19, 2014). Using community health development to increase community capacity: The physical activity and community engagement project. Poster presented at the 14th Annual American Academy of Health Behavior Meeting. Charleston, South Carolina.

\section{3}

Wendel, M. L., Garney, W. R., Cunningham, G., Ory, M., Ingram, M. \& Castle, B. (November 2-6, 2013). Geocaching for Exercise and Activity Research (GEAR): Exploring the Physical Activity Aspects of a Modern Recreational Activity . Poster presentation at the American Public Health Association (APHA) 141st Annual Meeting. Boston, MA.

Castle, B. and Thapa, S. (September 12, 2013). Geocaching for Exercise and Activity Research (GEAR) Study: Measurement of Physical Activity Engagement and Overall Health. Poster presentation at the 2013 RHP 17 Regional Health Summit. College Station, TX.

Castle, B., Jackson, V., Ingram, M., Finke, P., and Meece, L. (September 12, 2013). Grimes County Physical Activity and Community Engagement Project: Healthy Living Grimes County. Poster presentation at the 2013 RHP 17 Regional Health Summit. College Station, TX.

Ingram, M., Castle, B., Turner, J., and Danford, D. (September 12, 2013). 2013 Leon County Cache Dash. Poster presentation at the 2013 RHP 17 Regional Health Summit, College Station, TX. 